\title{
阿司匹林的结构修饰与生物活性研究进展
}

\begin{tabular}{|c|c|c|c|c|}
\hline 张芸溪 & 高湖川 & 张程瑞 & 孙茂盛 & 陈杨杰 \\
\hline 曾礼升 & 黄岗 & 陈 鹏 & 黄乾明 & 蒲 祥* \\
\hline
\end{tabular}

\begin{abstract}
摘要 阿司匹林(ASP)是第一个合成药物, 主要作为一种非甾体抗炎药而被广泛使用. 具有多种生物活性, 如抗血栓、 抗炎和抗肿瘤等, 不少文献报道了其衍生物的合成及相关活性评估. ASP 现有的衍生方法分为骨架衍生、前药衍生、孪 药衍生及金属配位衍生四个类别. 依据修饰位点的不同，骨架衍生进一步分为 $\mathrm{C}(1)-\mathrm{COOH}$ 位修饰、 $\mathrm{C}(1)-\mathrm{COOH}$ 位与 C(2)-OAc 位同时修饰、C(2)-OAc 位修饰及苯环修饰. NO-ASP 是制备抗血栓衍生物的主要方法, 金属配位修饰则是抗 癌衍生物的主要合成方案. 综述了近 20 年来阿司匹林的结构修饰与其活性研究进展，阐述了 353 种阿司匹林衍生物的 合成方法及部分衍生物的药理活性，为阿司匹林衍生物的进一步开发提供参考.
\end{abstract}

关键词 阿司匹林; 骨架衍生; 前药衍生; 孪药衍生; 金属配位衍生

\section{Advances in the Study of Structural Modification of Aspirin and Their Biological Activities}

\author{
Zhang, Yunxi \\ Gao, Huchuan \\ Zhang, Chenrui \\ Sun, Maosheng \\ Chen, Yangjie \\ Zeng, Lisheng Huang, Lan \\ Chen, Peng \\ Huang, Qianming \\ $\mathrm{Pu}$, Xiang* \\ (College of Science, Sichuan Agricultural University, Ya'an, Sichuan 625014)
}

\begin{abstract}
Aspirin (ASP), the first synthetic drug, is widely used as a non steroidal anti-inflammatory drug. It displays a variety of biological activities, such as anti-thrombosis, anti-inflammatory, anti-tumor, etc. A lot of works about the synthesis and related activity evaluation of its derivatives were reported. There are four kinds of derivatization methods: skeleton derivatization, prodrug derivatization, twin derivatization and metal coordination derivatization. According to the different modification sites, skeleton derivatization could be further divided into $\mathrm{C}(1)-\mathrm{COOH}$ site modification, $\mathrm{C}(1)-\mathrm{COOH}$ site and $\mathrm{C}(2)-\mathrm{OAc}$ site simultaneous modification, $\mathrm{C}(2)-\mathrm{OAc}$ site modification and benzene ring modification. NO-ASP is the main method to prepare antithrombotic derivatives, and metal coordination modification is the main synthesis scheme of anticancer derivatives. The structure modification and bioactivity research of aspirin in recent twenty years and the synthetic routes of 353 aspirin derivatives and the pharmacological activities of some derivatives are described, which provides a reference for the further development of aspirin derivatives.

Keywords aspirin; skeleton derivation; prodrug derivation; twin drug derivation ; metal coordination derivation
\end{abstract}

阿司匹林(Aspirin, ASP, 1)，别名乙酰水杨酸，化 学名 2-乙酰氧基苯甲酸, 是一种常用的解热抗炎药物, 其前体水杨酸最初是从白杨柳中提取而来. 1899 年, 费利克斯 - 霍夫曼成功地将水杨酸合成为乙酰水杨酸, 使其成为第一个人工合成的药物 ${ }^{[1]}$. 阿司匹林具有抗 血栓及抗炎等多种药理活性, 近年来还发现阿司匹林 具有抗肿瘤等其他活性, 目前抗肿瘤活性已成为其研
究热点. 阿司匹林的抗血栓机制为阿司匹林通过不可 逆地乙酰化血小板环氧化酶, 主要是乙酰化环氧化酶1 (COX-1)丝氨酸 530 位点, 抑制血栓素 A2 (TXA2)的 形成, 从而达到抗血小板聚集和抗血栓的作用 ${ }^{[2]}$. 抗 炎机制为阿司匹林能够抑制细胞环氧化酶从而抑制前 列腺素的合成, 发挥解热、镇痛及抗炎作用 ${ }^{[3]}$. 其抗肿 瘤机制尚不明确，但随着研究深入，越来越多的实验

\footnotetext{
* Corresponding author. E-mail: puxiang@sicau.edu.cn

Received July 31, 2019; revised October 20, 2019; published online November 7, 2019.

Project supported by the National Natural Science Foundation of China (No. 21708028), the Education Department of Sichuan Province (No. 17ZA0301) and the Scientific Innovation Cultivation Project of Sichuan Province (No. 2018080).

国家自然科学基金(No. 21708028)、四川省教育厅重点(No. 17ZA0301)和四川省科技创新苗子工程(No. 2018080)资助项目.
} 
结果证明了在众多肿瘤组织中都存在环氧合酶 -2 (COX-2)的过度表达 ${ }^{[4,5]}$. 当环氧化酶-2 表达过度时致 使机体过量合成前列腺素 E2 (PGE2), 而 PGE2 含量的 增加使机体的免疫系统功能遭到削弱. 这种情况下, 免疫系统对肿瘤细胞的监控能力就不可避免地减弱 了, 致使肿瘤组织不能被免疫系统及时清除, 所以阿 司匹林抑制 COX-2 的活性能够产生抗癌作用 ${ }^{[6]}$. 虽然 阿司匹林具有多种优良活性, 但长期使用阿司匹林会 造成对胃、肝、肾以及神经系统造成伤害. 此外, 对特 异体质的人群有可能引发过敏反应及贫血等症状. 为 了克服阿司匹林的副作用, 并提高阿司匹林的疗效, 大量科学家不断地对阿司匹林进行结构修饰, 并获得 了一定的成果.

\section{1 阿司匹林的骨架衍生与生物活性}

\section{$1.1 \mathrm{C}(1)-\mathrm{COOH}$ 修饰}

阿司匹林的结构修饰位点相对较少, 其中对 C(1)$\mathrm{COOH}$ 进行修饰是主要的衍生方式. 对 $\mathrm{C}(1)-\mathrm{COOH}$ 修 饰可利用羧基与醇、酚或胺等一步反应制得酯或酰胺
(Scheme 1), 如阿司匹林 $\mathrm{C}(1)-\mathrm{COOH}$ 直接与 5-(4-差基 苯基)-3H-1,2-二硫杂环戊烯-3-硫酮酯化，获得衍生物 $2^{[7]}$. 衍生物 2 可通过影响纤维蛋白原受体的活化, 增 加细胞内环磷酸腺苷(cAMP)的含量, 从而减少动脉血 栓的形成，抑制血小板聚集而显示出抗血栓活性，并 且还具有保护胃粘膜的作用 ${ }^{[8]}$. 与醇或胺反应制得的 衍生物 $\mathbf{3 a} \sim \mathbf{3 c}$ (Scheme 1) 对非小细胞肺癌细胞株 A549 (NSCLC A549)细胞显示出抗炎和抗肿瘤活性, 且成酯的衍生物 $3 \mathrm{a}$ 比成酰胺的衍生物 $3 \mathrm{~b}$ 和 $3 \mathrm{c}$ 活性更 高, 其中 $3 \mathbf{a}$ 对于 NSCLC A549 细胞的 $\mathrm{IC}_{50}$ 值为 130 $\mu \mathrm{mol} \cdot \mathrm{L}^{-1}$, 并在较高含量 $\left(180 \mu \mathrm{mol} \cdot \mathrm{L}^{-1}\right)$ 时对非小细胞 肺癌细胞株 H1299 (NCI-H1299)细胞显示出强烈的抑 制作用 ${ }^{[9]}$.

阿司匹林除可直接与醇、酚或胺等一步反应制得 衍生物之外, 更常将其 C(1)-COOH 酰化, 再与醇、酚 或胺等反应获得衍生物(Scheme 2). 阿司匹林酰氯与 十二醇、十六醇及胆固醇酰化获得衍生物 $\mathbf{4 a} \sim \mathbf{4 c}, \mathbf{4 a} \sim$ 4c 降低血栓素 B2 (TXB2)浓度的程度随化合物酰基链 长度的增加而减小 ${ }^{[10]}$. 与 4 -溴苯胺酰化获得衍生物 $\mathbf{5}$,

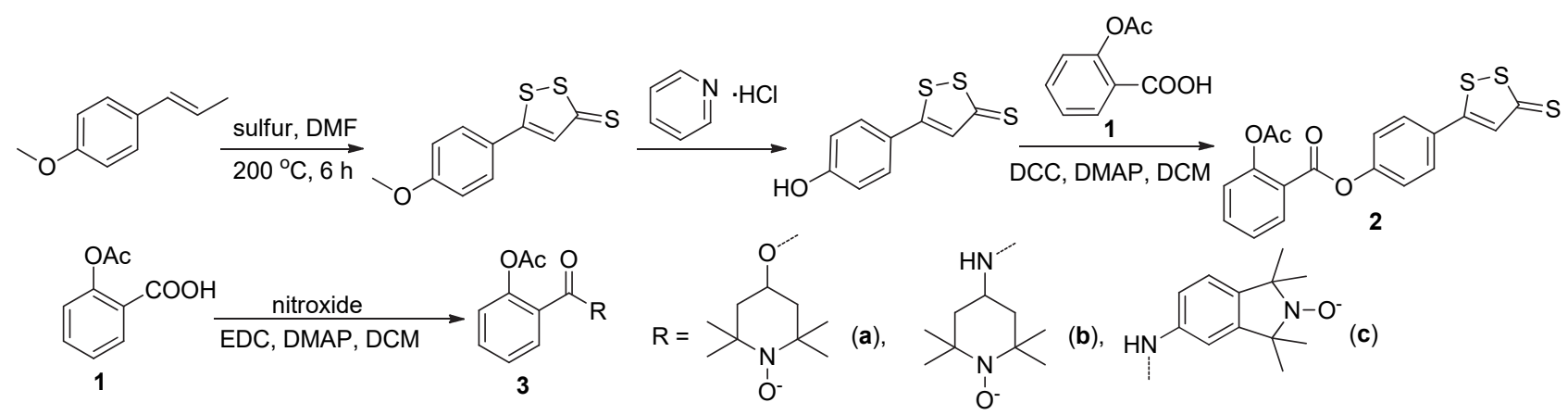

图式 1 阿司匹林衍生物 $\mathbf{2}$ 和 $\mathbf{3}$ 的合成路线

Scheme 1 Synthetic route of aspirin derivatives $\mathbf{2}$ and $\mathbf{3}$

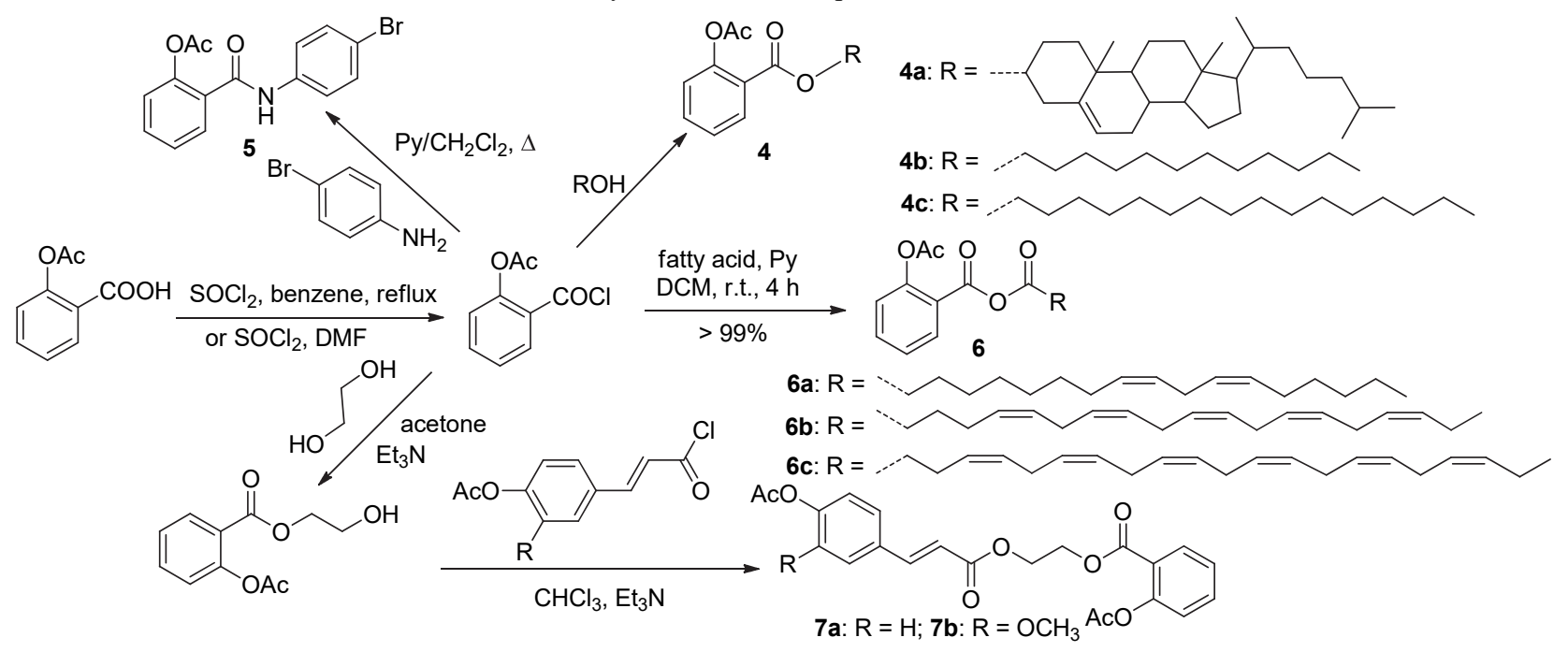

图式 2 阿司匹林衍生物 4 7 的合成路线

Scheme 2 Synthetic routes of aspirin derivatives $4 \sim 7$ 
其具有较好的抗真菌活性, 作用于核盘菌及灰葡萄孢 菌的 $\mathrm{ED}_{50}$ 值分别为 8.6 和 $1.8 \mathrm{mg} / \mathrm{L}^{[11]}$. 通过与不饱和 脂肪酸反应得到的衍生物 $\mathbf{6 a} \sim \mathbf{6} \mathbf{c}$ (Scheme 2) 可通过抑 制 COX-1-TXAS 途径, 减少血栓素的合成, 从而具有 抑制血小板聚集的抗血栓活性，其活性大小为 $6 \mathbf{a}>$ $\mathbf{6 b}>\mathbf{6 c}^{[12]}$. 与乙二醇酯化, 再与对乙酰氧基苯丙烯酸 酰氯或 3-甲氧基-4-乙酰氧基苯丙烯酸酰氯反应获得的 化合物 7a 和 7b (Scheme 2), 均显示出小鼠耳部巴豆油 炎症的抑制作用，其耳肿胀抑制率分别为 $43.5 \%$ 和 $37.1 \%$ ，高于耳肿胀抑制率为 $22.4 \%$ 的阿司匹林 ${ }^{[13]}$.
阿司匹林酰氯经成酯和脱叔丁基，随后酰化，再 与双羟基被保护的穿心莲内酯酯化，最后水解开环生 成衍生物 $8 \mathrm{a} \sim \mathbf{8 f}$, 或直接与双着基被保护的穿心莲内 酯酯化后水解开环生成衍生物 $8 \mathrm{~g}$ 和 $8 \mathrm{~h}$ (Scheme 3). 其 中 8a、8e、8f 和 $8 \mathrm{~g}$ 可通过抑制乙酰肝素酶的活性来 抑制肿瘤的血管新生和转移，体外测试中四者对 PC-3、MCF-7、MDA-MB-231 及 A549 癌细胞均显示 抑制活性, $\mathrm{IC}_{50}$ 值在 $8 \sim 30 \mu \mathrm{mol} \cdot \mathrm{L}^{-1}$, 强于阿司匹林 ${ }^{[14]}$. 同样地，阿司匹林酰氯与含硒化合物酰化制得衍生物 9a 9f (Scheme 4), 化合物 9b、9c 和 9e 具有显著的抗

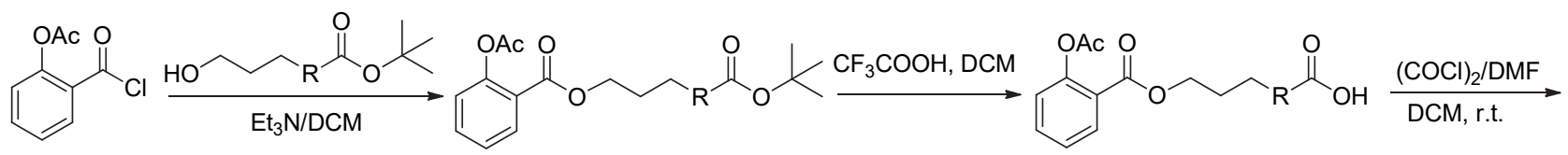

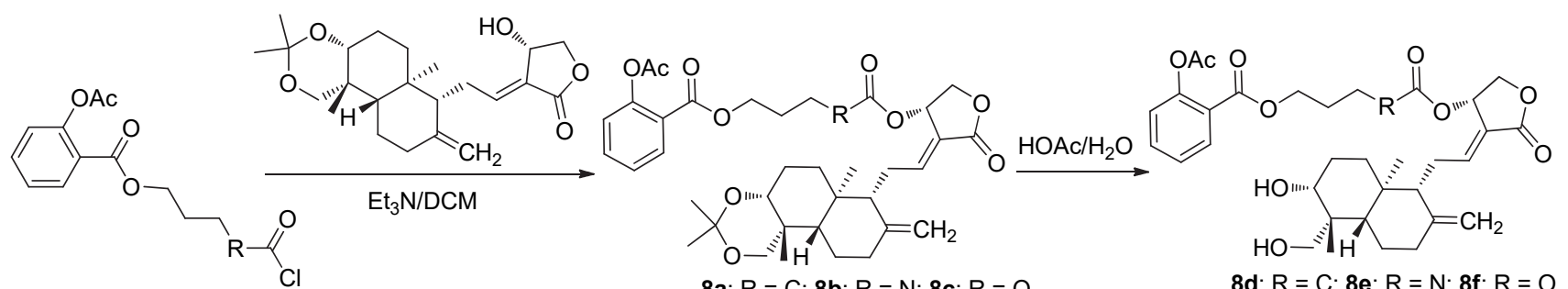

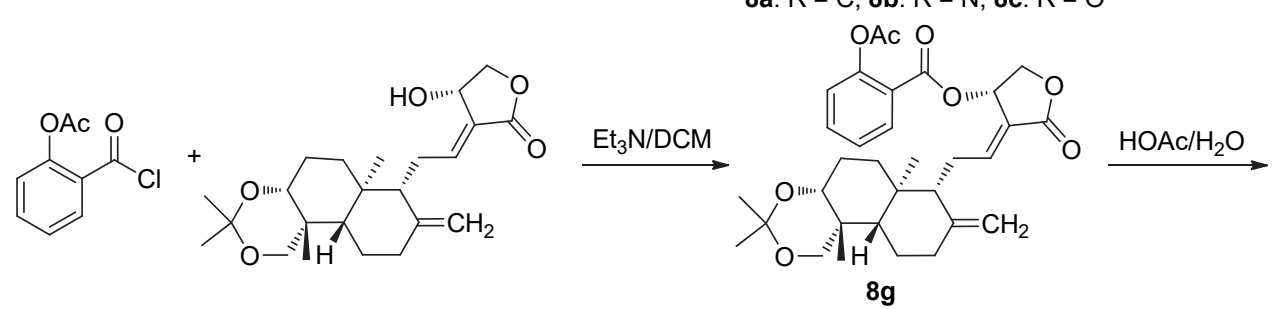

$\mathbf{8 d}: \mathrm{R}=\mathrm{C} ; \mathbf{8 e}: \mathrm{R}=\mathrm{N} ; \mathbf{8 f}: \mathrm{R}=\mathrm{O}$

图式 3 阿司匹林衍生物 $\mathbf{8}$ 的合成路线

Scheme 3 Synthetic route of aspirin derivative 8

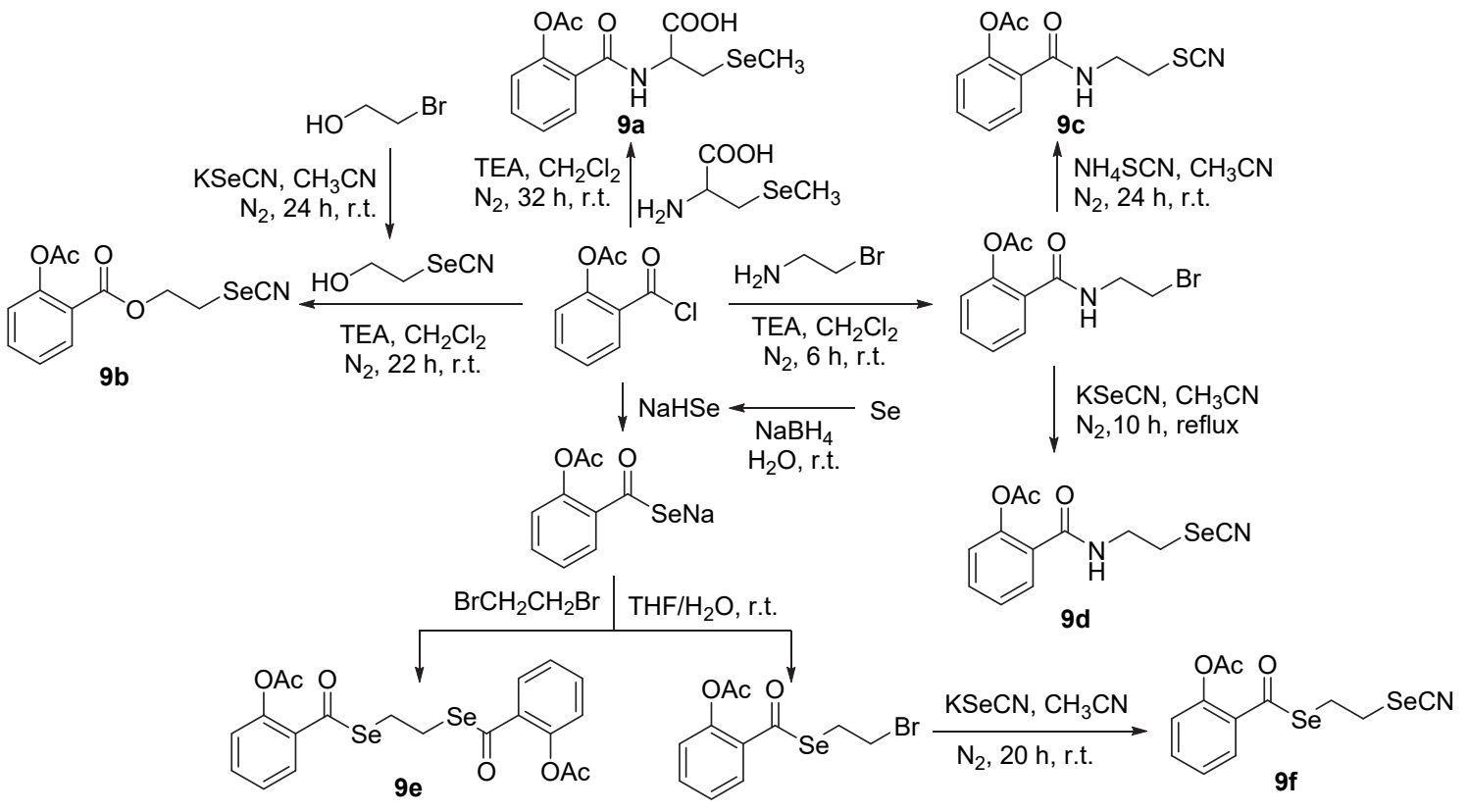

图式 4 阿司匹林衍生物 9 的合成路线

Scheme 4 Synthetic route of aspirin derivative 9 
癌活性, 对 HT29、DA-MB231、PANC 及 UACC903 细胞均有抑制活性, 对 $\mathrm{HT} 29$ 细胞的 $\mathrm{IC}_{50}$ 值分别为 (3.4 \pm 1.1$) 、(10.2 \pm 13.3)$ 和 $(18.6 \pm 3.8) \mu \mathrm{mol} \cdot \mathrm{L}^{-1}$. 其中 化合物 9c 具有优良的抗癌活性, 研究表明该衍生物可 通过抑制细胞增殖的 G1 期和 G2/M 期来抑制癌细胞的 生长, 并且选择性较高, 是潜在的化疗药物 ${ }^{[15]}$.

设计阿司匹林衍生物时, 除了从阿司匹林本体结 构为出发点之外, 还常以水杨酸、水杨醛等其他物质 出发合成设计阿司匹林的衍生物. 如水杨酸 C(1)$\mathrm{COOH}$ 与相应的醇酯化生成衍生物 10a 和 10b (Scheme 5), 两者能够抑制 NMDA 引起的神经毒性 ${ }^{[16]}$. 将 $\mathrm{C}(1)-\mathrm{COOH}$ 与戊醇、己醇、癸醇及十四醇酯化后, 再 将酚羟基酰化得到衍生物 11a 11d (Scheme 5), 化合 物 $11 \mathrm{a} \sim 11 \mathrm{c}$ 在体外实验中显示出与阿司匹林相同的抗 炎活性 ${ }^{[17]}$.

氧化应激与炎症的产生是与年龄相关的机体功能 下降的主要影响因素, 阿司匹林可通过减少类胰岛素 信号的释放, 从而防止氧化应激, 延缓与年龄相关的 机体功能衰退, 达到抗衰老的作用 ${ }^{[18,19]}$. 将水杨酸 $\mathrm{C}(1)-\mathrm{COOH}$ 醇酯化, 随后用乙酸修饰酚羟基获得衍生
物 12a 12d (Scheme 5), 其中 12a 对大鼠肝匀浆中丙 二醛的生成显示出良好的抑制活性，抑制率高于同等 剂量下食品防腐剂羟基茴香醚，达 $84.95 \%$ ，抗氧化效 果优异 ${ }^{[20]}$.

$\mathrm{NO} 、 \mathrm{H}_{2} \mathrm{~S}$ 和 $\mathrm{CO}$ 是一组具有生理活性的气体, 被 称为气体信号因子, 在适当的浓度下, 它们在调节多 种细胞的生理功能中起着重要作用. 例如, 它们可通 过心血管系统引起血管扩张, 促进血管生成, 并在心 脏保护中发挥关键作用 ${ }^{[21]}$. 其中内皮源性舒张因子 NO 是一种具有生理活性的气体，具有维持血管稳态、 调节血管张力及血压及舒张血管等功能 ${ }^{[22,23]}$, 此外还 可抗血小板聚集，具有胃肠道保护作用. 把含有 NO 供体的化合物与阿司匹林组合形成的 NO-ASP, 可在 体内同时释放 NO 和阿司匹林, 在抗血栓、抗肿瘤及 抗炎方面显示出药理活性 ${ }^{[24]}$, 是提高阿司匹林生物活 性的有效选择. 以该设计原理为出发点, 将经叔丁基 二甲基保护的对羟基苯甲醇与阿司匹林酯化，随后脱 去保护基团，再氯代后硝化，获得的衍生物 13 (Scheme 6), 作为一种治疗人结肠癌抗癌药物正在临 床前实验中 ${ }^{[25]}$.

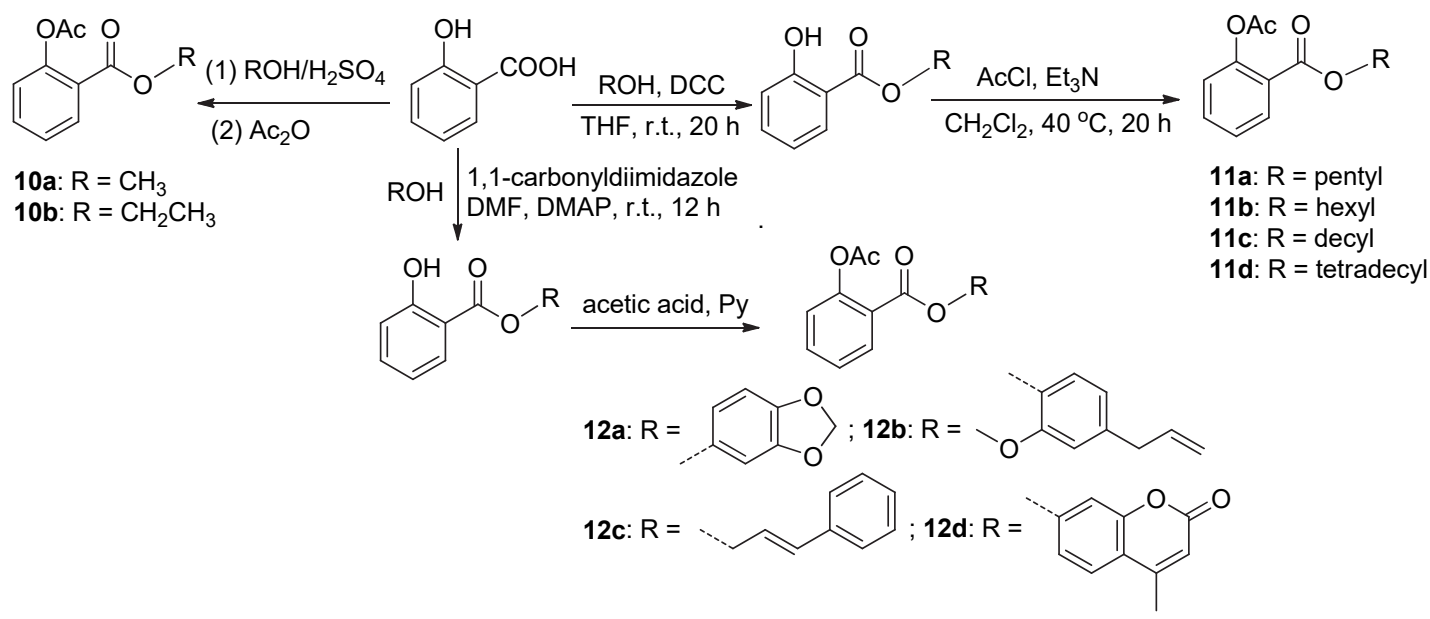

图式 5 阿司匹林衍生物 $10 \sim 12$ 的合成路线

Scheme 5 Synthetic route of aspirin derivatives $10 \sim 12$

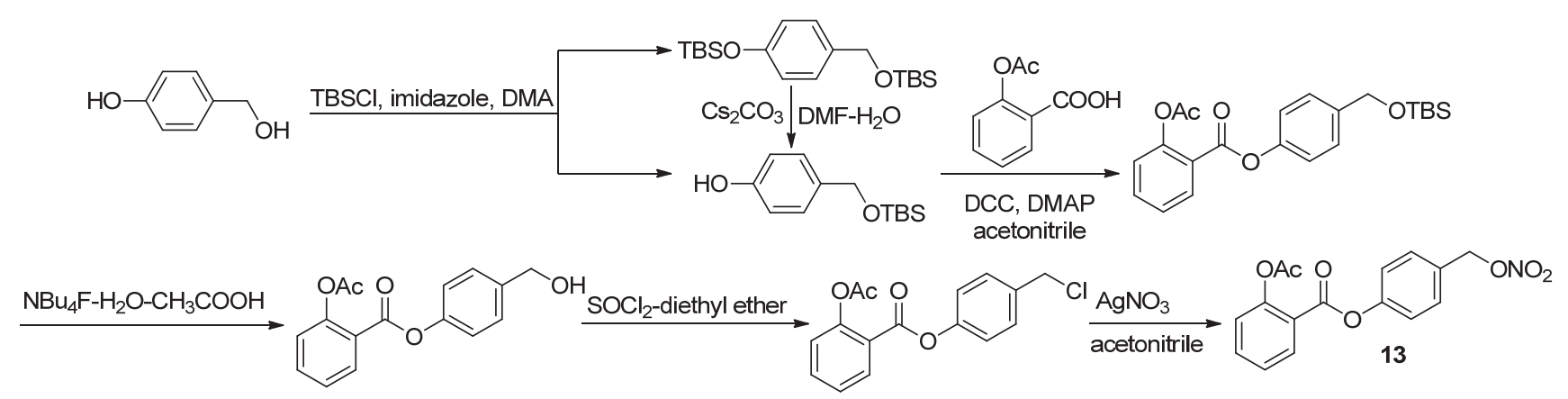

图式 6 阿司匹林衍生物 13 的合成路线

Scheme 6 Synthetic route of aspirin derivative 13 
在 2-(乙酰氧基)苯甲酸氯甲基酯的基础上, 将之 与适当的酸酰化获得衍生物 $14 \mathrm{a} \sim 14 \mathrm{~m}$, 并在 $14 \mathrm{k}$ 的基 础上氧化获得砜与亚砜衍生物 $14 \mathrm{n}$ 与 140 , 将阿司匹 林酰氯与乙醛加成, 随后与酸偶联获得衍生物 $14 p$, 在 $\mathbf{1 4 m}$ 的基础上与硝酸反应获得衍生物 14q (Scheme 7). 其中 $14 i 、 14 n$ 与 $14 q$ 具有较好的抗血小板聚集活
性，对由胶原蛋白诱导的富血小板血浆(PRP)的血小 板聚集抑制活性 $\mathrm{IC}_{50}$ 值分别为 $41 、 38$ 和 $20 \mu \mathrm{mol} \cdot \mathrm{L}^{-1}$, 优于阿司匹林 ${ }^{[26]}$.

周洲等 ${ }^{[27]}$ 在 $\mathrm{C}(1)-\mathrm{COCl}$ 引入 3 -芳基-1,2,3,4-噁三 唑-5-亚胺作 NO 供体，形成 NO-ASP 杂合体 15a $15 \mathrm{I}$

(Scheme 8), 测试表明除 15b、15c 和 $15 \mathrm{e}$ 外其他 9

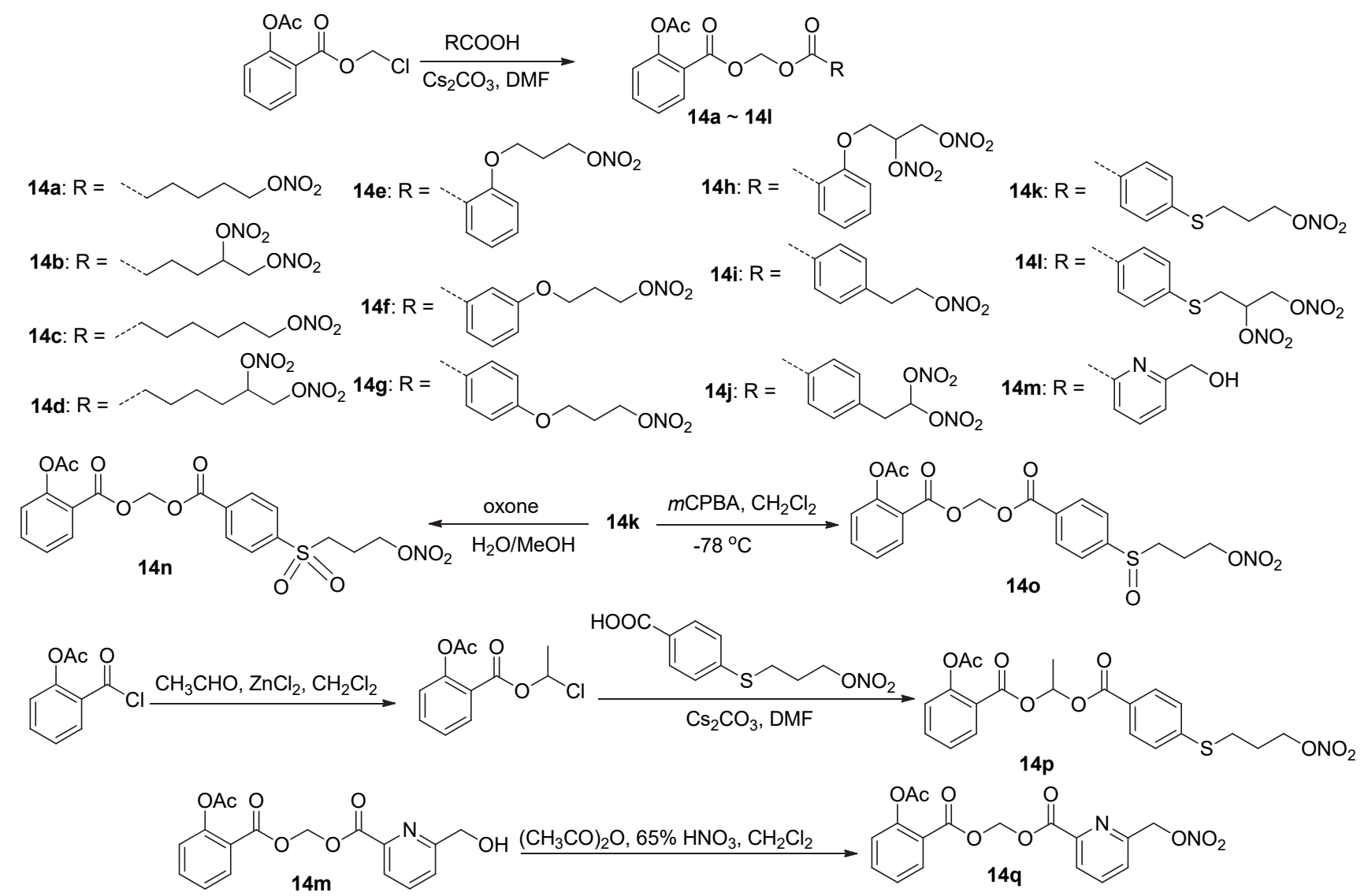

图式 7 阿司匹林衍生物 $\mathbf{1 4}$ 的合成路线

Scheme 7 Synthetic route of aspirin derivative 14
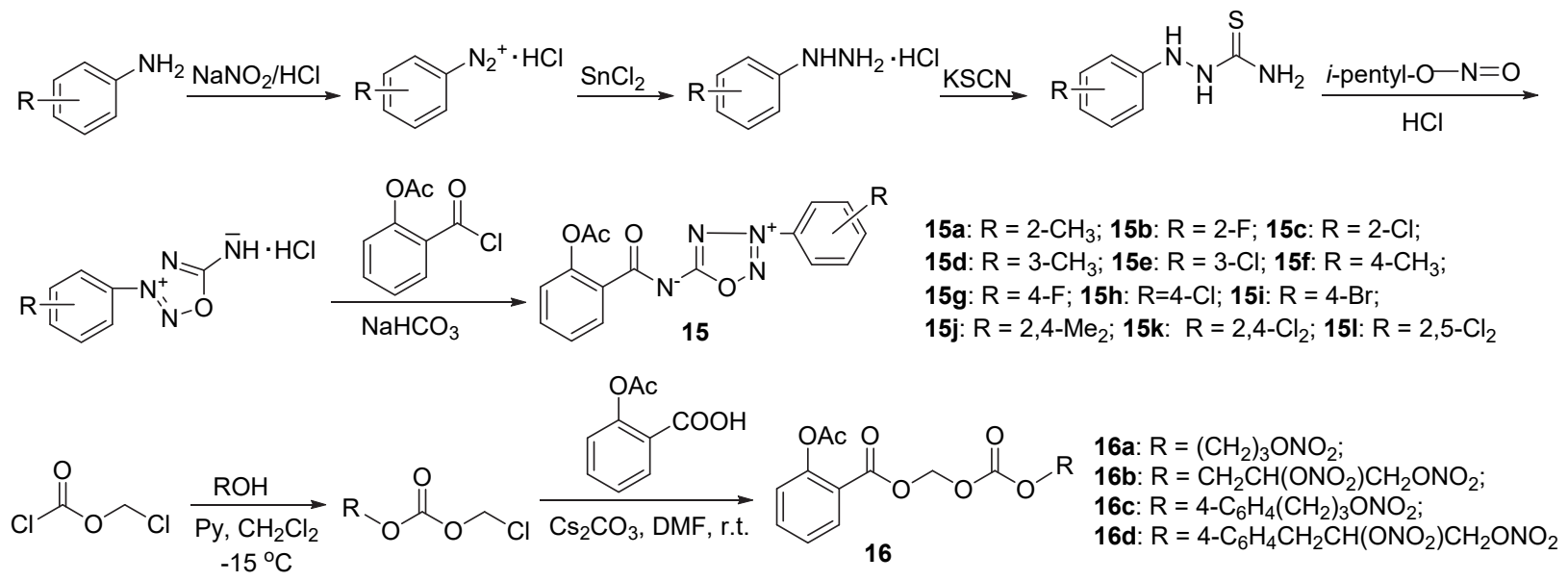

图式 8 阿司匹林衍生物 $\mathbf{1 5}$ 和 16 的合成路线

Scheme 8 Synthetic route of aspirin derivatives $\mathbf{1 5}$ and $\mathbf{1 6}$ 
种化合物均显示出一定的抑制血小板聚集的作用, $\mathbf{1 5 f}$ 抑制 ADP 诱导的血小板聚集率达 $30.7 \%$, 而 15b、15f、

$15 \mathrm{k}$ 和 $15 \mathrm{l}$ 在体内实验中对由胶原蛋白引发的小鼠肺 血栓也具有较好的抑制作用, 在 $0.33 \mathrm{mmol} \cdot \mathrm{L}^{-1} \cdot \mathrm{kg}^{-1}$ ) 的剂量下, 小鼠最高存活率达 $70 \%$. 体外抗血小板聚 集实验结果表明，当 NO 供体苯环上的 $\mathrm{R}$ 基为单一取 代基时, 取代基的位置与抗血小板聚集活性间存在一 定相关性, 对位取代时活性最高, 其次为间位, 而邻 位则较弱 $(15 \mathrm{f}>15 \mathrm{~d}>15 \mathrm{a}, 15 \mathrm{~g}>15 \mathrm{~b}, 15 \mathrm{~h}>15 \mathrm{e}>15 \mathrm{c})$; 当苯环上的单一取代基位置固定时，甲基取代物的活 性强于氟代物, 氟代物强于氯代物 $(15 \mathrm{a}>15 \mathrm{~b}>15 \mathrm{c}$, $15 \mathrm{~d}>15 \mathrm{e}, 15 \mathrm{f}>15 \mathrm{~g}>15 \mathrm{~h})$, 苯环上为二氯取代时活性 强于单一卤代物 $(15 \mathrm{k}, 15 \mathrm{l}>15 \mathrm{~b}, 15 \mathrm{c}, 15 \mathrm{e}, 15 \mathrm{~g}, 15 \mathrm{i})$, 2,4-二氯取代物活性略强于 2,5 -二氯取代物. 同样地, 以硝酸酯对阿司匹林 $\mathrm{C}(1)-\mathrm{COOH}$ 进行修饰, 获得的 NO-ASP 衍生物 16a 16d (Scheme 8), 均存在一定抗 血小板聚集活性, 但相对较弱 ${ }^{[28]}$.

阿司匹林 $\mathrm{C}(1)-\mathrm{COOH}$ 与 3-苯磺酰基呋咱氮氧化
物酯化修饰获得 NO-ASP 化合物 17a 17d (Scheme 9), 这四种化合物均表现出一定抗炎活性，在剂量 9.5 $\mathrm{mg} / \mathrm{kg}$ 时对由二甲苯致小鼠肿胀的抑制率为 $17.8 \%$ $40.4 \%$, 其中 $17 \mathbf{a}$ 和 $\mathbf{1 7 b}$ 的抗炎活性强于阿司匹林 ${ }^{[29]}$. 阿司匹林或阿司匹林酰氯与 NO 供体呋咱氮氧化物酯 化获得衍生物 18a 18d 和 19 25 (Scheme 9), 体内实 验显示这些衍生物均有一定的抗炎活性, 其中衍生物 18c、22、25 在剂量 $120 \mathrm{mg} / \mathrm{kg}$ 下对由鹿角菜胶诱导的 小鼠肿胀抑制率均高于 $50 \%$ ，抗炎活性与阿司匹林相 当. 同时所有衍生物的胃粘膜损伤均低于阿司匹林. 此外衍生物 18a、22 和 25 还表现出同阿司匹林类似的 抗血栓活性, 三者于富含血小板血浆(PRP) 中对由 $\mathrm{ADP}$ 诱导的血小板聚集抑制活性 $\mathrm{pIC}_{50}$ 值为(5.40土 $0.20) 、(7.22 \pm 0.10)$ 和 $(4.20 \pm 0.02) \mu \mathrm{mol} \cdot \mathrm{L}^{-1[30]}$.

将阿司匹林酰氯通过取代，再与 NO 供体酯化， 得到衍生物 26 (Scheme 10), 该化合物具有舒张血管 及抗心肌缺血活性, 推测可能是 NO 释放使得冠状动 脉舒张, 有待进一步的活性研究 ${ }^{[31]}$; 与 4-氨基-3-

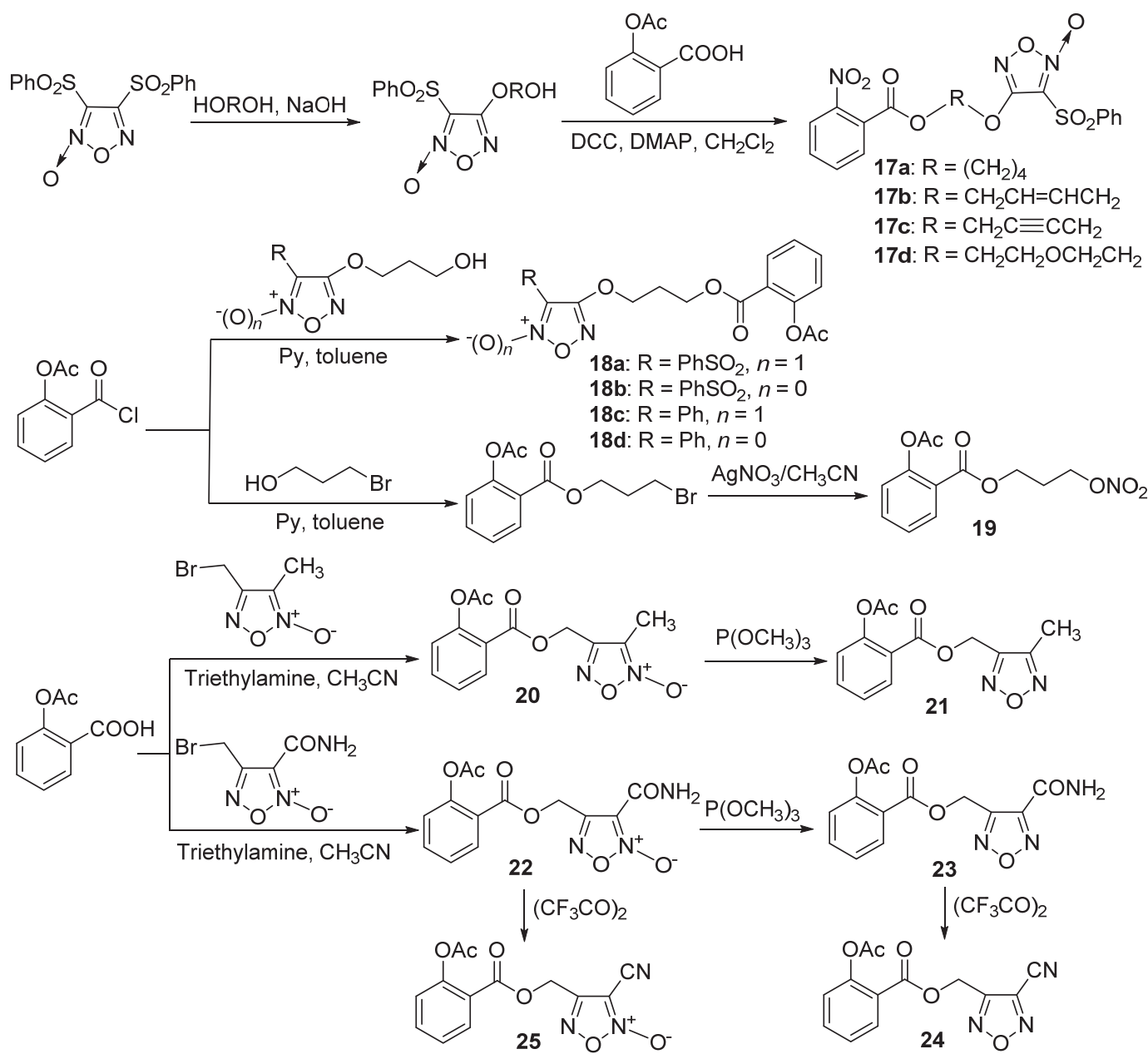

图式 9 阿司匹林衍生物 17 25 的合成路线

Scheme 9 Synthetic route of aspirin derivatives $17 \sim 25$ 
苯基呋咱取代获得的衍生物 27 , 具有微弱的抗血小板 聚集活性 ${ }^{[32]}$
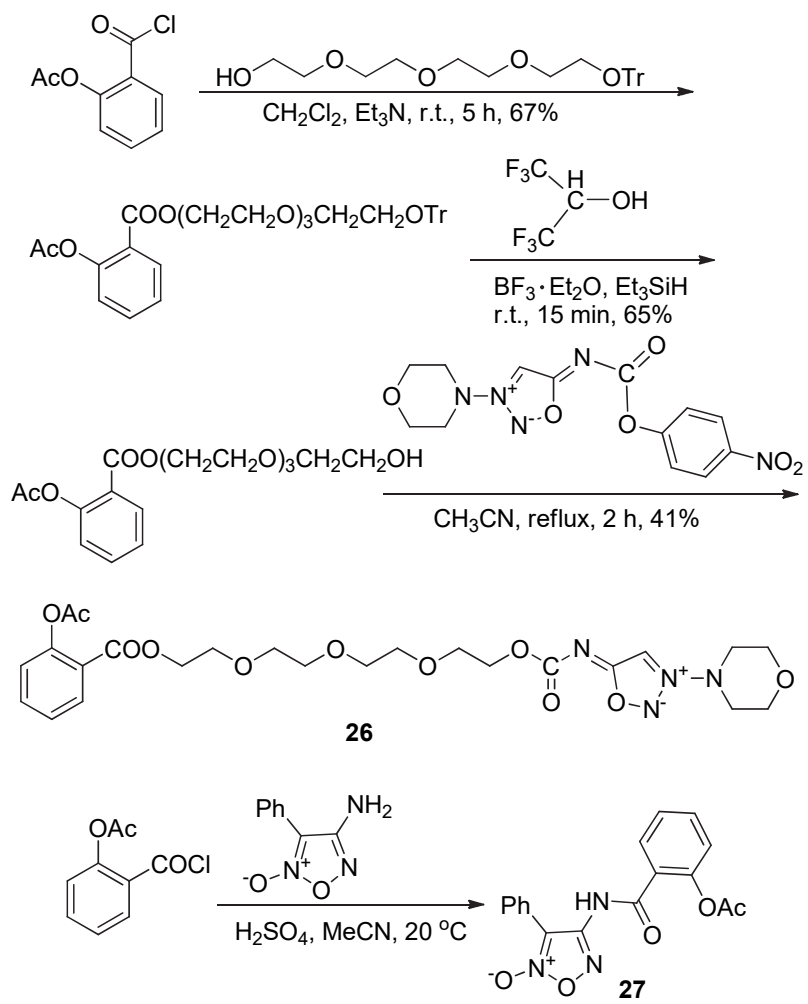

图式 10 阿司匹林衍生物 26 和 27 的合成路线

Scheme 10 Synthetic route of aspirin derivatives 26 and 27

$\mathrm{NO}$ 供体除可直接与阿司匹林 $\mathrm{C}(1)-\mathrm{COOH}$ 相连以外, 还可在 C(1)- $\mathrm{COOH}$ 与 $\mathrm{NO}$ 供体间插入具有相似活性的化 合物，这样可通过协同作用使衍生物活性更高，但其反 应路线相对复杂. 呋咱氮氧化物为 $\mathrm{NO}$ 供体, 可在体内通 过颈基还原释放气体信使分子 ${ }^{[33]}$. 以可抗血小板聚集的 阿魏酸为中间连接基团, 分别以 4-苯基呋咱氮氧化物、 3-苯磺酰基呋咱氮氧化物或硝酸酯为 NO 供体, 形成杂合 体 28a 28n (Scheme 11). 体内实验结果显示化合物 28a 28c、28i、281 和 28n 能显著抑制血小板聚集, 其中 抑制由 ADP 诱导的血小板聚集率最低为 $28.31 \%$, 最高达 $43.81 \%{ }^{[34]}$. 同样地，将对羟基桂皮酸作为中间连接基团， 以 4-苯基呋咱氮氧化物或硝酸酯为 NO 供体, 形成杂合 体 29a 29h (Scheme 11). 其中化合物 29f 具有显著的抗 血小板聚集作用，其抑制小鼠体内血小板聚集率 $43.9 \%$ 高于阿司匹林的 $28.05 \%$, 此外该衍生物还能够抑制鼠脑 血栓的形成, 降低血浆中 TXB2 的水平 ${ }^{[35]}$.

在 NO-NSAIDs 的基础上, Velázquez 等 ${ }^{[36]}$ 提出了 NONO-NSAIDs 的概念, NONO-NSAIDs 与传统 NO-NSAIDs 的区别在于, NONO-NSAIDs 可释放两分子 的 NO. 以 $N$-重氮-1-铵-1,2-二酸酯基团为设计点, 阿司 匹林 C(1)-COOH 位经磺酰氯酰化再与 NO 供体反应, 生

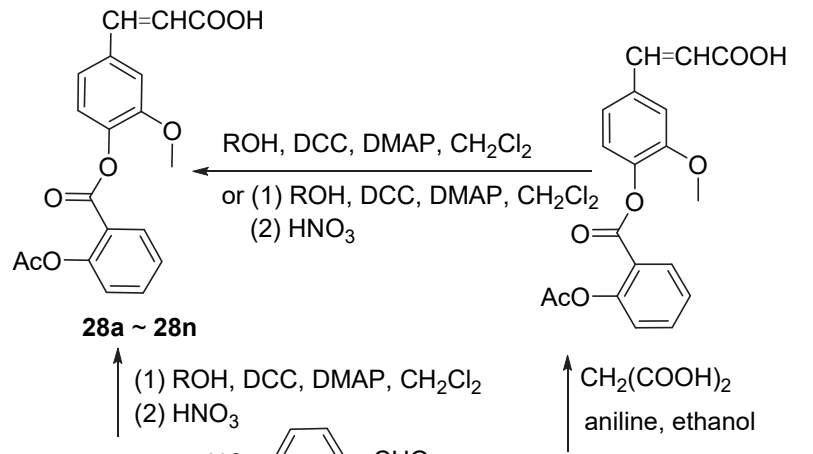

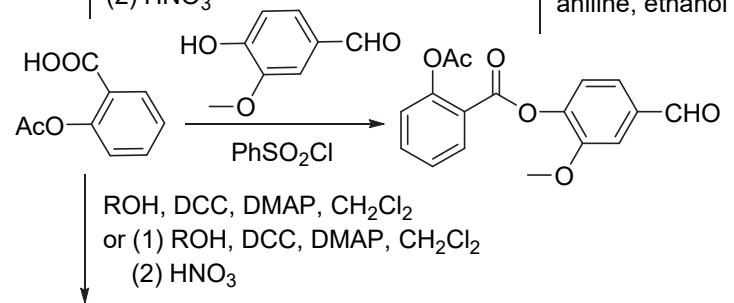<smiles>[R]OCC=Cc1ccc(OC(=O)c2ccccc2OC(C)=O)cc1</smiles>

$29 a \sim 29 h$

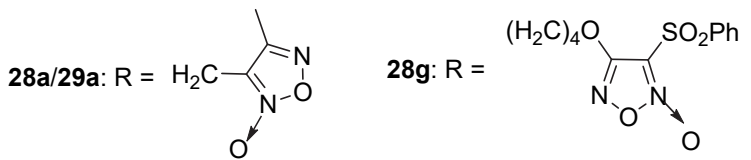

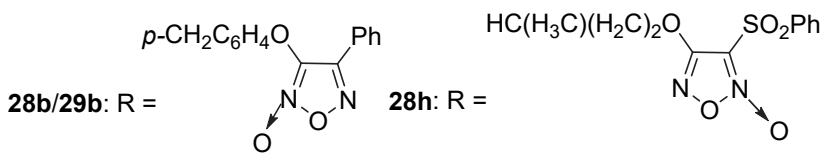

28c/29c: $R=$<smiles>[O-][n+]1onc(-c2ccccc2)c1O</smiles>
28i: $R=$ $\left(\mathrm{H}_{2} \mathrm{C}\right)_{2} \mathrm{O}\left(\mathrm{H}_{2} \mathrm{C}\right)_{2} \mathrm{O}$ $\mathrm{SO}_{2} \mathrm{Ph}$ 28j/29e: $\mathrm{R}=\left(\mathrm{CH}_{2}\right)_{3} \mathrm{ONO}_{2}$<smiles>[R]CPCCOc1c(-c2ccccc2)no[n+]1[O-]</smiles><smiles>[R6][14CH2][14CH2]Oc1c(-c2ccccc2)no[n+]1[O-]</smiles>

28f: $R=$<smiles></smiles>
29d: $\mathrm{R}=\left(\mathrm{CH}_{2}\right)_{2} \mathrm{ONO}_{2}$

图式 11 阿司匹林衍生物 $\mathbf{2 8}$ 和 29 的合成路线

Scheme 11 Synthetic route of aspirin derivatives $\mathbf{2 8}$ and 29

成了 NONO-ASP 衍生物 30 (Scheme 12), 该衍生物具有 更优良的抗炎活性, $\mathrm{ED}_{50}$ 值为 $314 \mu \mathrm{mol} / \mathrm{kg}$, 为阿司匹林 的 2.2 倍. 相似地, 阿司匹林 C(1)-COOH 经酯化生成了 衍生物 31a 和 31b, 体外实验表明, 衍生物 31a 在剂量 $121 \mathrm{mg} / \mathrm{kg}$ 时同 $129 \mathrm{mg} / \mathrm{kg}$ 的阿司匹林有相同的抗炎活 性, 衍生物 31b 抗炎活性相对较弱 ${ }^{[37]}$. 


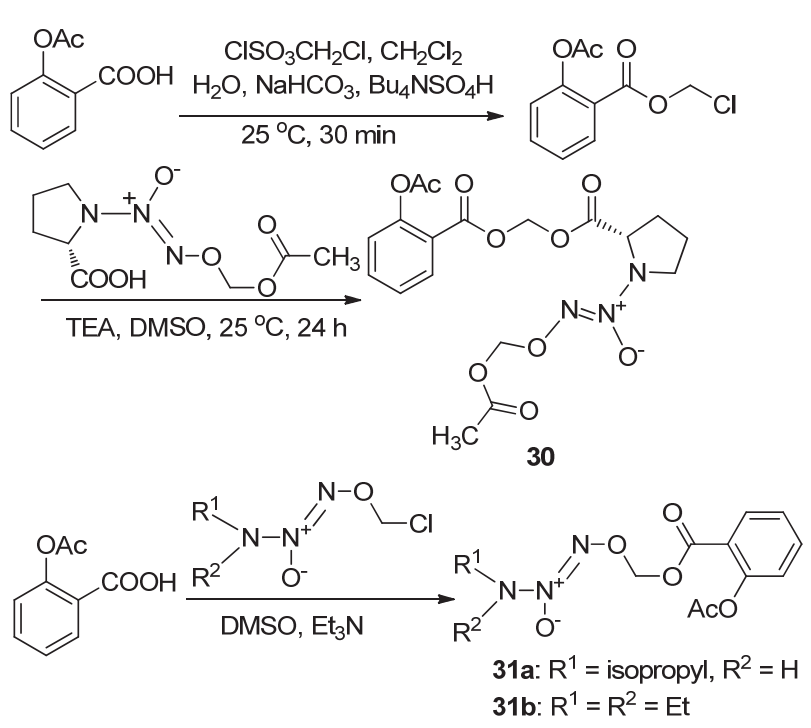

图式 12 阿司匹林衍生物 30 和 31 的合成路线

Scheme 12 Synthetic route of aspirin derivatives $\mathbf{3 0}$ and $\mathbf{3 1}$

偶氮是另外一种具有抗糖尿病、抗肿瘤及抗菌等药 理作用的活性化合物 ${ }^{[38]}$, 其抗癌和抑制蛋白质合成活 性等得到了广泛研究 ${ }^{[39,40]}$. 将苯酚与 4-卤代苯胺经过偶 合反应制备得到 4-[(4-卤代苯基)重氮基]苯酚, 再与阿 司匹林 $\mathrm{C}(1)-\mathrm{COOH}$ 酯化生成阿司匹林偶氮衍生物 32a 32d (Scheme 13). 这些衍生物在 HK-1 癌细胞中均 显示出一定的抗癌活性, 其中化合物 32a 及 32b 的抗癌 活性优于阿司匹林, 两者的 $\mathrm{IC}_{50}$ 分别为(38.7 \pm 1.5$)$ 和 $(44.9 \pm 9.4) \mu \mathrm{mol} \cdot \mathrm{L}^{-1[41]}$. 同样地, 阿司匹林与偶氮化合 物酯化获得了衍生物 33a 33d (Scheme 13), 该系列化 合物对大肠杆菌和金黄色葡萄球菌显示出较差的抗菌 活性, 最低抑菌浓度 $(\mathrm{MIC})>220 \mathrm{mg} / \mathrm{L}$, 综合抗菌活性 较弱. 将化合物 33a 33d 与未酯化的偶氮化合物比较, 推测可能为阿司匹林与偶氮化合物酯化后失去了羟基, 使得与相应酶结合时缺乏氢键, 致使抗菌活性较低, 实 验表明羟基、羧基和卤素基团的存在对提高化合物的抗 菌活性起着重要作用 ${ }^{[42]}$.

硫嫝是一种反应性前体物质, 具有抗菌、抗癌、抗 结核和抗 HIV 等多种生物学活性, 其存在的 $\mathrm{C}=\mathrm{S}$ 和 $\mathrm{C}=\mathrm{O}$ 在许多生物过程中发挥着重要作用 ${ }^{[43]}$. 将阿司匹 林 $\mathrm{C}(1)-\mathrm{COOH}$ 经过酰化再于碱性条件下与氨基酸反应, 生成阿司匹林硫胀衍生物 34a $~ 34 h$ (Scheme 14), 总收 率为 $46 \% \sim 73 \%$. 此 8 种化合物均对大肠杆菌显示出抗 菌活性 ${ }^{[44]}$. 类似地, Nordin 等 ${ }^{[43]}$ 合成了系列含硫艮的阿 司匹林衍生物 $35 \mathrm{a} \sim 35$ I, 与阿司匹林相比, 该系列化合 物具有中等至优良的抗菌活性. 其中取代基的位置与类 型均对抗菌活性存在影响, 间位取代基相较于邻位和对 位取代基具有更好的抗菌活性, 并且烷基链较短与烷
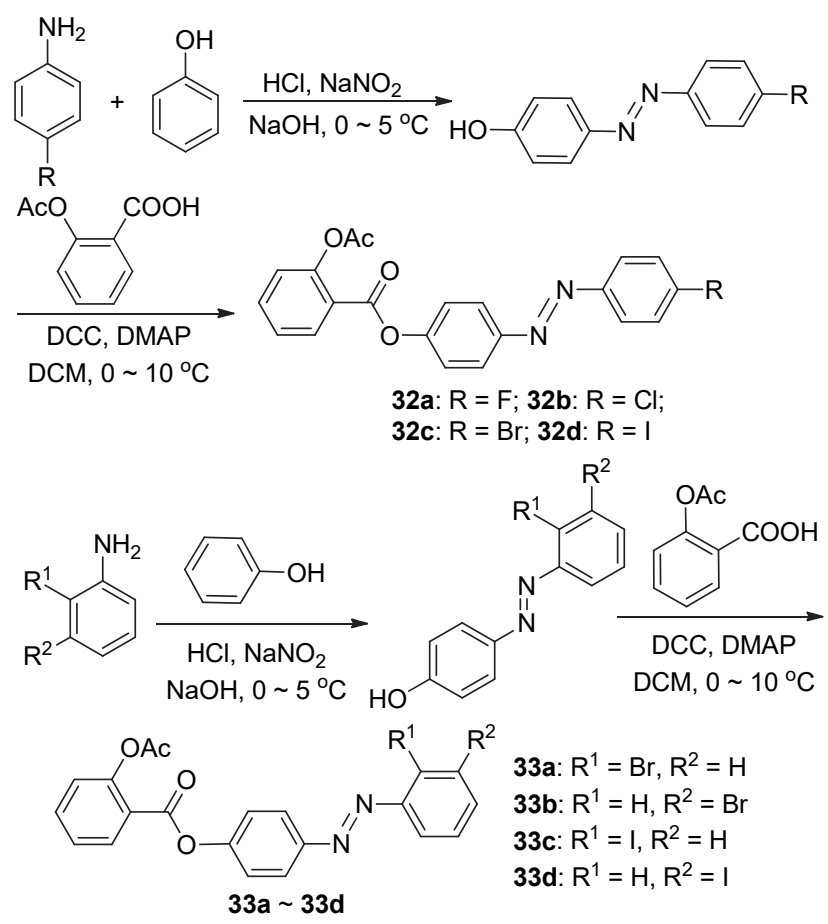

图式 13 阿司匹林衍生物 $\mathbf{3 2}$ 和 $\mathbf{3 3}$ 的合成路线

Scheme 13 Synthetic route of aspirin derivatives $\mathbf{3 2}$ and $\mathbf{3 3}$
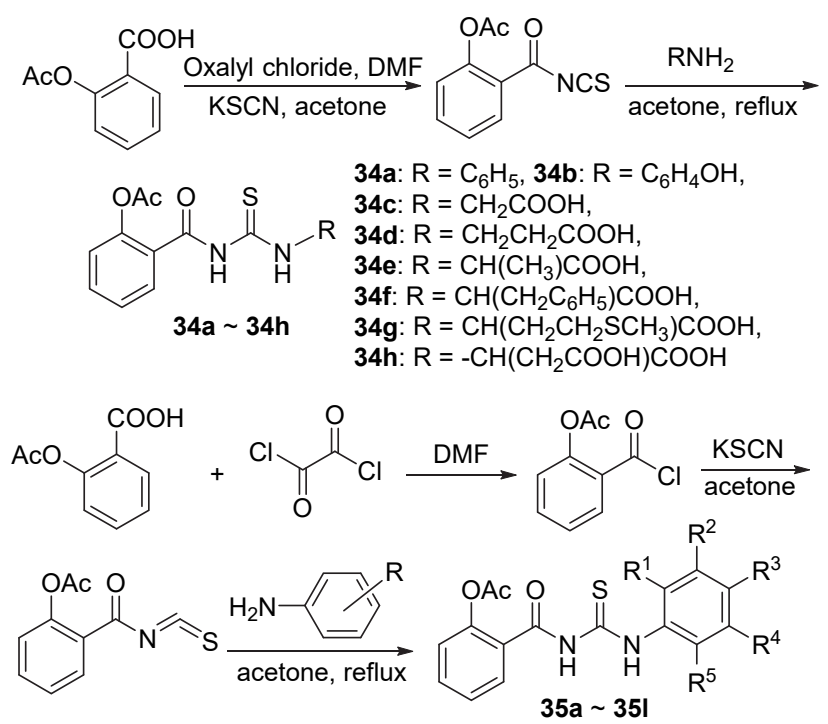
35a: $\mathrm{R}^{1}=\mathrm{CH}_{3} ; \mathrm{R}^{2}=\mathrm{CH}_{3} ; \mathrm{R}^{3}=\mathrm{H} ; \mathrm{R}^{4}=\mathrm{H} ; \mathrm{R}^{5}=\mathrm{H}$
35b: $\mathrm{R}^{1}=\mathrm{CH}_{3} ; \mathrm{R}^{2}=\mathrm{H} ; \mathrm{R}^{3}=\mathrm{CH}_{3} ; \mathrm{R}^{4}=\mathrm{H} ; \mathrm{R}^{5}=\mathrm{H}$
35c: $\mathrm{R}^{1}=\mathrm{CH}_{3} ; \mathrm{R}^{2}=\mathrm{H} ; \mathrm{R}^{3}=\mathrm{H} ; \mathrm{R}^{4}=\mathrm{CH}_{3} ; \mathrm{R}^{5}=\mathrm{H}$
35d: $R^{1}=\mathrm{CH}_{3} ; \mathrm{R}^{2}=\mathrm{H} ; \mathrm{R}^{3}=\mathrm{H} ; \mathrm{R}^{4}=\mathrm{H} ; \mathrm{R}^{5}=\mathrm{CH}_{3}$
35e: $\mathrm{R}^{1}=\mathrm{H} ; \mathrm{R}^{2}=\mathrm{CH}_{3} ; \mathrm{R}^{3}=\mathrm{H} ; \mathrm{R}^{4}=\mathrm{H} ; \mathrm{R}^{5}=\mathrm{H}$
35f: $\mathrm{R}^{1}=\mathrm{OCH}_{3} ; \mathrm{R}^{2}=\mathrm{H} ; \mathrm{R}^{3}=\mathrm{H} ; \mathrm{R}^{4}=\mathrm{OCH}_{3} ; \mathrm{R}^{5}=\mathrm{H}$
35g: $\mathrm{R}^{1}=\mathrm{H} ; \mathrm{R}^{2}=\mathrm{OCH}_{3} ; \mathrm{R}^{3}=\mathrm{OCH}_{3} ; \mathrm{R}^{4}=\mathrm{H} ; \mathrm{R}^{5}=\mathrm{H}$
35h: $R^{1}=\mathrm{H} ; \mathrm{R}^{2}=\mathrm{OCH}_{3} ; \mathrm{R}^{3}=\mathrm{H} ; \mathrm{R}^{4}=\mathrm{OCH}_{3} ; \mathrm{R}^{5}=\mathrm{H}$
35i: $\mathrm{R}^{1}=\mathrm{H} ; \mathrm{R}^{2}=\mathrm{H} ; \mathrm{R}^{3}=\mathrm{OC}_{6} \mathrm{H}_{13} ; \mathrm{R}^{4}=\mathrm{H} ; \mathrm{R}^{5}=\mathrm{H}$
35j: $\mathrm{R}^{1}=\mathrm{H} ; \mathrm{R}^{2}=\mathrm{H} ; \mathrm{R}^{3}=\mathrm{OC}_{10} \mathrm{H}_{21} ; \mathrm{R}^{4}=\mathrm{H} ; \mathrm{R}^{5}=\mathrm{H}$
35k: $R^{1}=H ; R^{2}=H ; R^{3}=O_{12} H_{25} ; R^{4}=H ; R^{5}=H$
35I: $\mathrm{R}^{1}=\mathrm{H} ; \mathrm{R}^{2}=\mathrm{H} ; \mathrm{R}^{3}=\mathrm{OC}_{14} \mathrm{H}_{29} ; \mathrm{R}^{4}=\mathrm{H} ; \mathrm{R}^{5}=\mathrm{H}$

图式 14 阿司匹林衍生物 34 和 35 的合成路线

Scheme 14 Synthetic route of aspirin derivatives $\mathbf{3 4}$ and $\mathbf{3 5}$ 
基链较长的衍生物相比, 烷基链短的衍生物比烷基链长 的衍生物活性高 ${ }^{[43]}$.

$\mathrm{C}(1)-\mathrm{COOH}$ 修饰是阿司匹林骨架衍生的主要方向, 其活性涉及抗血栓、抗癌、抗炎、抗衰老及抗菌等. 将 阿司匹林直接酯化和先制得乙酰水杨酸酰氯再与醇或 胺反应, 是制备 C(1)-COOH 位衍生物的两种方法. 酰氯 相较于羧酸的反应活性更高, 因此第二种方法是主要的 合成路径. 而相较于酰胺化衍生物, 酯化物的脂水分配 系数更佳, 更易透过血脑屏障而发挥药效. $\mathrm{C}(1)-\mathrm{COOH}$ 修饰的衍生物多为阿司匹林与活性物质结合为主, 如 $\mathrm{NO}$ 供体、偶氮和硫嫝. 这当中又以抗血栓化合物居多, 占比 $43.39 \%$, 而抗血栓衍生物中 $93.75 \%$ 为 NO-ASP 或 NONO-ASP, 且大多活性优良, NO 供体均为呋咱氮氧化 物类或硝酸酯类. 即用 $\mathrm{NO}$ 供体对阿司匹林进行 C(1)-COOH 结构修饰是制备抗血栓衍生物的主要方法.

\section{$1.2 \mathrm{C}(1)-\mathrm{COOH}$ 和 C(2)-OAc 同时修饰}

用羟基磷灰石对阿司匹林进行结构修饰, 得到 $\mathrm{C}(1)-\mathrm{COOH}$ 和 C(2)-OAc 以氢键闭合成环的衍生物 36 (Eq. 1), 该衍生物与阿司匹林在相同剂量下具有类似的 抗血栓活性，由于羟基磷灰石具有上调 PGE2 的功效, 使得该衍生物降低了阿司匹林对胃粘膜的损伤 ${ }^{[45]}$.

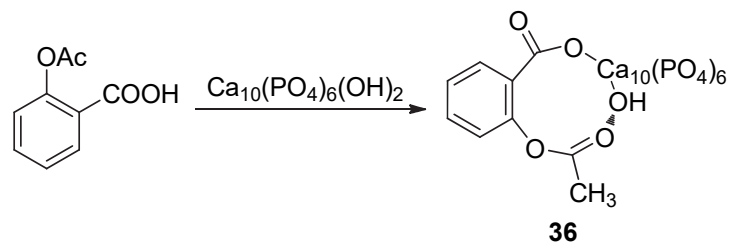

$\mathrm{H}_{2} \mathrm{~S}$ 作为一种重要的内源性调节剂, 对心血管系统 具有与 NO 同样的有益作用, 并具有抗炎和抗过氧化物 作用. 如上述衍生物 2 在 HT-29、SKBR3、MCF7 等多 种细胞中表现出强的抗癌活性, 其 $\mathrm{IC}_{50}$ 值分别为 $(3.7 \pm 0.9) 、(3.3 \pm 0.9) 、(4.2 \pm 1.1) \mu \mathrm{mol} \cdot \mathrm{L}^{-1[7]}$. 将 $\mathrm{NO}$ 和 $\mathrm{H}_{2} \mathrm{~S}$ 两者结合的阿司匹林衍生物被称为 NOSH-ASP, 此 类衍生物能够在体内同时释放 $\mathrm{NO}$ 和 $\mathrm{H}_{2} \mathrm{~S}$ 这两种活性气 体. 基于这种设计思路, 以硝酸酯为 NO 供体, 以 5-(4羟基苯基)-3H-1,2-二硫杂环戊烯-3-硫酮为 $\mathrm{H}_{2} \mathrm{~S}$ 供体, 将 水杨醛 C(1)位和 C(2)位同时修饰得到两种 NOSH-阿司 匹林衍生物 37a 和 37b (Scheme 15), 这两种衍生物表现 出较好的抗癌活性, 体外实验测试得到它们在 HT-29癌 细胞中的 $\mathrm{IC}_{50}$ 值分别为 $(200 \pm 50)$ 和 $(380 \pm 150) \mu \mathrm{mol} \cdot$ $\mathrm{L}^{-1}$, 在 $\mathrm{HCT} 15$ 癌细胞中的 $\mathrm{IC}_{50}$ 值分别为 $(400 \pm 150)$ 和 $(170 \pm 30) \mu \mathrm{mol} \cdot \mathrm{L}^{-1}$, 活性远高于阿司匹林 ${ }^{[46]}$.

类似地, 在水杨醛和阿司匹林的基础上合成了四种 NOSH-阿司匹林衍生物 38 41 (Scheme 16), 四种衍生 物在体内可同时释放出 $\mathrm{NO}$ 与 $\mathrm{H}_{2} \mathrm{~S}$, 达到抗癌效果, 它

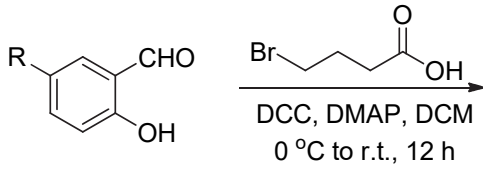<smiles>[R]c1ccc(OC(=O)CCBr)c(C=O)c1</smiles>

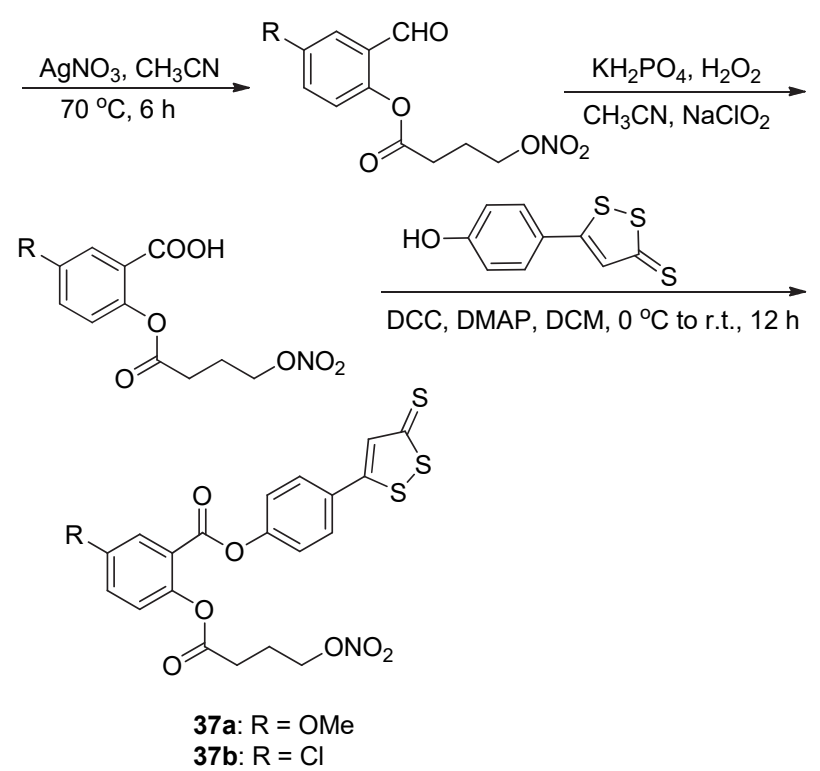

图式 15 阿司匹林衍生物 $\mathbf{3 7}$ 的合成路线

Scheme 15 Synthetic route of aspirin derivatives 37

们对结肠、乳腺、胰腺、前列腺、肺以及白血病中的 11 种癌细胞系均表现出强大的抗癌活性, 其中化合物 $\mathbf{3 8}$ 对 HT-29 细胞的抗癌活性至少是阿司匹林的十万倍，且 化合物 39 41 在同一细胞系中的增效作用分别为 $>6$ 万倍、 $>600$ 倍和 $>1.6$ 万倍. 此外, 化合物 $\mathbf{3 8}$ 还显示出 一定的抗炎活性, 其抗炎能力与阿司匹林相近 ${ }^{[47]}$.

阿司匹林 $\mathrm{C}(1)-\mathrm{COOH}$ 与 $\mathrm{C}(2)-\mathrm{OAc}$ 为阿司匹林的重 要活性位点，目前同时修饰制备得到的衍生物仅 7 种. 衍生物以抗癌活性为主, 效力强于阿司匹林. 同 C(1)$\mathrm{COOH}$ 修饰的衍生物类似，此类衍生物也为阿司匹林与 活性物质结合为主, 为 NOSH-ASP, 相较于 NO-ASP 而 言, NOSH-ASP 由于引入两种活性物, 且需对 C(1)$\mathrm{COOH}$ 与 C(2)-OAc 位同时修饰, 因此 NOSH-ASP 合成 步骤相对复杂. 但其活性更佳, 如衍生物 38 对 HT-29 细 胞的 $\mathrm{IC}_{50}$ 为 $(48 \pm 3) \mathrm{nmol} \cdot \mathrm{L}^{-1}$, 而在纳摩尔级别阿司匹 林与 NO-ASP 衍生物均无抗癌活性.

\section{$1.3 \mathrm{C}(2)-\mathrm{OAc}$ 修饰}

以水杨醛为底物，将酚羟基分别与单硝基氧基和双 硝基氧基取代化合物连接，再氧化醛基获得 NO-ASP 衍 生物 42a 42f 与 43a $\sim 43 \mathrm{e}$ (Scheme 17), 体外实验结果 显示, 衍生物 42a $\sim 42 \mathrm{c}$ 和 43a 显示出一定的抗血小板聚 集活性，它们 $\mathrm{IC}_{50}$ 值分别为 $162 、 30 、 91$ 和 $126 \mu \mathrm{mol} \cdot$ $\mathrm{L}^{-1}$ ，其中 42b 活性高于阿司匹林. 同时，由角叉菜胶引 


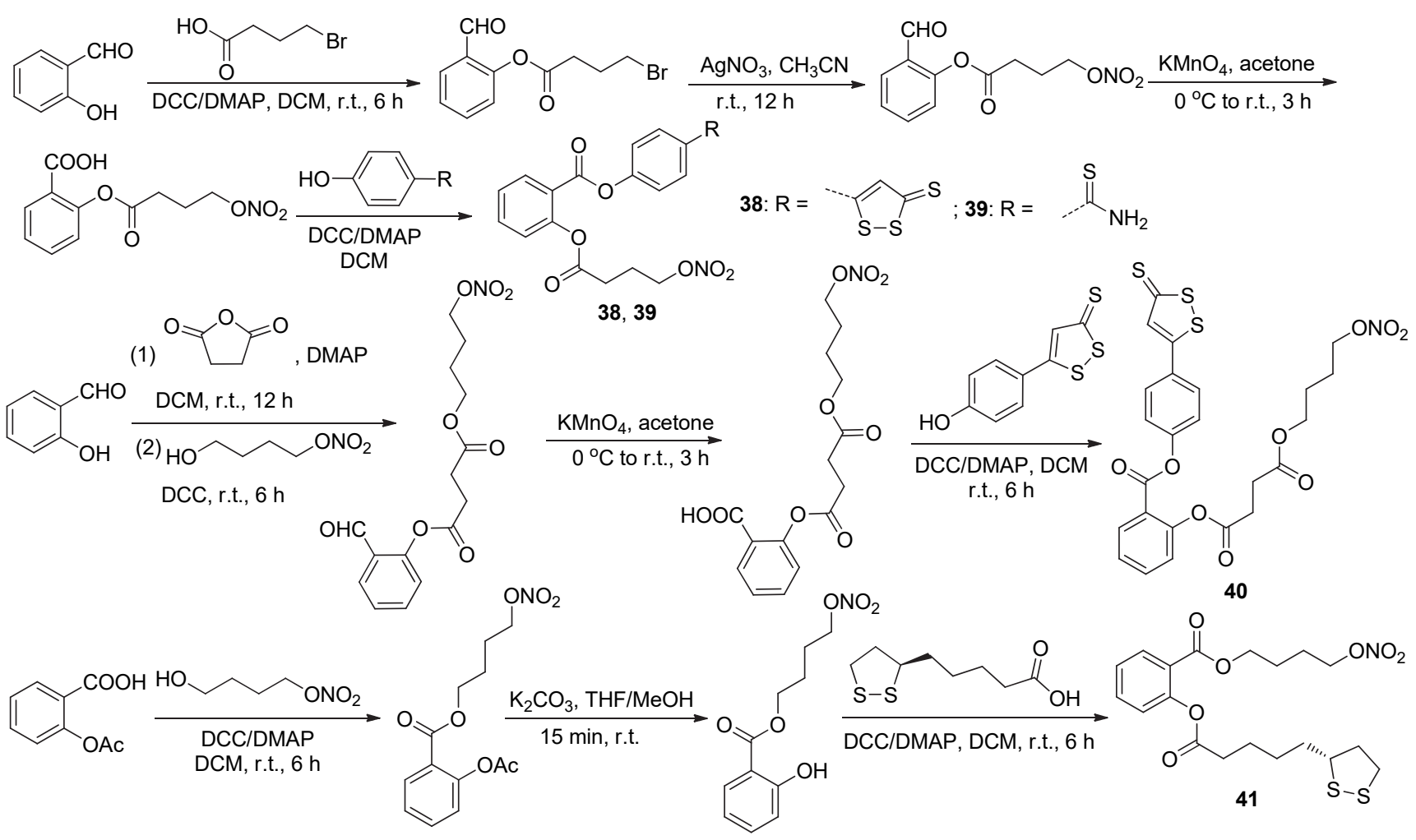

图式 16 阿司匹林衍生物 $38 \sim 41$ 的合成路线

Scheme 16 Synthetic route of aspirin derivatives $38 \sim 41$

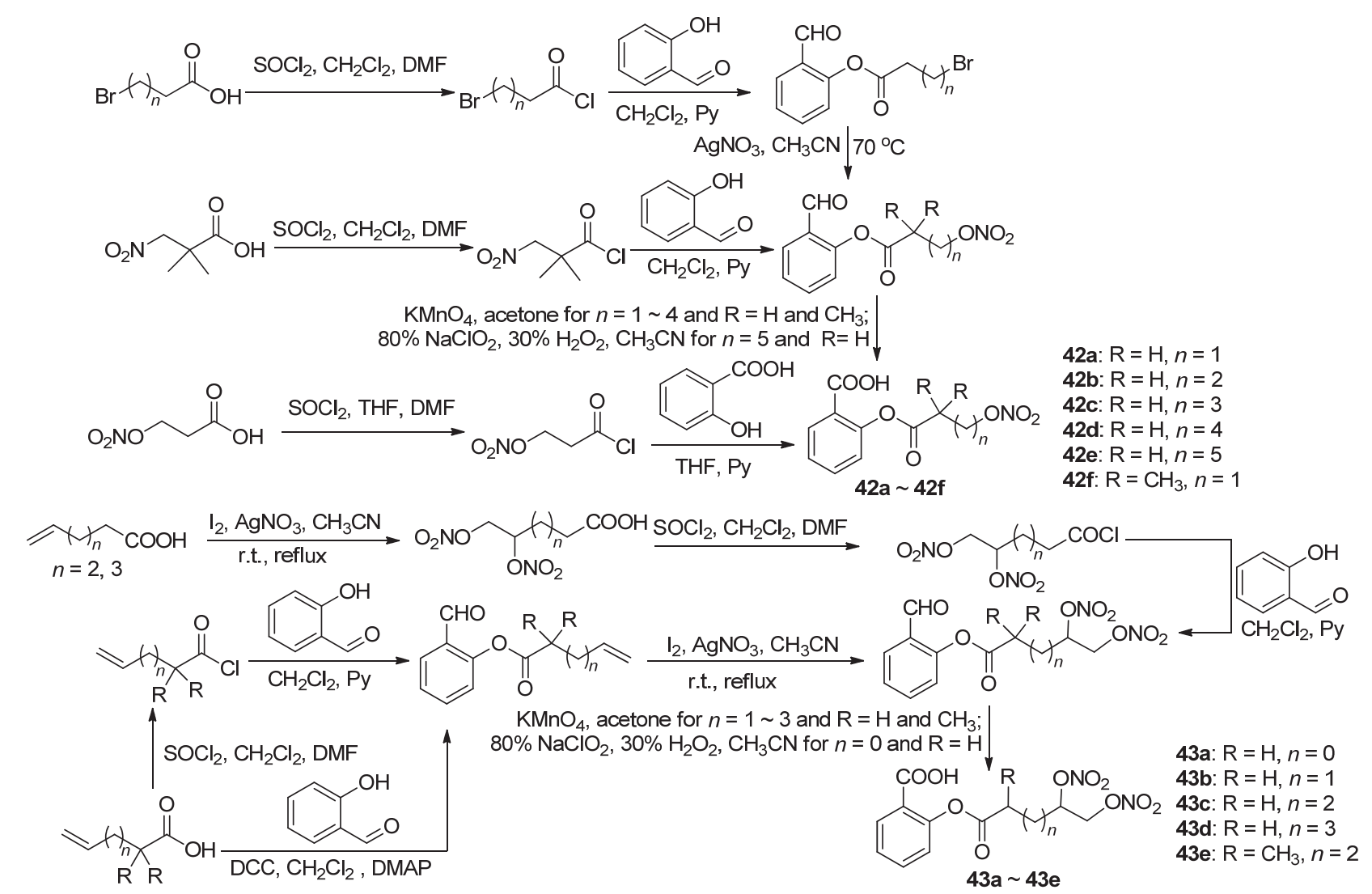

图式 17 阿司匹林衍生物 $\mathbf{4 2}$ 和 $\mathbf{4 3}$ 的合成路线

Scheme 17 Synthetic route of aspirin derivatives $\mathbf{4 2}$ and $\mathbf{4 3}$ 
起的小鼠爪水肿实验中, 各个衍生物均显示出不同程度 的抑制水肿能力, 其中衍生物 42c、42d、42f 和 $43 \mathrm{~b} \sim$ 43d 的抑制水肿能力同阿司匹林相近, 即显示出抗炎活 性. 此外, 在胃粘膜损伤实验中, 除衍生物 $42 \mathrm{a} \sim \mathbf{4 2 c}$ 外, 其余衍生物的胃粘膜细胞的病变率均小于 $10 \%$, 远低于 胃粘膜细胞病变率 $>50 \%$ 的阿司匹林, 副作用明显减 少 ${ }^{[48]}$.

以水杨酸为底物, 将酚差基酰化制得了阿司匹林衍 生物 44a 44d (Scheme 18), 44a 与 44d 的活性均低于阿 司匹林, $44 \mathbf{a}$ 在含量为 $100 \mu \mathrm{mol} \cdot \mathrm{L}^{-1}$ 时的血小板聚集抑 制率为 $70 \%, 44 \mathrm{~b}$ 则在 $500 \mu \mathrm{mol} \cdot \mathrm{L}^{-1}$ 时才显示出相近的 血小板聚集抑制率 ${ }^{[10,16]}$. 戊炔酸在二环己基碳二亚胺 (DDC)作用下制得戊炔酸酐，再与阿司匹林的 C(2)-OAc 发生酯交换反应获得了衍生物 45 (Scheme 18), 该化合 物在 HCT-15 结肠癌细胞中显示出抗癌活性 ${ }^{[49]}$. Thomas 等 ${ }^{[9]}$ 以药效团杂交的原理开发了双效抗炎/抗肿瘤类的 阿司匹林化合物 46a 46c (Scheme 18), 衍生物 46a 对 NSCLC A549 细胞显示出抗炎和抗肿瘤活性.

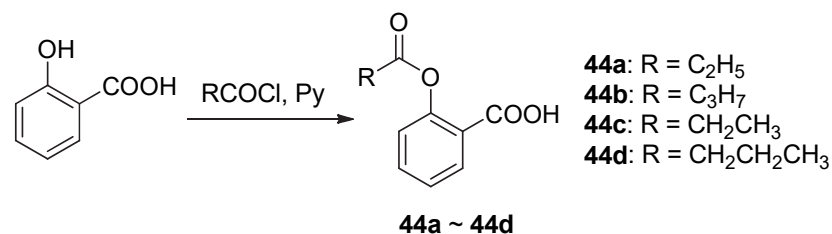<smiles>C#CCCC(=O)OC(=O)CCC(=O)Oc1ccccc1C(=O)OCC(=O)OCC(=O)OCC(=O)Oc1ccccc1C(=O)O</smiles><smiles>[R]C(=O)Oc1ccccc1COc1ccccc1ONC(=O)OCC(=O)O</smiles><smiles>[R]C(=O)Oc1ccccc1C(=O)O</smiles>

图式 18 阿司匹林衍生物 $44 \sim 46$ 的合成路线

Scheme 18 Synthetic route of aspirin derivativevs $44 \sim 46$

水杨酸与呋咱氮氧化物酰化生成了 NO-ASP 47a 47h (Scheme 19), 它们在 $120 \mathrm{mg} / \mathrm{kg}$ 的剂量下作用于由 角叉菜胶引起的小鼠足肿胀时, 均显示出同阿司匹林类 似的抗炎活性，抑制率均在 37\% 55\%之间，其中衍生 物 47c 和 $47 \mathrm{~g}$ 的抑制率最高达 $50 \% \sim 55 \%$. 此外, 衍生
物 $47 \mathrm{c}$ 与 $47 \mathrm{~g}$ 还显示出较好的抗血小板聚集活性, $\mathrm{IC}_{50}$ 值分别为 7.8 与 $7.3 \mu \mathrm{mol} \cdot \mathrm{L}^{-1[50]}$.<smiles>[R]c1c(OCCC(=O)O)no[n+]1[O-]</smiles><smiles>[R]c1c(OCCC(=O)Oc2ccccc2C(=O)O)no[n+]1[O-]</smiles>

47a: $\mathrm{R}=\mathrm{Ph}, n=1$

47b: $\mathrm{R}=\mathrm{Ph}, n=0$

47c: $\mathrm{R}=\mathrm{PhSO}_{2}, n=1$

47d: $\mathrm{R}=\mathrm{PhSO}_{2}, n=0$<smiles>[R]c1c(CSCC(=O)O)no[n+]1[O-]</smiles><smiles>O=C(O)c1ccccc1O</smiles><smiles>[R]c1c(CSCC(=O)Oc2ccccc2C(=O)O)no[n+]1[O-]</smiles>

47e: $\mathrm{R}=\mathrm{CONH}_{2}, n=1$ 47f: $\mathrm{R}=\mathrm{CONH}_{2}, n=0$

47g: $\mathrm{R}=\mathrm{CN}, n=1$

47h: $\mathrm{R}=\mathrm{CN}, n=0$

图式 19 阿司匹林衍生物 $\mathbf{4 7}$ 的合成路线 Scheme 19 Synthetic route of aspirin derivative 47

阿司匹林 C(2)-OAc 修饰的衍生物相对较少, 仅 27 种，常以其他底物如水杨酸和水杨醛等合成制备出具有 阿司匹林母体结构的衍生物. 衍生物活性涉及抗炎、抗 血栓及抗癌, 其中 NO-ASP 占 17 种, 各种衍生物的活性 大小与阿司匹林相近，即阿司匹林 C(2)-OAc 修饰活性 提高不明显.

\section{4 苯环修饰}

阿司匹林苯环上的结构修饰并不常见，并且合成相 对较难, 故常常从其他简单化合物出发制备其衍生物. 对着基苯乙醇经 C(1)位氯代、 C(3)位甲酰化、氧化和水 解, 最后再使 C(4)-OH 酰化获得了化合物 48 (Scheme 20). 体外实验显示该化合物具有抗炎活性, 以剂量 100 $\mathrm{mg} / \mathrm{kg}$ 给药, $4 \mathrm{~h}$ 后其改善角叉菜胶诱导的肿胀率为 $(28.40 \pm 0.18)^{\left[{ }^{[51]}\right.}$. Huang 等 ${ }^{[52]}$ 以 5 -氨基水杨酸与乙酸 酐酰化或先与 2-甲基-4-溴-2-丁烯制得中间产物，再与 乙酸酤酰化分别得到了衍生物 49 和 50 , 这两种衍生物 经测试具有抗衰老活性的可能性较低, 但这预示了阿司 匹林结构修饰的新方向. 
阿司匹林是一种有效的预防血栓药物，它能够与 COX-1 上的 Arg120 或 Tyr385 相互作用, 使乙酰基传递 到 Ser530, 从而抑制前列腺素的合成. Alagha 等 ${ }^{[53]}$ 为了 使阿司匹林能够进一步沿着 COX 活性位点通道前进, 同时在 $\operatorname{Arg} 120$ 上保留一个盐桥, 利用分子对接模型在
阿司匹林 C(3)位引入了一条戊酸酯链，制备了该类型化 合物 51 54 (Scheme 21). 其中化合物 52 戊酸盐基团能 够与活性位点 $\operatorname{Arg} 120$ 相互作用, 同时水杨酸羧酸盐也 能与 Tyr385 相互作用，乙酰基与 Ser530接近，但无抗血 栓活性；进一步制备的化合物 51、53、54 中，分子对接

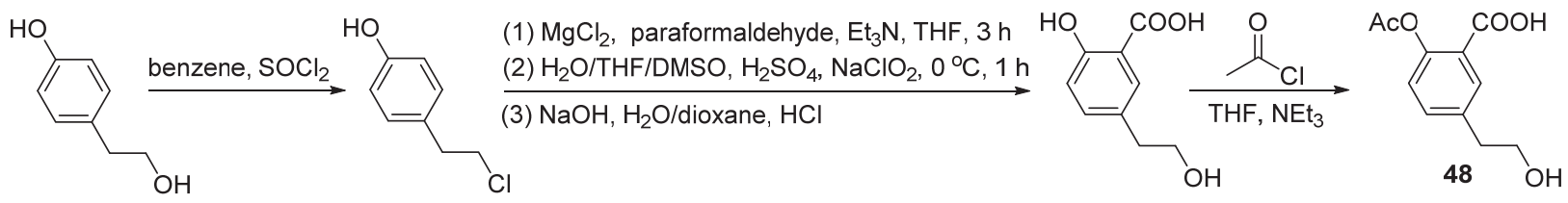<smiles>C=CCN(CC=C)c1ccc(OC(=O)C(C)=O)c(C(=O)O)c1</smiles>

图式 20 阿司匹林衍生物 $\mathbf{4 8 \sim 5 0}$ 的合成路线

Scheme 20 Synthetic route of aspirin derivatives $\mathbf{4 8} \sim \mathbf{5 0}$

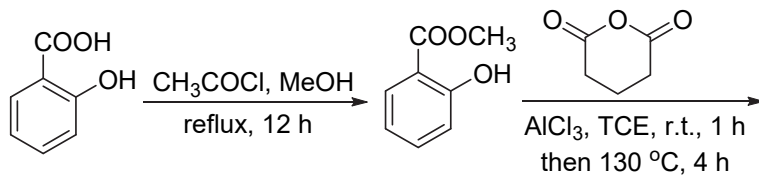<smiles>COC(=O)c1cccc(C(=O)CCCC(=O)O)c1O</smiles><smiles>COc1c(CCCCC(=O)O)cccc1C(=O)O[Mg]</smiles>

$\mathrm{Ac}_{2} \mathrm{O}, \mathrm{Py}, \mathrm{DMF}$, r.t., $24 \mathrm{~h}$

$\mathrm{COOH}$<smiles>C1CC1</smiles><smiles>CCCCCC(=O)c1cccc(C)c1OC(C)=O</smiles><smiles>COC(C)=O</smiles><smiles>CCCCCCc1cccc(CCCC(=O)OC)c1OC(C)=O</smiles><smiles>COC(=O)OC(C)(C)C</smiles>

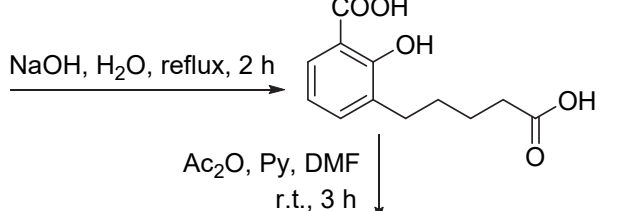

$\mathrm{COOH}$<smiles>COC(=O)c1ccccc1O</smiles><smiles>O=C1C=CC(=O)O1</smiles>
$\mathrm{AICl}_{3}, \mathrm{TCE}$, r.t., $1 \mathrm{~h}$
then $130^{\circ} \mathrm{C}, 2 \mathrm{~h}$<smiles>COC(=O)c1cccc(C(=O)C=CC(=O)O)c1O</smiles><smiles>COCC(C)(C)O</smiles><smiles>CO[14C](=O)c1cccc(CCCC(=O)O)c1O</smiles><smiles>O=C(O)CCCc1cccc(C(=O)O)c1O</smiles>

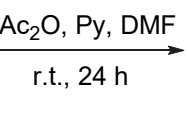<smiles>CC(=O)Oc1c(CCCC(=O)O)cccc1C(=O)O</smiles>

图式 21 阿司匹林衍生物 51 54 的合成路线

Scheme 21 Synthetic route of aspirin derivatives 51 $\sim 54$ 
模型显示化合物 $\mathbf{5 3}$ 能够通过氢键与 $\operatorname{Arg} 120$ 和 Tyr385 同时作用，同时准确定位 Ser530 并将其乙酰化，抑制血 小板聚集, $\mathrm{IC}_{50}$ 值为 $(720 \pm 85) \mu \mathrm{mol} \cdot \mathrm{L}^{-1}$.

通过 Wittig 反应可制备阿司匹林的衍生物 55a, $55 b$ 与 56a, 56b, 其中 56a 和 56b 可与 $\mathrm{BBr}_{3}$ 反应脱甲基 得中间物 $57 \mathrm{a}$ 和 $57 \mathrm{~b}$, 最后经乙酸酲酰化得到衍生物 $55 \mathrm{c}$ 和 55d (Scheme 22), 该系列化合物与白愁芦醇相比, 具 有甲酯结构的化合物对致癌活性 CYP1A1 酶有中等抑 制活性, 具有潜在的抗肿瘤活性 ${ }^{[54]}$. 以药效团杂交的原 理开发的阿司匹林衍生物 $\mathbf{5 8}$, 显示出较弱的抗炎活 性 ${ }^{[9]}$.

阿司匹林苯环修饰不是阿司匹林的主要修饰方式. 由于直接对苯环进行结构修饰较为困难, 因此通常选择 结构更为简单的底物先进行苯环修饰, 再将结构调整为 阿司匹林这一母体结构. 制备的衍生物大多不具备活性 或者活性低, 即从阿司匹林的苯环进行结构修饰不是优 良的衍生方案.

阿司匹林的骨架衍生存在 C(1)- $\mathrm{COOH}$ 修饰、 $\mathrm{C}(1)-$ $\mathrm{COOH}$ 与 $\mathrm{C}(2)-\mathrm{OAc}$ 同时修饰、 $\mathrm{C}(2)-\mathrm{OAc}$ 修饰以及苯环 修饰这四种, 其中以 $\mathrm{C}(1)-\mathrm{COOH}$ 修饰为主. 阿司匹林 $\mathrm{C}(1)-\mathrm{COOH}$ 修饰的衍生物大多成酯或成酰胺, 以酯类 化合物为佳. 其中将阿司匹林与 $\mathrm{NO}$ 和 $\mathrm{H}_{2} \mathrm{~S}$ 等活性供体 结合是较好的选择方案, 制备获得的衍生物大多活性优 良并以抗血栓为主. $\mathrm{C}(1)-\mathrm{COOH}$ 与 $\mathrm{C}(2)-\mathrm{OAc}$ 同时修饰 得到的衍生物活性高, $85.71 \%$ 为 NOSH-ASP, 且呈现出 较好的抗癌活性, 但该类衍生物目前较少. C(2)-OAc 修 饰以及苯环修饰不是阿司匹林进行结构修饰的优选方 案.

\section{2 阿司匹林的前药修饰与生物活性}

除了将阿司匹林进行结构衍生之外, 将阿司匹林制 成前药也是改善其副作用与物化性质，增强药物靶向 性, 提高药理活性的较好方案. 前药可分为载体前药和 生物前体前药. 药物载体是指能改变药物进入人体的方 式和在体内的分布, 控制药物的释放速度, 并将药物输 送到靶向器官的体系, 其中纳米级药物载体近年来得到 迅速发展. 纳米级药物载体是一种属于纳米级微观范畴 的亚微粒药物载体输送系统, 可精确控制药物的生物分 布、细胞靶向、体内药物稳定性、循环动力学和药物释 放机制 ${ }^{[55]}$. 阿司匹林 $\mathrm{C}(1)-\mathrm{COOH}$ 与蛋白载体共价结合, 再还原获得衍生物 59 (Scheme 23), 该化合物能够在血 液中以纳米颗粒选择性地转运, 到达血栓形成部位之后 与被激活的血小板表面 $\mathrm{GPIIb} / \mathrm{Ha}$ 受体作用, 释放阿司 匹林, 即通过靶向给药而发挥抗血栓活性 ${ }^{[56]}$.

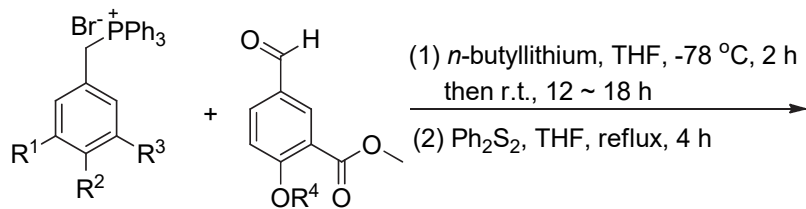

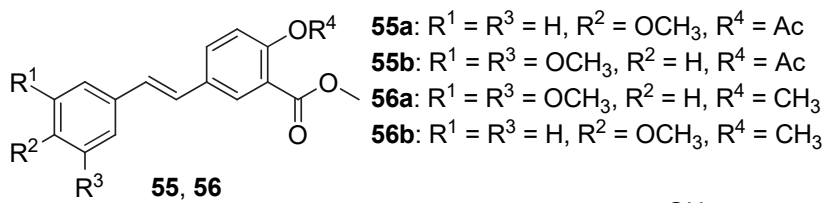

56
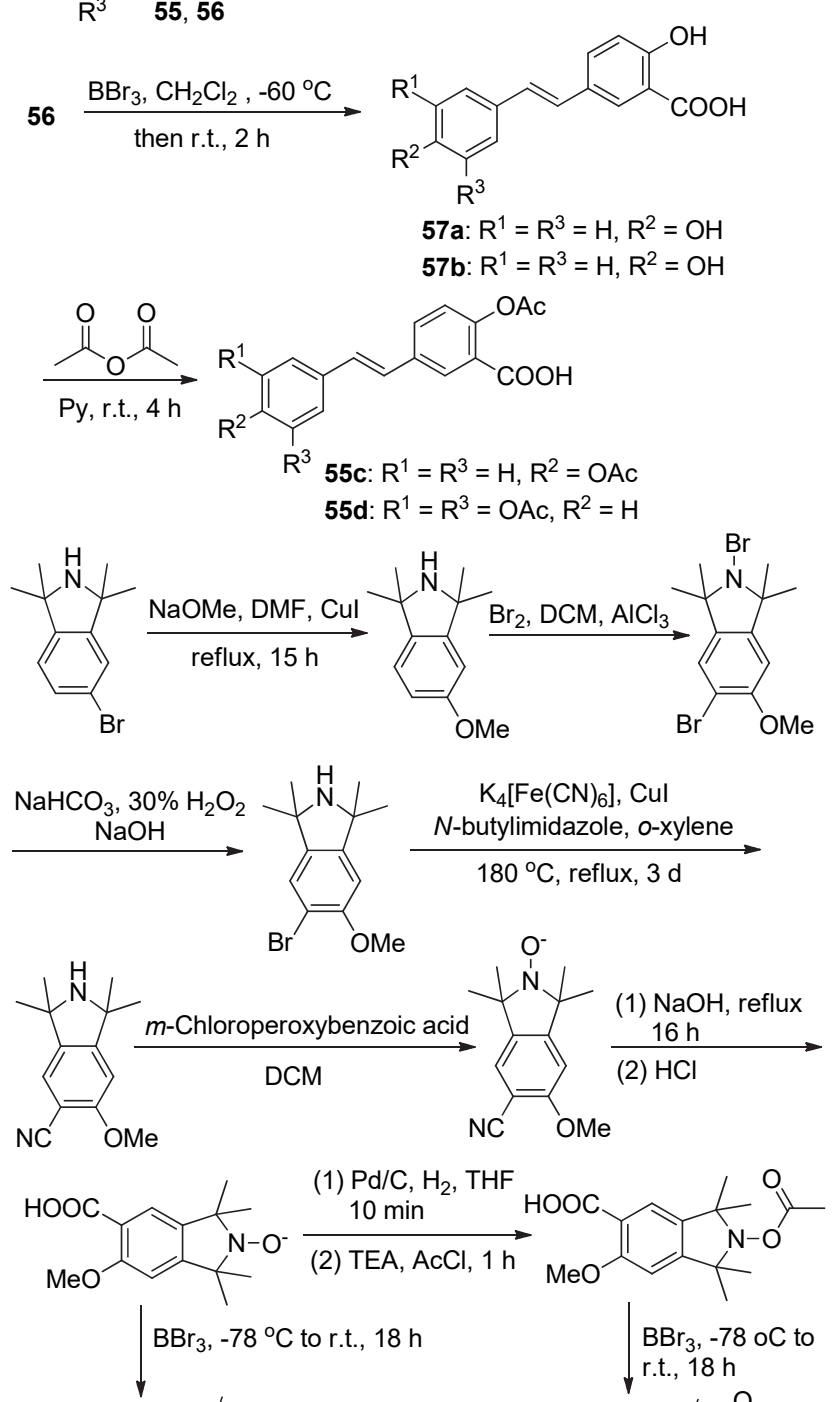

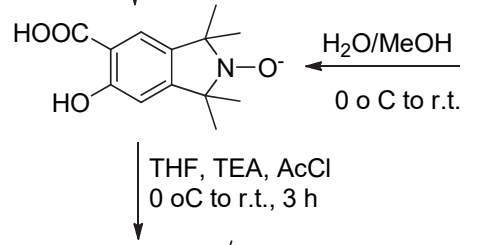<smiles>CC(=O)ON1C(C)(C)c2cc(O)c(C(=O)O)cc2C1(C)C</smiles><smiles>CC(=O)Oc1cc2c(cc1C(=O)O)C(C)(C)N([O])C2(C)C</smiles>

图式 22 阿司匹林衍生物 $\mathbf{5 5} \sim \mathbf{5 8}$ 的合成路线

Scheme 22 Synthetic route of aspirin derivatives $\mathbf{5 5} \sim \mathbf{5 8}$ 


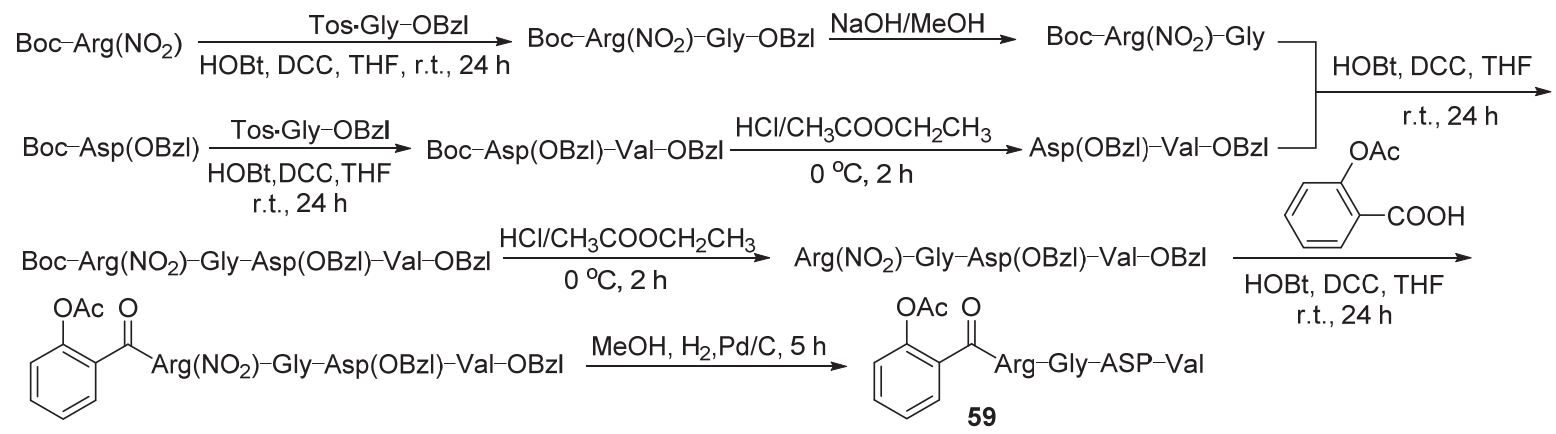

图式 23 阿司匹林衍生物 $\mathbf{5 9}$ 的合成路线

Scheme 23 Synthetic route of aspirin derivative $\mathbf{5 9}$

同样地, 将阿司匹林 $\mathrm{C}(1)-\mathrm{COOH}$ 与支链淀粉载体 结合获得了衍生物 60 (Scheme 24), 该衍生物在阿司匹 林原有的活性基础上，还改善了阿司匹林的热稳定性与 有机可溶性 ${ }^{[57]}$. 将阿司匹林与木糖醇载体线性聚合获 得衍生物 61, 该化合物具有良好的细胞相容性, 并以可 控的方式释放阿司匹林, 于四周之内可释放出 $20 \%$ 的阿 司匹林, 具有较好的抗炎活性 ${ }^{[58]}$. 葡萄糖与阿司匹林偶 联得到了葡萄糖-阿司匹林 62, 其对 SKBR3、PANC-1 和 PC3 细胞系的抗癌活性为阿司匹林的 8 9 倍, 对 WI38 细胞系的抗癌活性与阿司匹林相近. 阿司匹林由 于水溶性差, 长期以来均为口服且副作用较多, 而由于 葡萄糖的引入，使得衍生物 $\mathbf{6 2}$ 的水溶性为阿司匹林的 7 倍, 为阿司匹林的注射液的发展提供了研究方向 ${ }^{[59]}$. 阿 司匹林与载体 $\alpha$ - $D$-半乳糖基溴酰化制得衍生物 63. 体 外测试显示, 该衍生物在剂量 $1.25 \sim 20 \mathrm{mmol} / \mathrm{L}$ 时对人 肺腺癌 A549 细胞的抑制率为 $6.3 \% \sim 90.2 \%$, 高于同剂 量下的阿司匹林抑制率 ${ }^{[60]}$.

生物前体前药不同于载体前药, 活性物质无需与载 体暂时性结合, 而是通过自身分子结构的改变来发挥作 用. 阿司匹林直接与阿魏酸单酯酯化可得衍生物 $64 \mathbf{a} \sim$ 64h (Scheme 25), 其中 64a $\sim 64 \mathrm{c}$ 和 64e $\sim 64 \mathrm{~h}$ 具有一定 的抗血小板聚集活性, 它们对二磷酸腺苷体外诱导血小 板聚集抑制的 $\mathrm{IC}_{50}$ 值分别为 87.4、44.7、107.4、43.1、 27.6、79.9、35.8 mmol/L, 同时研究了其抗血小板聚集 活性大小与取代基碳链长度以及是否含有支链的关系, 结果表明, 碳链越长其抗血小板聚集活性越好, 相同碳 链的衍生物在带有支链时的抑制血小板聚集活性更 佳 ${ }^{[61]}$. 同丁香酚酯制得的阿司匹林丁香酚酯 $\mathbf{6 5}$ 能降低 血脂水平和血管壁厚度, 防止血管内壁脂质沉积及管腔 狹窄, 从而预防或冶疗动脉弹样硬化疾病 ${ }^{[62]}$. 与此同 时, 阿司匹林丁香酚酯与阿司匹林于相同剂量下有相近 的抗炎活性, 两者对于由二甲苯引起的小鼠耳肿胀的抑 制率均在 $45 \%$ 左右 ${ }^{[63]}$; 与白揫芦醇酯化, 再脱甲基得到 了衍生物 66a 66c , 其中衍生物 66a 表现出一定的抗癌
活性，对 HCT-116、HT-29 细胞的 $\mathrm{IC}_{50}$ 值分别为 $(39.39 \pm 0.55)$ 和 $(34.37 \pm 0.79) \mu \mathrm{mol} \cdot \mathrm{L}^{-1[64]}$.

阿司匹林酰氯和 2-羟基荎醛反应获得的中间产物 再与可抑制肿瘤细胞生长的一种鞘氨醇激酶抑制剂酰 化, 获得了阿司匹林衍生物 $\mathbf{6 7}$, 或者将阿司匹林酰氯与 另一种鞘氨醇激酶抑制剂直接酰化得到了衍生物 68 (Scheme 26), 体外实验显示这两种衍生物在多种肿瘤 细胞均具有较好的抑制活性, 如对人脑组织中的 $\mathrm{U} 87 \mathrm{MG}$ 癌细胞的 $\mathrm{IC}_{50}$ 值分别为 $(1.5 \pm 0.5)$ 和 $(8.1 \pm 1.6)$ $\mu \mathrm{mol} \cdot \mathrm{L}^{-1}$, 对肺组织中的 H460、H226、H441 及 A549 癌细胞的 IC50 值分别为 $(1.2 \pm 0.5)$ 与 $(9.1 \pm 0.8) 、(1.7 \pm$ $0.3)$ 与 $(6.7 \pm 1.6) 、(0.6 \pm 0.2)$ 与 $(5.7 \pm 1.9)$ 和 $(0.9 \pm 0.1)$ 与 $(5.9 \pm 2.1) \mu \mathrm{mol} \cdot \mathrm{L}^{-1[65]}$.

阿司匹林酰氯 C(1)- $\mathrm{COCl}$ 位与单硝酸异山梨醇于碱 性条件下取代，随后还原脱 $\mathrm{NO}_{2}$, 再与 2-芐氧基苯甲酸 酯化，最后还原脱苄基，制得化合物 69～76 (Scheme 27). 其中化合 72 是一种有效的阿司匹林前药，该化合 物可通过释放阿司匹林而具有抗血栓活性 ${ }^{[66]}$. Jones 等 ${ }^{[24]}$ 在化合物 70 的基础上，使 $\mathrm{C}(1)$ 位衍生物的羟基与 适当的酸在 DCC 和 4-二甲氨基吡啶(DMAP)的催化下 酯化获得化合物 77a $\sim 77 \mathbf{a a}$ (Scheme 28)，其中 3/4-差基 苯甲酸与 3/4-羟基苯甲酸反应时, 羟基与羧基存在竞争 反应，故用苄基对 3/4-羟基苯甲酸的羟基进行保护，再 参与酯化反应，随后还原脱茮基获得化合物 77a、77b; 与酸类化合物结合获得 78a 与 78b (Scheme 29), 与 2/3/4-氯甲基苯甲酰氯先取代再硝化获得化合物 $78 \mathrm{c} \sim$ 78e. 动力学研究发现, 衍生物苯甲酸基团上具有邻位 取代基和空间位阻小的间位取代基时，在人体血浆中有 较好的阿司匹林释放特性, 其中衍生物 78c 和 78d 可分 别释放出 $30 \%$ 和 $50 \%$ 的阿司匹林，是有效的阿司匹林前 药. 同时在活性研究中发现, 衍生物 77c、78c 和 78d 在 PRP 中抑制由胶原蛋白诱导的血小板聚集的 $\mathrm{IC}_{50}$ 值分别 为 20.6、90.3 和 $17.1 \mu \mathrm{mol} \cdot \mathrm{L}^{-1}$, 即具有较好的抗血小板 聚集活性. 

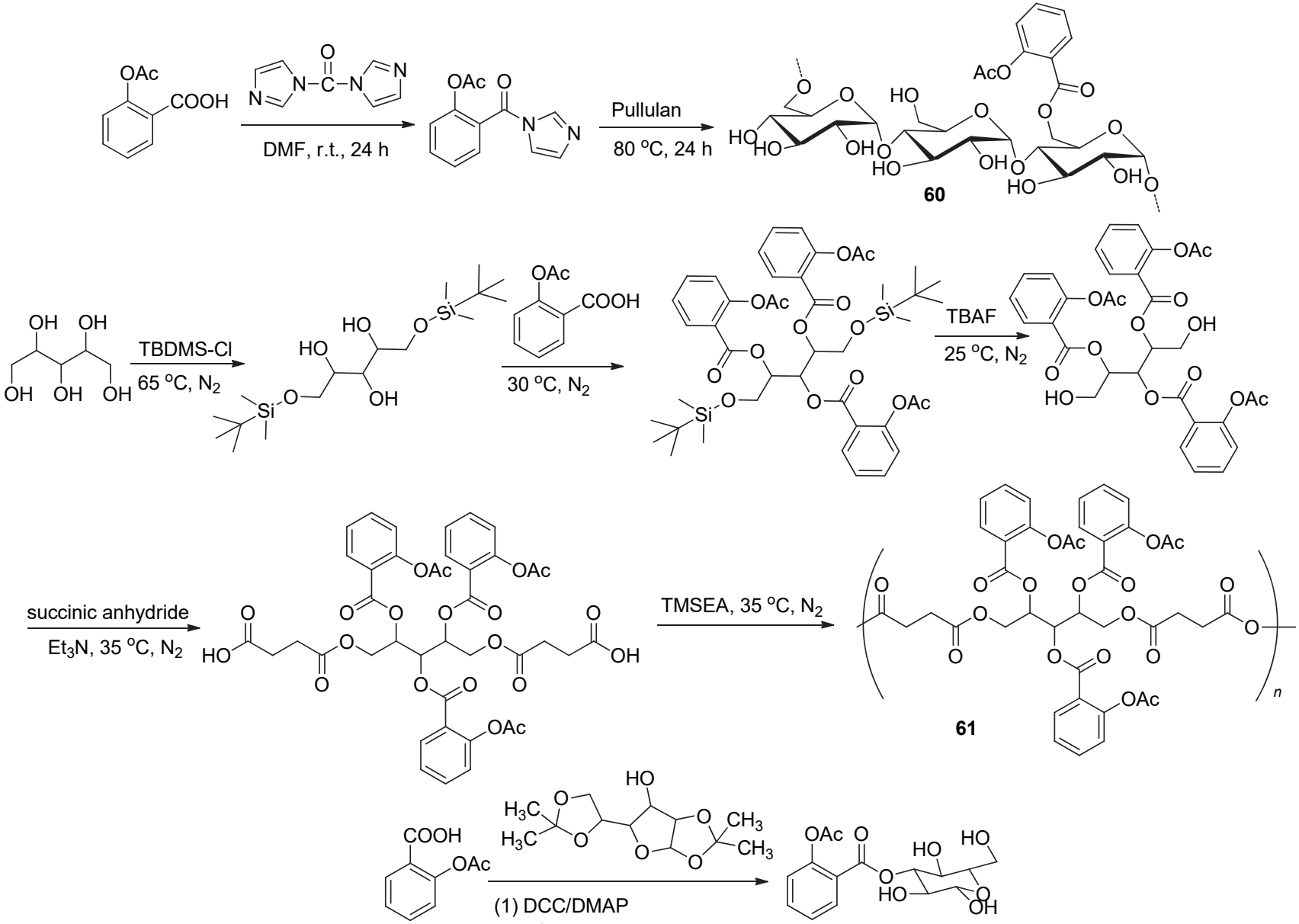

(2) $\mathrm{H}^{+}$

$\underbrace{}_{\mathrm{OH}}$

图式 24 阿司匹林衍生物 $60 \sim 63$ 的合成路线

Scheme 24 Ssynthetic route of aspirin derivatives $60 \sim 63$

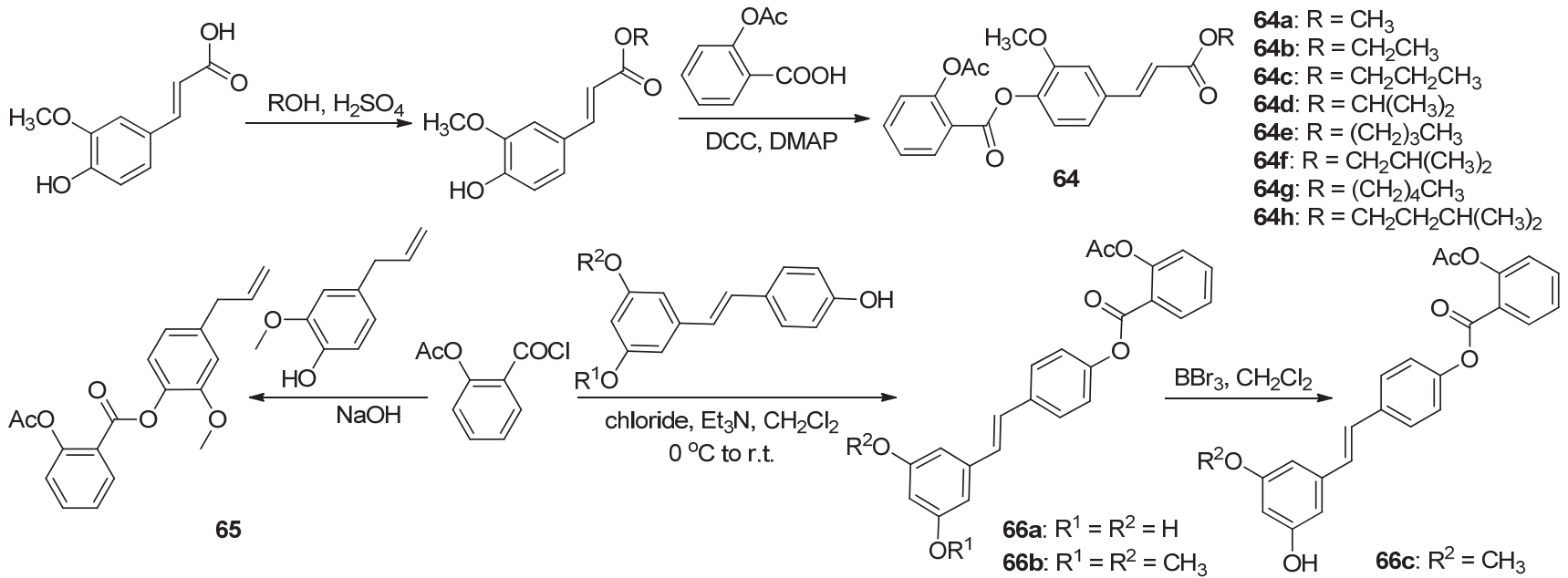

图式 25 阿司匹林衍生物 64 和 65 的合成路线

Scheme 25 Synthetic route of aspirin derivatives 64 and 65 


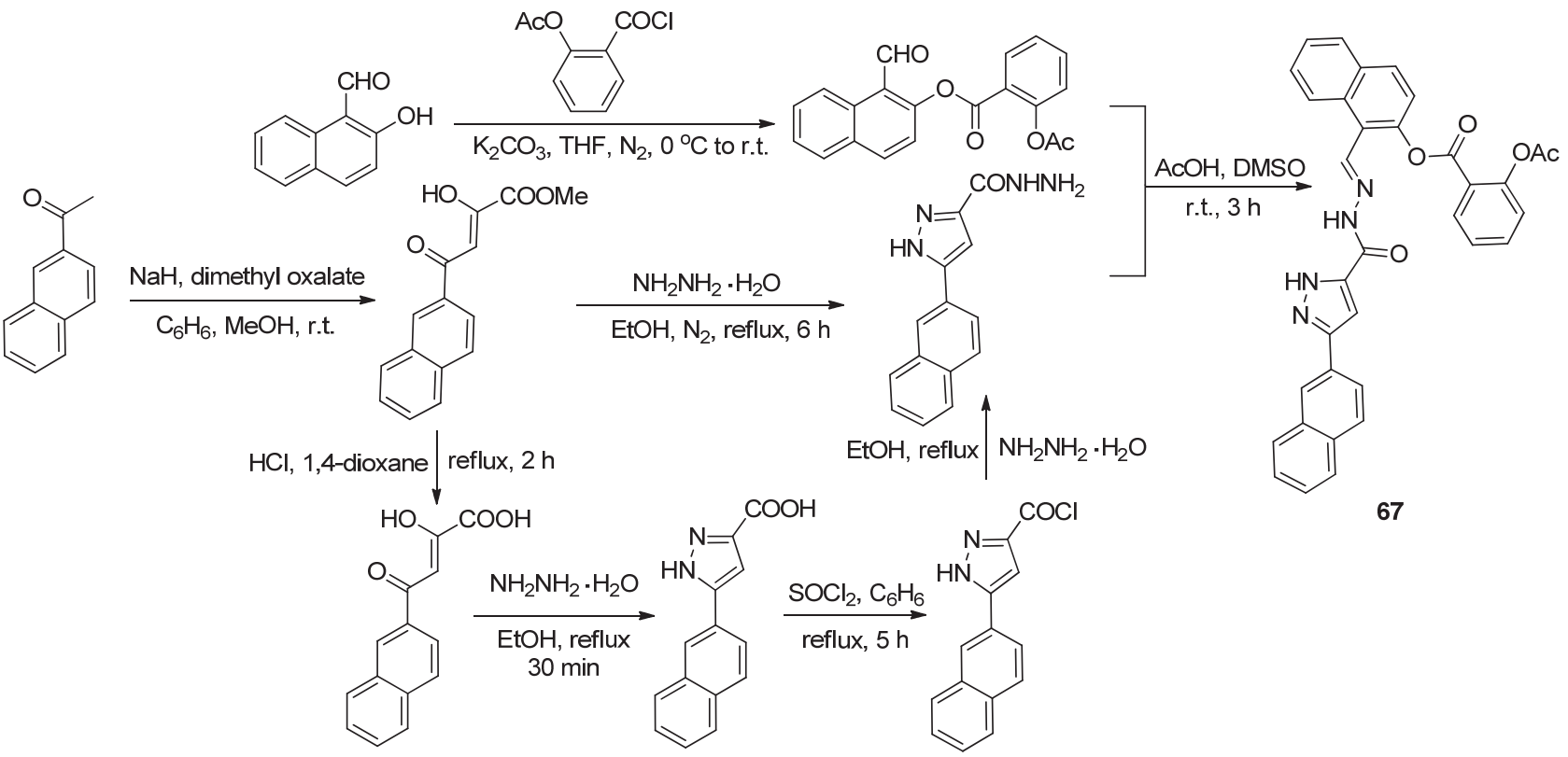

图式 26 阿司匹林衍生物 67 和 68 的合成路线

Scheme 26 Synthetic route of aspirin derivatives 67 and 68<smiles>CCOC(=O)c1ccccc1OC(=O)c1ccccc1C(=O)Oc1ccc(Nc2nc(-c3ccc(Cl)cc3)cs2)cc1</smiles>

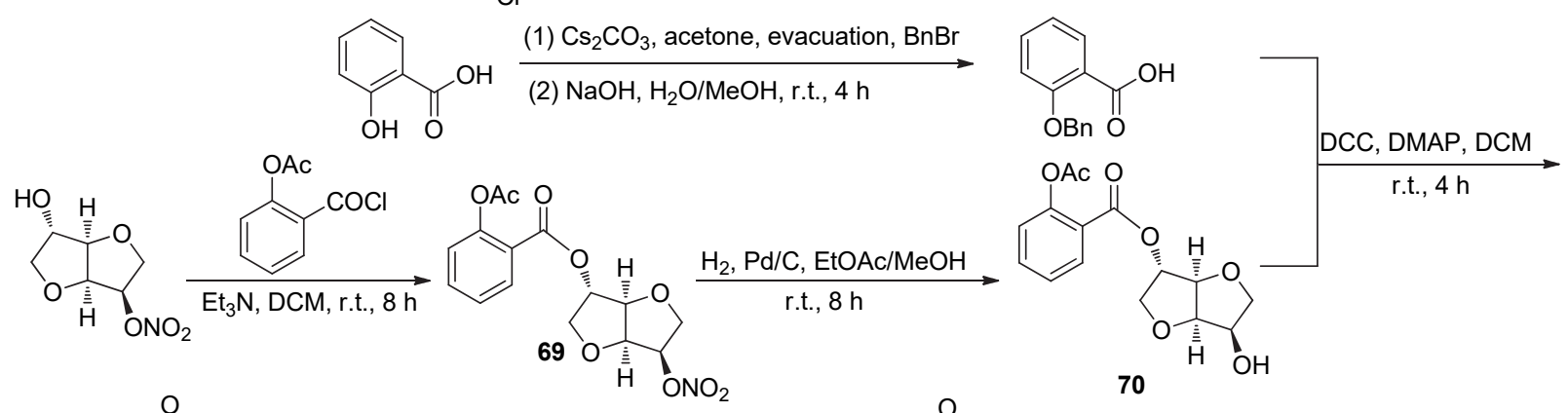<smiles>CC(=O)Oc1ccccc1C(=O)O[C@H]1CO[C@@H]2[C@@H](OC(=O)c3ccccc3OC(C)=O)CO[C@H]12</smiles>

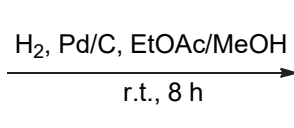<smiles>CC(=O)Oc1ccccc1C(=O)O[C@H]1CO[C@H]2[C@@H](OC(=O)c3ccccc3O)CO[C@H]12</smiles><smiles>O=[N+]([O-])C1COC2C(O)COC21</smiles><smiles>CCOCCOc1ccccc1C(=O)Cl</smiles><smiles>CC(C)OOCC(O)C1CCCO1</smiles><smiles>CC(=O)Oc1ccccc1C(=O)OC1CO[C@]2(C)CCO[C@H]12</smiles>

73 $\stackrel{\mathrm{H}_{2}, \mathrm{Pd} / \mathrm{C}, \mathrm{EtOAc} / \mathrm{MeOH}}{\longrightarrow}$ r.t., $8 \mathrm{~h}$

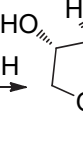<smiles>COC(=O)OOCc1ccccc1</smiles><smiles>CC(=O)c1ccccc1O</smiles><smiles>CC(=O)Oc1ccccc1C(=O)OC1CO[C@@H]2[C@H](OC(=O)c3ccccc3OCc3ccccc3)CO[C@H]12</smiles>

图式 27 阿司匹林衍生物 69 76 的合成路线

Scheme 27 Synthetic route of aspirin derivatives $69 \sim 76$ 

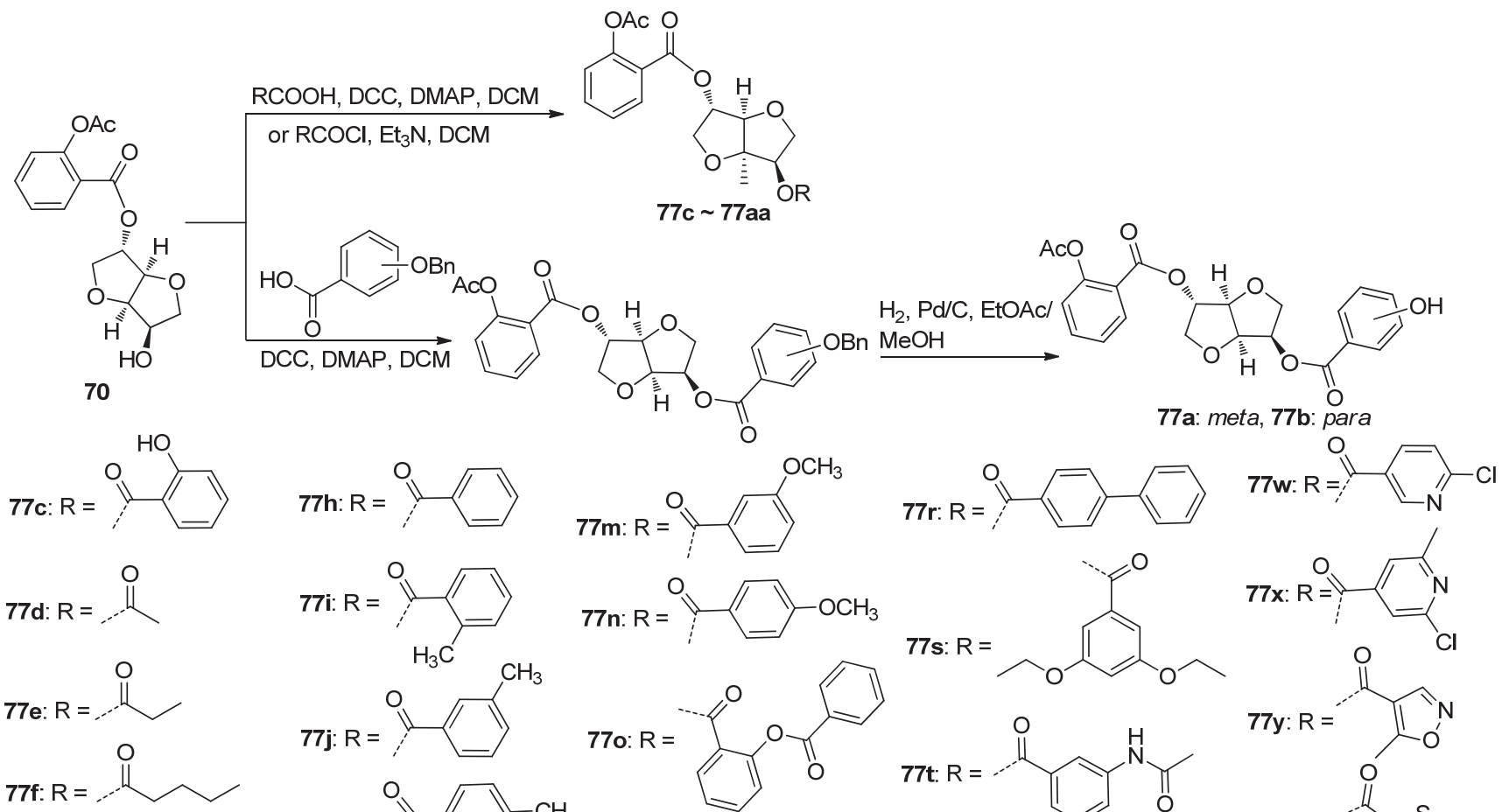<smiles>CC(=O)c1ccccc1C</smiles><smiles>COc1ccc(C(=O)C(C)=O)cc1</smiles><smiles>CCOc1cc(OCC)cc(C(C)=O)c1</smiles><smiles>Cc1cc(C(=O)OCC(C)C)cc(Cl)n1</smiles><smiles>CC(=O)c1cccc(C)c1</smiles><smiles>CC(=O)c1ccccc1OC(=O)c1ccccc1</smiles><smiles>CC(=O)Nc1cccc(C(C)=O)c1</smiles>

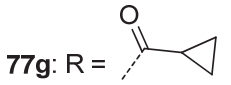<smiles></smiles><smiles>CC(=O)c1ccc(C#N)cc1</smiles><smiles>CC(=O)c1ccnc2cccnc12</smiles><smiles></smiles>

图式 28 阿司匹林衍生物 77 的合成路线

Scheme 28 Synthetic route of aspirin derivative $\mathbf{7 7}$



78d (meta), 78e (para)

图式 29 阿司匹林衍生物 78 的合成路线

Scheme 29 Synthetic route of aspirin derivative $\mathbf{7 8}$

阿司匹林前药衍生中载体前药及生物前体前药均 有涉及, 其中以生物前体前药为主. 载体前药中载体多 为蛋白质或糖类, 两者在提高阿司匹林水溶性、脂水分 配系数及稳定性方面作用突出, 同时靶向性增加使得部 分载体前药活性得到了提升. 改变阿司匹林结构获得的
生物前体前药，仅为具有抗癌及抗血栓活性这两类化合 物，其中以抗血栓为主，占比 $83 \%$.

\section{3 阿司匹林的孪药修饰与生物活性}

孪药是指两个或两个以上具有相似或不同治疗效 
果的化合物通过共价键结合在一起, 在生物体内代谢生 成两种(或更多)不同的药物而产生协同作用, 用以增强 活性或者产生新的药理作用以及提高药物的选择性. 阿 司匹林因其具有的多种药理活性, 常常与其他药物依据 拼合原理进行孪药设计, 同样地, 结构修饰上主要是将 $\mathrm{C}(1)-\mathrm{COOH}$ 成酯或成酰胺. 如阿司匹林 C(1)-COOH 与 丙氨酸在碱性条件下酰化, 再与具有心脏保护作用的益 母草碱酯化获得衍生物 79 (Scheme 30). 在 H9c2 心肌细 胞中, 衍生物 79 与益母草碱相比其药效提高了 10 倍左 右, 并且该化合物还可通过抑制促炎介质保护心肌细 胞 $^{[67]}$; 与 3-羟基亚胺齐墩果酸在 DDC 作用下酯化获得 化合物 80, 该化合物具有抗炎镇痛活性, 其抗炎活性与 该衍生物剂量呈倒 “ $U$ ” 型关系, 在剂量 $30 \mathrm{mg} / \mathrm{kg}$ 时显
示出最大的抗炎活性 ${ }^{[68]}$; 通过与烟酸酯化物取代获得 化合物 $81 \mathrm{a} \sim 81 \mathrm{e}$, 五种衍生物的体外实验测试均呈现 出一定的抗血小板聚集活性，但其最高抑制率 $28.23 \%$ 仍低于阿司匹林, 活性较低 ${ }^{[69]}$.

阿司匹林酰氯与 6-姜酚酰化制得衍生物 82 (Scheme 31 ), 其在 HCT-116 及 HT-29 癌细胞的 $\mathrm{IC}_{50}$ 值分别为 75.97 和 $84.49 \mu \mathrm{mol} \cdot \mathrm{L}^{-1}$, 抗癌活性优于阿司匹林, 且在 浓度为 20、40 和 $60 \mu \mathrm{mol} \cdot \mathrm{L}^{-1}$ 时均能显著抑制 HCT-116 和 HT-29 癌细胞的增殖, $60 \mu \mathrm{mol} \cdot \mathrm{L}^{-1}$ 时对这两种癌细胞 的抑制率高达 100\%和 $97 \%$. 除此之外, 衍生物 82 相较 于阿司匹林而言，具有显著的胃粘膜保护作用 ${ }^{[70]}$; 与熊 果酸取代制得的衍生物 83 对于 $\mathrm{MCF}-7$ 细胞的 $\mathrm{IC}_{50}$ 值为 $70 \mu \mathrm{mol} \cdot \mathrm{L}^{-1}$ ，活性明显高于阿司匹林 ${ }^{[71]}$; 与薯蓣皇<smiles>CC(=O)Oc1ccccc1C(=O)O[C@@H](C(C)COC(=O)Cl)C(F)(F)F</smiles><smiles>COc1cc(C(=O)OCCCCNC(=NC(=O)OC(C)(C)C)NC(C)(C)C)cc(OC)c1O</smiles>

DPTs/DIC, $\mathrm{CH}_{2} \mathrm{Cl}_{2}$, r.t., $12 \mathrm{~h}$<smiles>COc1cc(C(=O)OCCCCNC(=O)NC(=O)OC(C)(C)C)cc(OC)c1OC(=O)CCNC(=O)c1ccccc1OC(C)=O</smiles><smiles>COc1cc(C(=O)OCCCCNC(=N)N)cc(OC)c1OC(=O)CCNC(=O)c1ccccc1OC(C)=O</smiles>

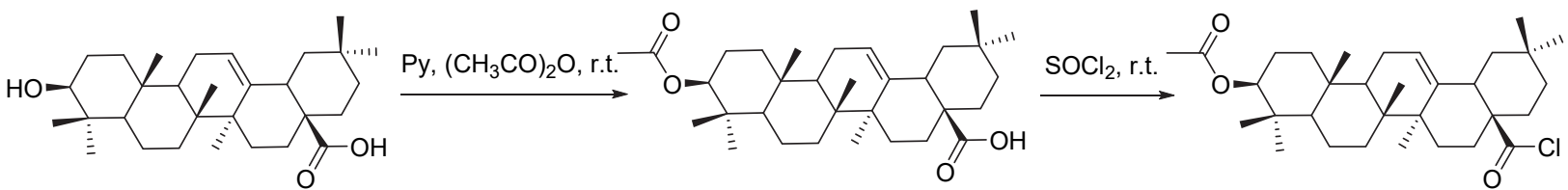

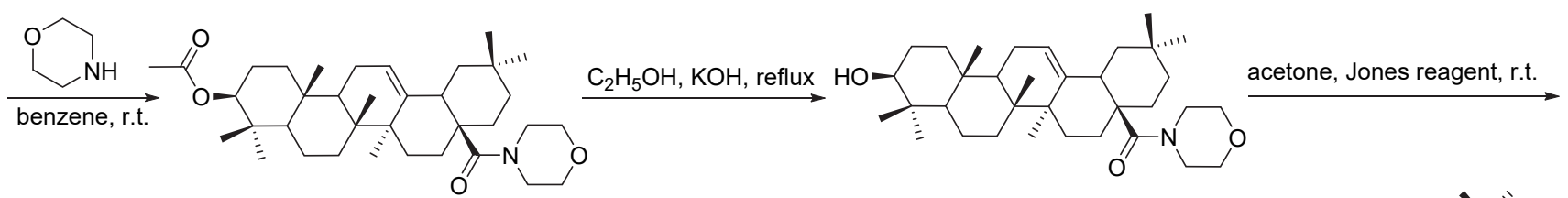

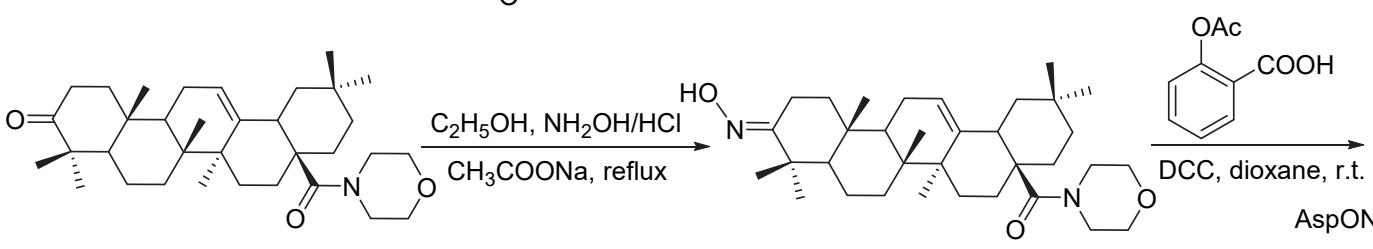<smiles>CC1(C)CCC2(C(=O)N3CCOCC3)CC[C@]3(C)C(CCC4[C@@]5(C)CCC(=N)C(C)(C)C5CC[C@]43C)C2C1</smiles>

80

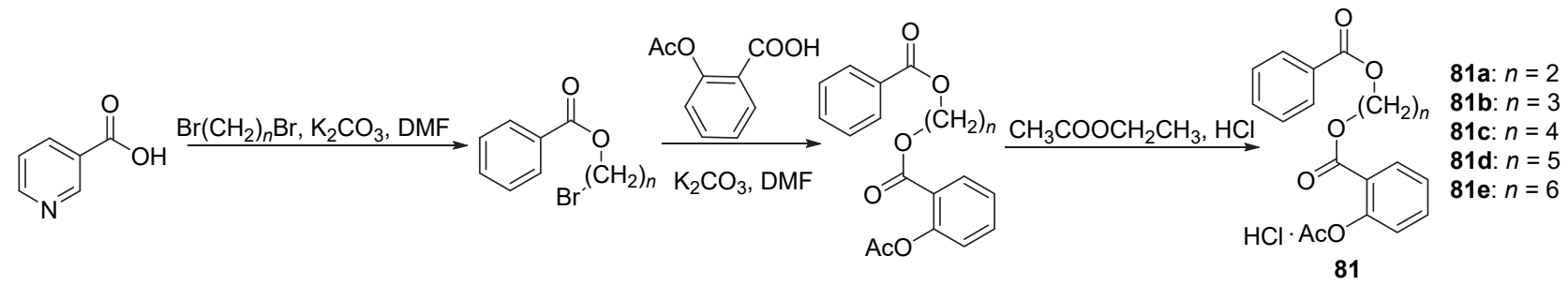

图式 30 阿司匹林衍生物 79 $>$ 81 的合成路线

Scheme 30 Synthetic route of aspirin derivatives $79 \sim 81$ 


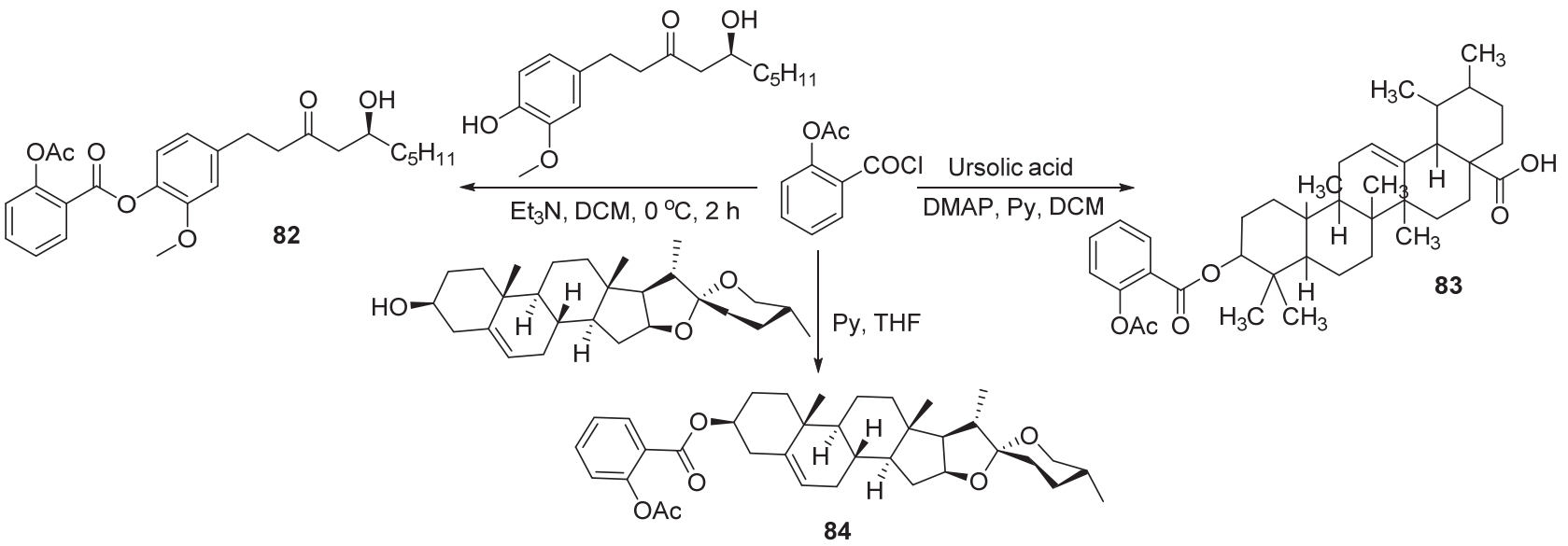

图式 31 阿司匹林衍生物 $82 \sim 84$ 的合成路线

Scheme 31 Synthetic route of aspirin derivatives $82 \sim 84$

苷元发生取代制得衍生物 $\mathbf{8 4}^{[72]}$, 该化合物能明显抑制 血栓的形成，其对血小板的抑制率为 $(29.42 \pm 3.1) \%$, 与 阿司匹林相当 ${ }^{[73]}$. 此外, 衍生物 84 还具有抗炎活性, 其 在剂量为 $21.9 \mathrm{mg} / \mathrm{kg}$ 时对小鼠耳朵的肿胀抑制率为 $18.03 \%$, 并随剂量的增加抑制率不断上涨 ${ }^{[72]}$.

阿司匹林 C(1)-COOH 经酰化及酯化后, 再与 7-乙 基-10-羟基喜树碱(SN38)酯交换获得四种 SN38-阿司匹 林 85a $\sim 85 d$ (Scheme 32), 这四种衍生物均可同时释放 SN38 及阿司匹林, 体外实验都显示出明显的抗癌活性, 它们对于 $\mathrm{HepG} 2$ 细胞的 $\mathrm{IC}_{50}$ 值均小于 $0.21 \mu \mathrm{mol} \cdot \mathrm{L}^{-1}$, 对 于 BEL-7404 细胞的 $\mathrm{IC}_{50}$ 值均小于 $6 \mu \mathrm{mol} \cdot \mathrm{L}^{-1}$, 其中活 性最强的衍生物 85b 对这两种癌细胞的 $\mathrm{IC}_{50}$ 值分别为 $(0.1208 \pm 0.0081)$ 和 $(2.5295 \pm 0.7884) \mu \mathrm{mol} \cdot \mathrm{L}^{-1}$, 抗肿瘤 活性较高 ${ }^{[74]}$.
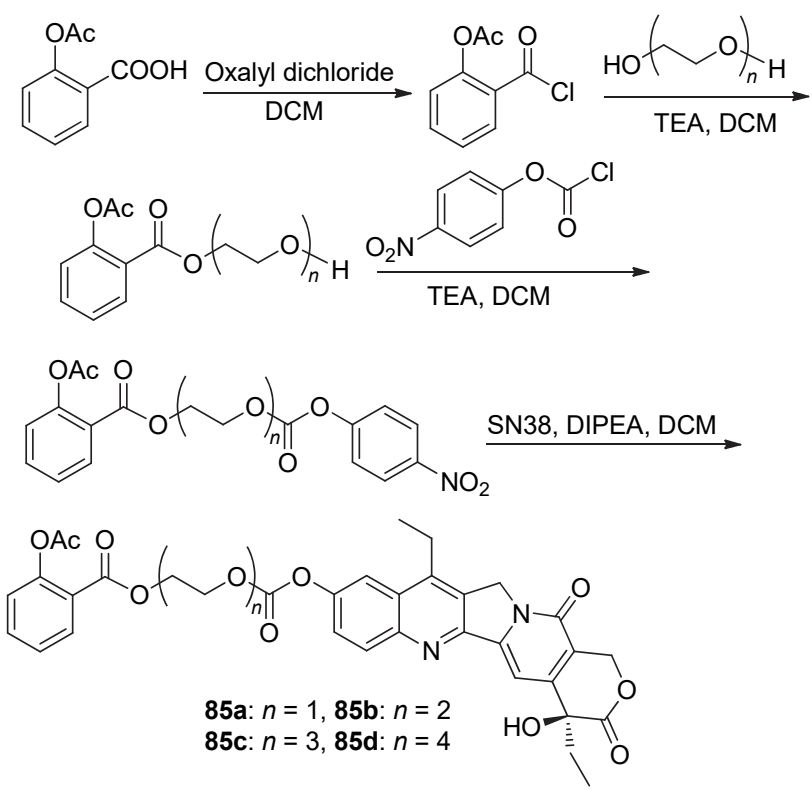

图式 32 阿司匹林衍生物 $\mathbf{8 5}$ 的合成路线

Scheme 32 Synthetic route of aspirin derivative $\mathbf{8 5}$
同样地，阿司匹林酰氯与肉桂醛类化合物酰化制得 了衍生物 86a $\sim 86 \mathrm{~h}$ (Scheme 33), 其中化合物 86b 和 $86 \mathrm{e} \sim \mathbf{8 6 h}$ 对 HTC -8 人结直肠癌细胞的 $\mathrm{IC}_{50}$ 值 $(9.3 \pm 0.7)$ 、

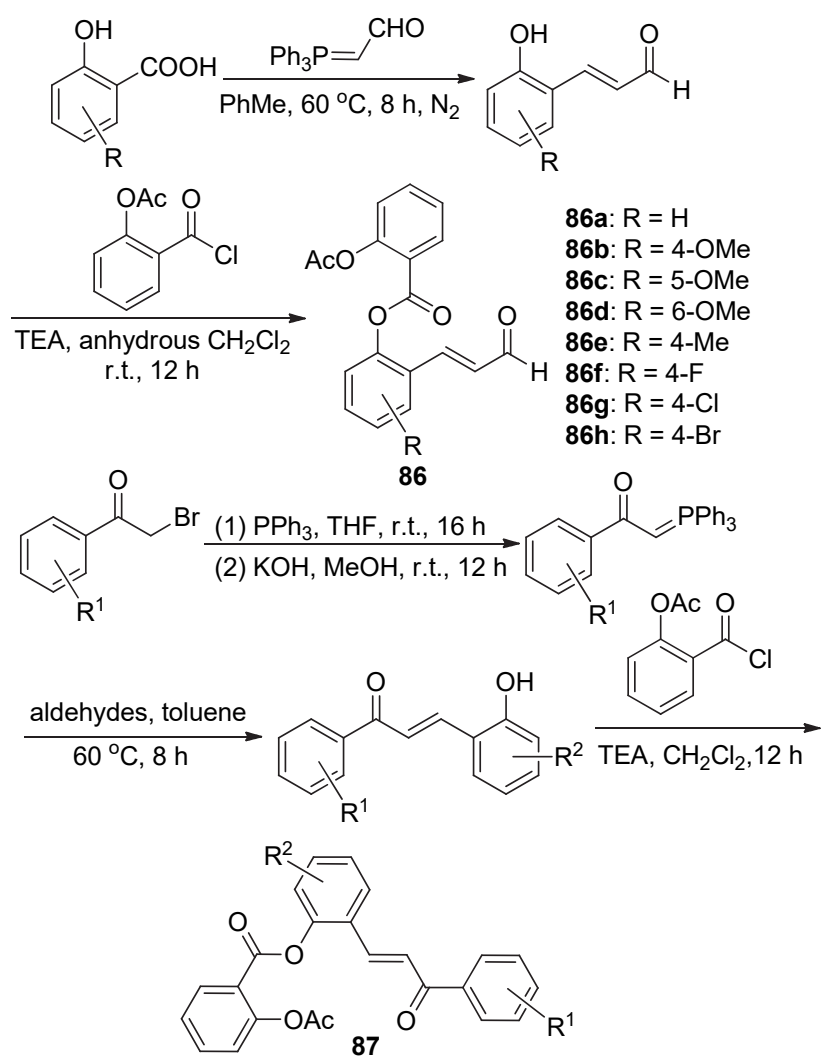

$$
\begin{aligned}
& \text { 87a: } R^{1}=4-M e, R^{2}=H ; \text { 87b: } R^{1}=4-O M e, R^{2}=H \\
& \text { 87c: } R^{1}=4-C l, R^{2}=H ; 87 d: R^{1}=4-B r, R^{2}=H \\
& \text { 87e: } R^{1}=4-C N, R^{2}=H ; 87 f: R^{1}=4-N O_{2}, R^{2}=H \\
& \text { 87g: } R^{1}=4-C l, R^{2}=4-O M e ; 87 h: R^{1}=4-C l, R^{2}=5-O M e \\
& \text { 87i: } R^{1}=4-C l, R^{2}=5-F ; 87 j: R^{1}=4-C l, R^{2}=5-C l \\
& \text { 87k: } R^{1}=4-C l, R^{2}=5-B r ; 87 l: R^{1}=4-C l, R^{2}=5-O M e \\
& \text { 87m: } R^{1}=4-C l, R^{2}=5-M e ; 87 n: R^{1}=4-O M e, R^{2}=5-O M e \\
& \text { 87o: } R^{1}=4-O M e, R^{2}=5-B r ; 87 p: R^{1}=4-O M e, R^{2}=5-C l
\end{aligned}
$$

图式 33 阿司匹林衍生物 86 和 87 的合成路线

Scheme 33 Synthetic route of aspirin derivatives 86 and 87 
$(8.5 \pm 0.4) 、(2.6 \pm 0.6) 、(4.3 \pm 0.9)$ 和 $(5.6 \pm 0.7) \mu \mathrm{mol} \cdot \mathrm{L}^{-1}$, 明显高于阿司匹林的 $\mathrm{IC}_{50}\left(>100 \mu \mathrm{mol} \cdot \mathrm{L}^{-1}\right)$, 活性最高 的衍生物 $86 f$ 经体外测试显示出可阻碍结直肠癌细胞增 殖的 $\mathrm{G} 1$ 期, 同时对于 DLD-1 癌细胞 $\mathrm{IC}_{50}$ 为 $(4.3 \pm 0.5)$ $\mu \mathrm{mol} \cdot \mathrm{L}^{-1}$, 相较于非癌细胞 $\mathrm{CCDB} 41$ 的 $\mathrm{IC}_{50}(30.7 \pm 2.9)$ $\mu \mathrm{mol} \cdot \mathrm{L}^{-1}$, 其抗增殖选择较好, 此外还可诱导癌细胞凋 亡, 这些生物作用暗示衍生物 86f 可作为抗结直肠癌的 化疗药 物 ${ }^{[75]}$. 而将通过 Wittig 反应制得的查尔酮类 化合物, 与阿司匹林酰氯反应获得了衍生物 $87 \mathbf{a} \sim 87 \mathbf{p}$ (Scheme 33)，其中 87c、87f、87h 和 $87 \mathrm{i}$ 在 $10 \mu \mathrm{mol} \cdot \mathrm{L}^{-1}$ 时对 CRC 癌细胞显示出强的抑制活性, 而对比衍生物 结构与癌细胞抑制率发现衍生物 $\mathrm{R}^{1}$ 取代基为 $\mathrm{Cl}$ 或 $\mathrm{NO}_{2}$ (87c 和 87f) 或 $\mathrm{R}^{2}$ 取代基为 5-OMe 或 5-F 时的衍生物抑 制率更高. 其中衍生物 $87 \mathrm{~h}$ 和 $87 \mathrm{i}$ 的抑制率最高, 活性 测试得出这两种衍生物对 HCT-8 癌细胞的 $\mathrm{IC}_{50}$ 值分别 为 $(2.4 \pm 0.1)$ 和 $(2.7 \pm 0.5) \mu \mathrm{mol} \cdot \mathrm{L}^{-1}$, 对 DLD- 1 癌细胞的 $\mathrm{IC}_{50}$ 值分别为 $(2.7 \pm 0.2)$ 和 $(3.5 \pm 0.4) \mu \mathrm{mol} \cdot \mathrm{L}^{-1}$, 同样地, 87h 也可阻碍结直肠癌细胞增殖的 G1 期, 且抗增殖选 择较好, 可诱导癌细胞调亡 ${ }^{[76]}$.

将阿司匹林酰氯 C(1)-COCl 与薯蓣㿝苷衍生物酯化 获得衍生物 88 和 89 (Scheme 34), 两者在 $100 \mathrm{mg} / \mathrm{kg}$ 时 对水肿的抑制率分别为 $46.5 \%$ 和 $39.1 \%$, 具有抗炎活 性 ${ }^{[77]}$. 将 1,3/1,4/1,5/1,6-二澳烷基作为阿司匹林和冬青 素 $\mathrm{A}$ 的连接基团, 制备了衍生物 90 92 (Scheme 35),

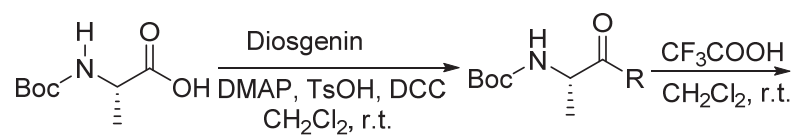<smiles>[R]C(=O)[C@H](C)N</smiles>

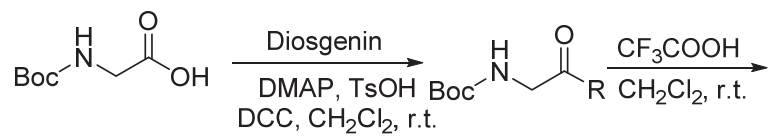<smiles>[R]C(=O)CNC(=O)c1ccccc1O[C-]Oc1ccccc1OC(C)=O</smiles>

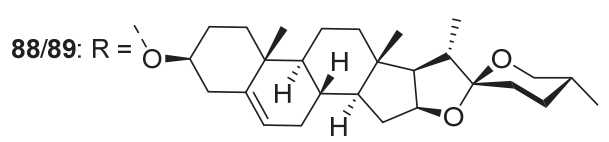

图式 34 阿司匹林衍生物 $88 \sim 92$ 的合成路线

Scheme 34 Synthetic route of aspirin derivatives 88 $\sim 92$
体外实验测试显示衍生物 $91 \mathrm{a} \sim 91 \mathrm{~d}$ 在浓度为 0.25 $\mathrm{mmol} / \mathrm{L}$ 时, 对由 $\mathrm{ADP}$ 诱导的血小板聚集抑制率为 $41.3 \% \sim 77.2 \%$, 其中衍生物 91d 的抑制率 $77.2 \%$ 是阿司 匹林的 8 倍 ${ }^{[78]}$.

近年来发现阿司匹林具有改善精神疾病的作用，如 长期服用低剂量阿司匹林可能保护神经 ${ }^{[79]}$, 有预防阿 尔兹海默病及改善抑郁的可能性 ${ }^{[80]}$. He 等 ${ }^{[81]}$ 通过合成 了系列阿司匹林抗癫㾁衍生物 93 95 (Scheme 36), 这 些化合物均显示出一定的抗癫㾁的活性. 其中 93a、

93e $\sim 93 \mathrm{~h} 、 94 \mathrm{c} \sim 94 \mathrm{~h}$ 和 95e $\sim 95 \mathrm{~h}$ 这 13 种化合物在剂量 为 $240 \mathrm{mg} / \mathrm{kg}$ 时显示出显著的抗癫㾋活性, 并且有效比 超过 60\%，其中化合物 93e $\sim 93 \mathrm{f} 、 93 \mathrm{~h} 、 94 \mathrm{c}, 94 \mathrm{~d}$ 和 95f $~$ 95h 有效比高达 $83 \%, 93 \mathrm{e} 、 95 \mathrm{~h} 、 95 \mathrm{e}$ 和 $95 \mathrm{~g}$ 是活性最高 的化合物; 化合物 $93 \mathbf{h}$ 的 $\mathrm{ED}_{50}$ 为 $0.4189 \mathrm{mmol} / \mathrm{kg}, \mathrm{LD}_{50}$ 为 $1.321 \mathrm{mmol} / \mathrm{kg}$, 化合物 $95 \mathrm{~g}$ 的 $\mathrm{ED}_{50}$ 为 0.3684 $\mathrm{mmol} / \mathrm{kg}, \mathrm{LD}_{50}$ 为 $1.1487 \mathrm{mmol} / \mathrm{kg}$, 这两种化合物有待于 开发成抗癲㾁药物; 此外, 化合物 $95 \mathrm{~h}$ 与 $95 \mathrm{~g}$ 能够进入 中枢神经系统释放 GABA 和阿司匹林从而达到抗癫㾋 作用. 同时构效关系测试表明酯类化合物比酰胺类化合 物更容易通过血脑屏障途径而释放阿司匹林. 活性评价 表明, 不同结构的目标化合物对活性影响较大: 当端部 与空间位阻较大的酯连接时, 化合物活性较高; 相反, 当空间位阻较小时, 活性较差并且毒性增加; 苯环上带 有给电子基团取代基的化合物, 其抗癫㾁作用降低, 毒 性增加, 而吸电子基团呈现相反的效果; 脂水分配系数 与 $\mathrm{ED}_{50} 、 \mathrm{LD}_{50}$ 及治疗指数 $\mathrm{TI}$ 具有明显的相关性, 尤其 是 TI 与脂水分配系数具有明显的平行关系.

阿司匹林酰氯 C(1)-COCl 与脱甲基的小檗碱酯化获 得衍生物 96 (Scheme 37), 体外实验显示该衍生物可抑 制由二甲苯引起的小鼠耳肿胀 ${ }^{[82]}$. 阿司匹林酰氯 C(1)$\mathrm{COCl}$ 与两种乳香脂酸反应获得衍生物 $97 \mathbf{a}$ 和 $97 \mathrm{~b}$, 体内 实验显示这两种衍生物在 $10 \mathrm{mg} / \mathrm{kg}$ 剂量时, $2 \mathrm{~h}$ 的水肿 抑制率分别为 $58.51 \%$ 和 $56.22^{\%}$ [83]. 水杨酸 $\mathrm{C}(1)-\mathrm{COOH}$ 位与紫花前胡醇酯化，再将酚羟基与乙酸酐取代获得阿 司匹林衍生物 98, 该衍生物 $20 \mathrm{mg} / \mathrm{kg}$ 时可保护神经元 免受短暂局灶性和全身性脑缺血损伤, 远高于同剂量下 是阿司匹林治疗效果; 此外可降低缺血诱导的神经胶质 增生, 维持相应损伤区域的抗氧化水平 ${ }^{[84]}$.

阿司匹林的孪药衍生可有效提高药理活性. 阿司匹 林孪药衍生物乃是阿司匹林与活性相同或相似的化合 物依据拼合原理制备所得, 研发新的衍生物具有一定目 的性, 可缩短新药研发的进程. 孪药衍生物以同孪药为 主, 少数为异孪药, 衍生物活性在抗炎、抗癌、抗血栓 及保护神经系统等方面均有涉及, 其中绝大部分衍生物 

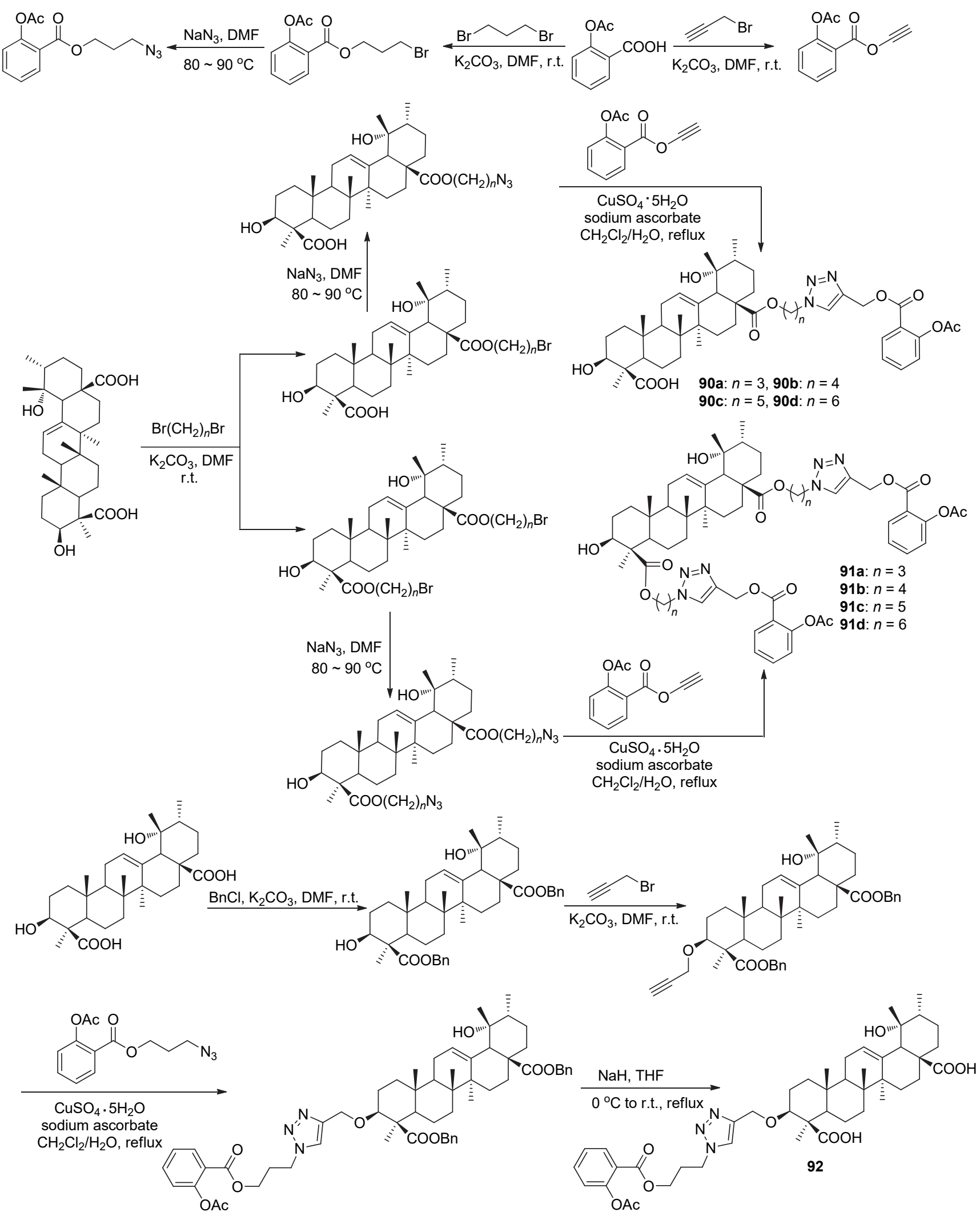

图式 35 阿司匹林衍生物 90 92 的合成路线

Scheme 35 Synthetic route of aspirin derivatives $90 \sim 92$

活性得到了极大的提高, 如衍生物 91d 的血小板聚集抑 制率 $77.2 \%$ 是阿司匹林的 8 倍.

\section{4 阿司匹林的金属配位修饰与生物活性}

顺铂的发现意味着金属抗癌药物时代的到来 ${ }^{[85]}$. 


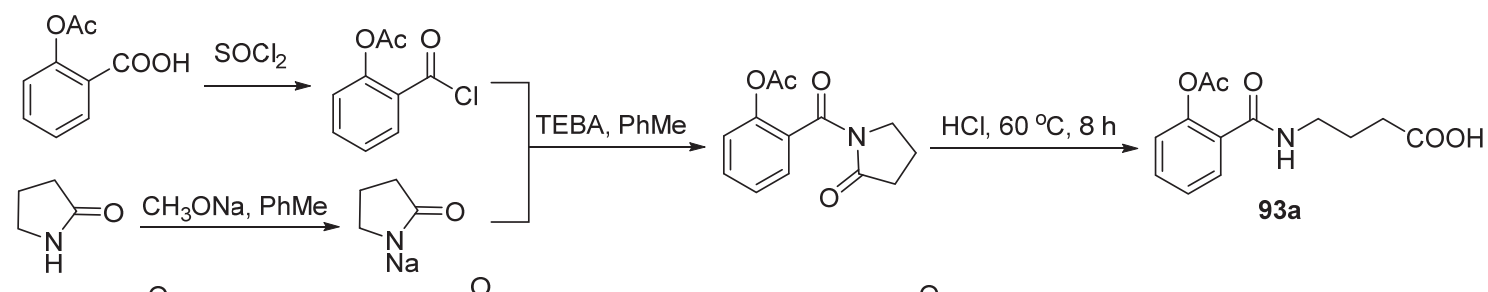

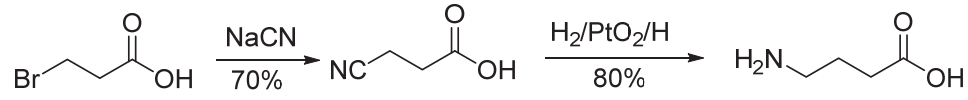

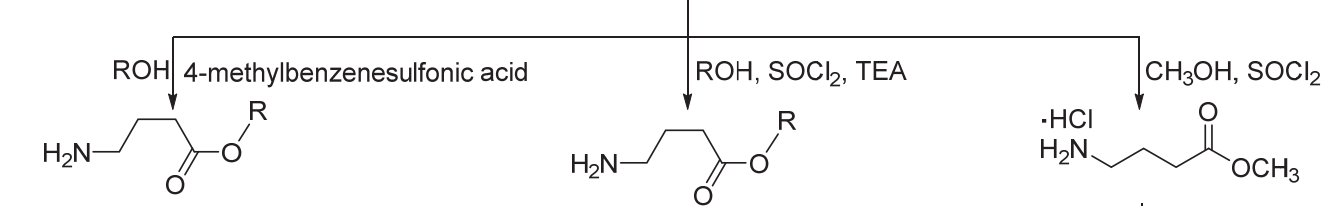<smiles>[R]OC(=O)CCCNC(=O)c1ccccc1O</smiles>

$\mathrm{Et}_{3} \mathrm{~N}, \mathrm{AcCl}, \mathrm{CH}_{2} \mathrm{Cl}_{2} 0^{\circ} \mathrm{C}$, r.t.<smiles>[R]OC(=O)CCCNC(=O)c1ccccc1OC(C)=O</smiles>

93b: $\mathrm{R}=\mathrm{C}_{2} \mathrm{H}_{5}$

93c: $\mathrm{R}=\mathrm{CH}\left(\mathrm{CH}_{3}\right)_{2}$

93d: $\mathrm{R}=\left(\mathrm{CH}_{2}\right)_{3} \mathrm{CH}_{3}$

93e: $\mathrm{R}=\mathrm{C}_{6} \mathrm{H}_{11}$

93f: $\mathrm{R}=\mathrm{CH}_{2} \mathrm{C}_{6} \mathrm{H}_{5}$

93g: $\mathrm{R}=\mathrm{CH}_{2} \mathrm{C}_{6} \mathrm{H}_{4} \mathrm{OCH}_{3}-p$

93h: $\mathrm{R}=\mathrm{CH}_{2} \mathrm{C}_{6} \mathrm{H}_{4} \mathrm{Cl}-p$<smiles>[R]OC(=O)CCCNC(=O)c1ccccc1OC(C)=O</smiles>

94a: $\mathrm{R}=\mathrm{CH}_{3}$

94b: $\mathrm{R}=n-\mathrm{C}_{3} \mathrm{H}_{7}$

94c: $R=2,6$-dinmethyl phenyl

94d: $R=1$-phenyl ethyl

94e: $R=0$-tolyl

94f: $\mathrm{R}=n$-amyl

94g: $\mathrm{R}=$ iso-amyl

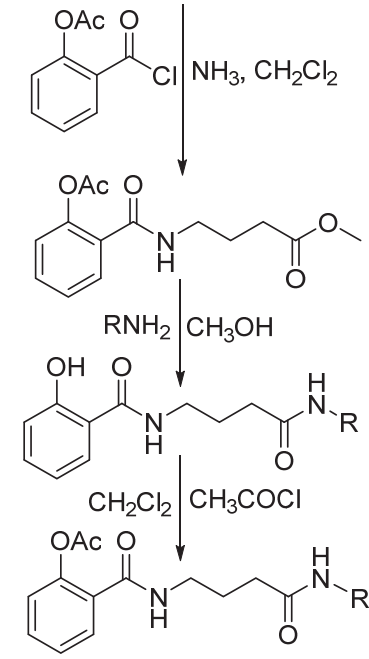

95a: $\mathrm{R}=\mathrm{CH}_{3} ; 95 \mathrm{~b}: \mathrm{R}=\mathrm{C}_{2} \mathrm{H}_{5}$

95c: $\mathrm{R}=\mathrm{CH}\left(\mathrm{CH}_{3}\right)_{2} ; 95 \mathrm{~d}: \mathrm{R}=\left(\mathrm{CH}_{2}\right)_{2} \mathrm{CH}_{3}$

95e: $\mathrm{R}=\left(\mathrm{CH}_{2}\right)_{3} \mathrm{CH}_{3} ; 95 \mathrm{f}: \mathrm{R}=\left(\mathrm{CH}_{2} \mathrm{CH}_{3}\right)_{2}$

95g: $\mathrm{R}=\left(\left(\mathrm{CH}_{2}\right)_{3} \mathrm{CH}_{3}\right)_{2} ; 95 \mathrm{~h}: \mathrm{R}=$ Cyclohexyl

95i: $\mathrm{R}=$ Methylpyrazine

图式 36 阿司匹林衍生物 $93 \sim 95$ 的合成路线

Scheme 36 Synthetic route of aspirin derivatives $93 \sim 95$

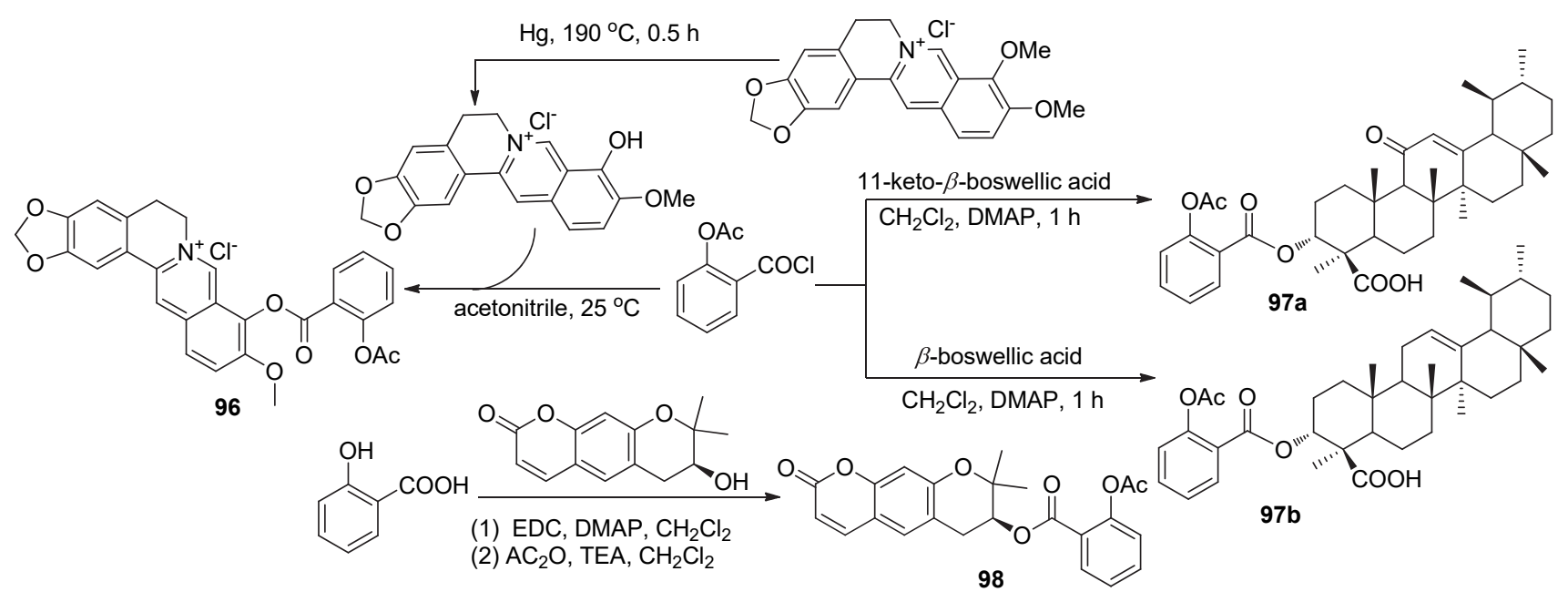

图式 37 阿司匹林衍生物 96 98 的合成路线

Scheme 37 Synthetic route of aspirin derivatives $96 \sim 98$. 
此后，多种金属配合物，如 Pt、Pd、 $\mathrm{Au}$ 与 $\mathrm{Ru}$ 等相继被 设计为抗癌药物并应用于临床 ${ }^{[86]}$. 而金属化合物与阿 司匹林的结合，也成为了开发新型抗肿瘤药物的途径. 将由环戊二烯制得的环戊二烯醇与阿司匹林酰氯 $\mathrm{C}(1)-\mathrm{COCl}$ 取代得到中间产物, 随后与乙醇铊反应获得 阿司匹林金属配合物 99a 99c, 再在衍生物 99b 的基础 上与 Co、 $\mathrm{Mn}$ 等金属发生金属交换反应获得化合物 99d 99h (Scheme 38). 除衍生物 99a 以外, 衍生物 99b 99h 对于 MCF-1、MDA-MB-231 及 HT-29 癌细胞 系均显示出抗癌活性, 且活性均高于阿司匹林, 如 $\mathbf{9 9 f}$
对三种癌细胞的 $\mathrm{IC}_{50}$ 值分别为(10.2 \pm 3.4$) 、(26.6 \pm 0.5)$ 和(9.2 \pm 1.7$) \mu \mathrm{mol} \cdot \mathrm{L}^{-1}$ ，但其抗癌机制有待进一步研究. 此外, 所有衍生物均能抑制 COX-1 和 COX-2, 对 COX-1 的抑制率为 30\%, 同阿司匹林相近. 但 99f 对 COX-1 的抑制率达 $(57.3 \pm 1.4) \%$ ，而对 COX-2 的抑制率 均高于阿司匹林 ${ }^{[87]}$.

将 3/4/5/6-氯水杨酸与乙酸酐结合获得 3/4/5/6-氯乙 酰水杨酸, 随后与丙炔醇进行酯化，再与羰基钴结合， 由此产生阿司匹林金属抗癌衍生物 3/4/5/6-Cl-Co-ASS, 100a 100d (Scheme 39)，这四种化合物在 HT-29、

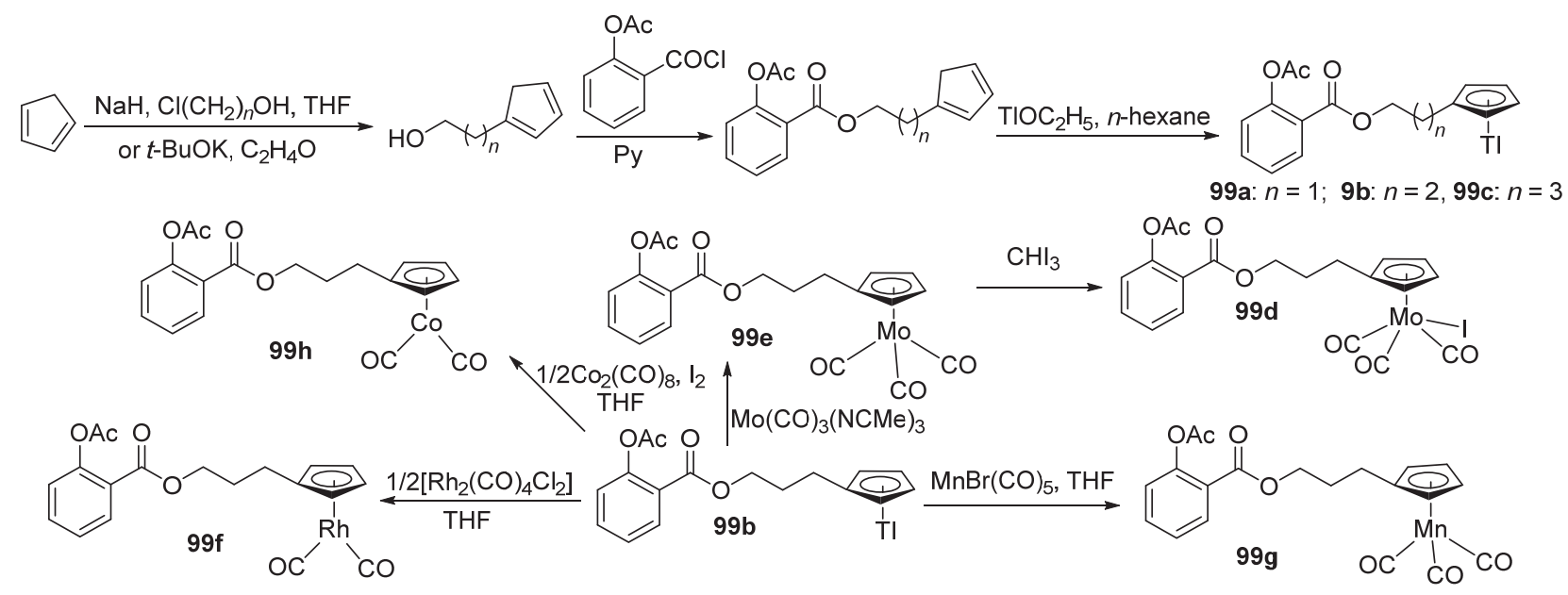

图式 38 阿司匹林衍生物 99 的合成路线

Scheme 38 Synthetic route of aspirin derivative $\mathbf{9 9}$

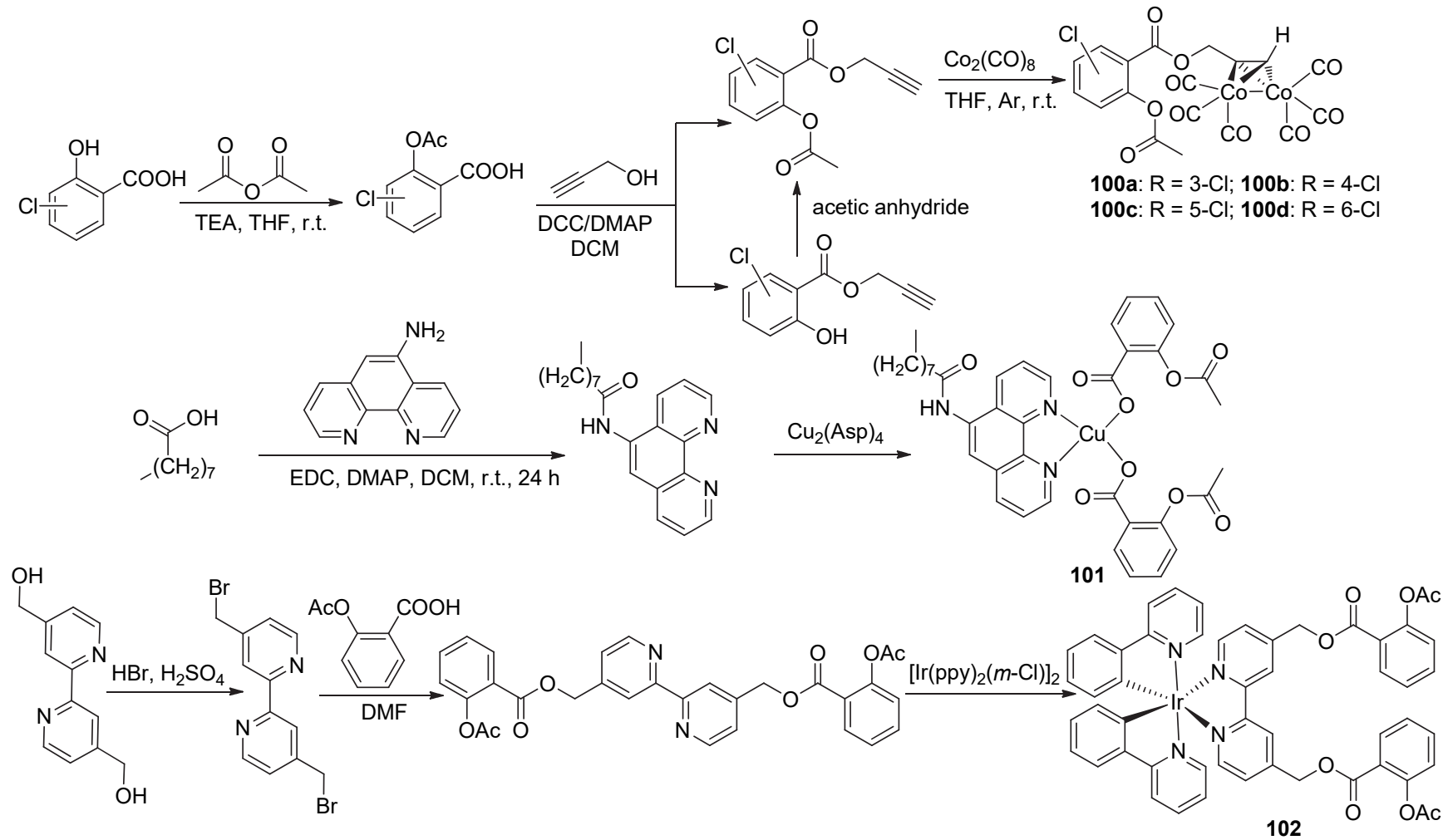

图式 39 阿司匹林衍生物 100 102 的合成路线

Scheme 39 Synthetic route of aspirin derivatives $100 \sim 102$ 
MDA-MB-231 和 MCF-7 癌细胞系中显示出较好的生长 抑制能力, 对 COX-2 的抑制率达 $60 \% \sim 80 \%$, 如 100b 对这三种癌细胞的 $\mathrm{IC}_{50}$ 值分别为 $(1.51 \pm 0.12) 、(5.24 \pm$

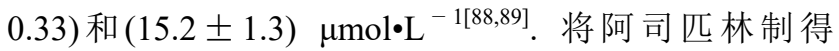
CuLA (101), 该化合物对 SKOV-3、HeLa 与 HK-2 三种 癌细胞有强抗癌活性, 尤其是对于 SKOV-3 癌细胞, $\mathrm{IC}_{50}$ 值为 $(1.1 \pm 0.6) \mu \mathrm{mol} \cdot \mathrm{L}^{-1}$, 同时, 该化合物增加了癌细胞 与癌细胞线粒体中的铜含量, 使得其中 SKOV-3 癌细胞 的 ATP 产量显著降低, 表明该化合物干扰了线粒体功能 与细胞存活. 此外, 化合物还显示出抗炎潜能, 可见具 有抗肿瘤和抗炎活性的铜配合物可能代表一种新型的 多功能金属配合物, 预示着抗癌药物的新趋势 ${ }^{[90]}$. 阿司 匹林与 Ir 配合物反应制得金属衍生物 102, 其在 PC3、

CT26、HT29 癌细胞中的 $\mathrm{IC}_{50}$ 值分别为 $(4.5 \pm 0.5)$ 、
$(4.4 \pm 0.7)$ 和 $(2.8 \pm 0.3) \mu \mathrm{mol} \cdot \mathrm{L}^{-1}$, 具有抗癌活性 ${ }^{[91]}$.

阿司匹林 $\mathrm{C}(1)-\mathrm{COOH}$ 与脂肪醇酯化再与 $\mathrm{Pt}$ 金属配 体反应制得衍生物 103a 103d (Scheme 40), 这四种衍 生物在 $10 \mu \mathrm{mol} \cdot \mathrm{L}^{-1}$ 时均能够抑制 COX -2 与 $\mathrm{COX}-1$, 且 对 COX-2 的抑制活性非常明显, 103c 与 103d 对其抑制 率近 $100 \%$. 此外, 衍生物 $103 \mathbf{a} \sim 103 \mathbf{d}$ 对 HT-29 及 MCF-7 癌细胞均显示出高于阿司匹林的抗癌活性, 其 $\mathrm{IC}_{50}$ 值均在 $30 \sim 50 \mu \mathrm{mol} \cdot \mathrm{L}^{-1[92]}$. 将阿司匹林酰氯经醇 修饰，再与金属配合物反应制得衍生物 $104 \mathrm{a} \sim 104 \mathrm{k}$, 或 阿司匹林酰氯直接与二茂铁甲醇取代得到衍生物 1041 (Scheme 40), 其中 104a 和 104d 104i 对 MCF-7、 MDA-MB 231 及 HT-29 癌细胞均呈现出优于阿司匹林 的抗癌活性, 如 $104 d$ 对三种癌细胞的 $\mathrm{IC}_{50}$ 值分别为 $(1.4 \pm 0.2) 、 2.4$ 和 $(2.2 \pm 0.2) \mu \mathrm{mol} \bullet \mathrm{L}^{-1[93]}$. Ashraf 等 ${ }^{[94]}$ 将

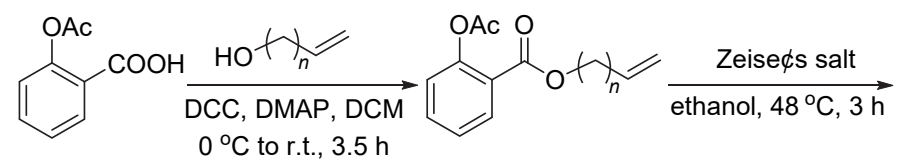<smiles>CC(=O)Oc1ccccc1C(=O)OCCCCCC(C)(C)C</smiles>

103a: $n=1 ; 103 \mathbf{b}: n=2$

103c: $n=3$; 103d: $n=4$

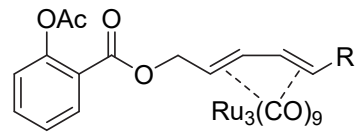

104a: $\mathrm{R}=\mathrm{H}$

$\mathrm{Ru}_{3}(\mathrm{CO})_{12} \uparrow \mathrm{n}$-hexane, reflux, $18 \mathrm{~h}$

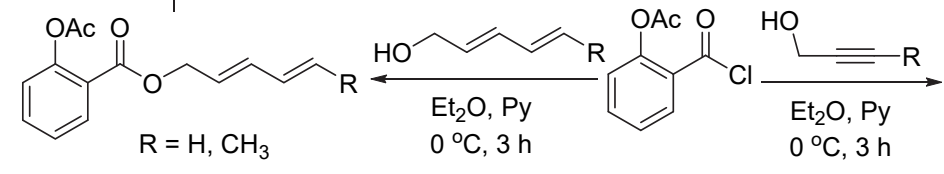
$\mathrm{OAc} O$<smiles>[R4]OC([R])=O</smiles>

104d: $\mathrm{R}=\mathrm{H} ;$ 104e: $\mathrm{R}=\mathrm{CH}_{3}$ 104f: $\mathrm{R}=\mathrm{CH}_{2}-\mathrm{ASP}$ $n$-hexane, reflux, $6 \mathrm{~h} \uparrow \mathrm{Ru}_{3}(\mathrm{CO})_{12}$<smiles>[R]C#CCOC(=O)c1ccccc1OC(C)=O</smiles>
$\mathrm{Fe}_{3}(\mathrm{CO})_{12},\left(\mathrm{CH}_{3}\right)_{3} \mathrm{~N}-\mathrm{O} \mid \begin{aligned} & n \text {-pentane, DCM } \\ & \text { reflux, } 3 \mathrm{~d}\end{aligned}$

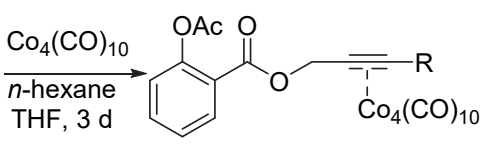

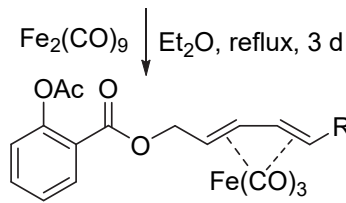
104b: $\mathrm{R}=\mathrm{H} ; 104 \mathrm{c} ; \mathrm{R}=\mathrm{CH}_{3}$

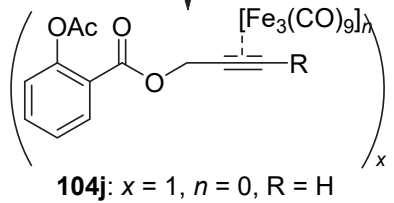
104k: $x=2, n=1, \mathrm{R}=\mathrm{H}$

104g: $\mathrm{R}=\mathrm{H}$ 104h: $\mathrm{R}=\mathrm{CH}_{3}$ 104i: $\mathrm{R}=\mathrm{CH}_{2}-\mathrm{ASP}$

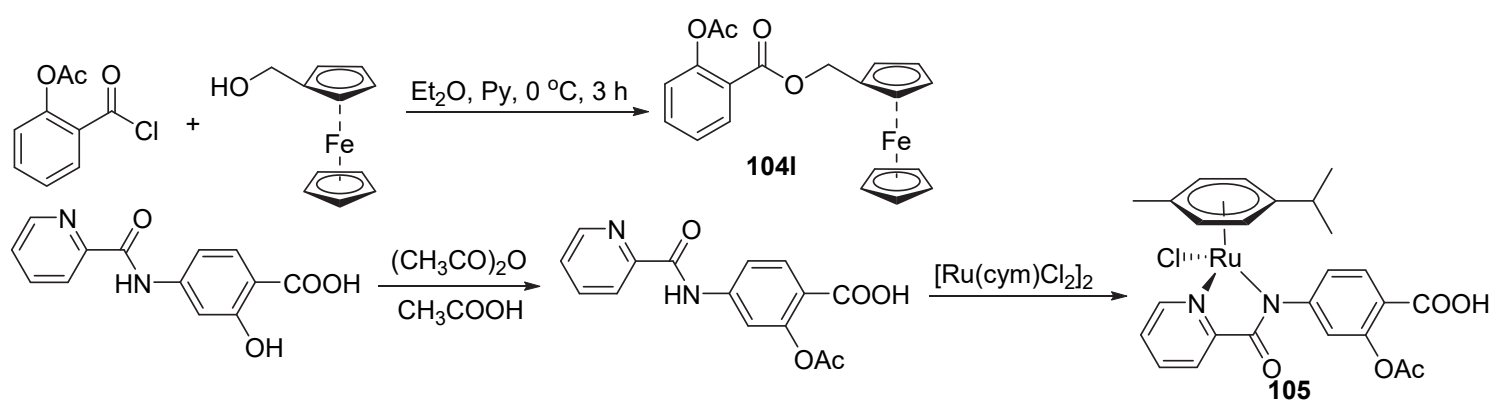

图式 40 阿司匹林衍生物 103 105 的合成路线

Scheme 40 Synthetic route of aspirin derivatives $\mathbf{1 0 3} \sim \mathbf{1 0 5}$ 
2-差基-4-吡啶酰氨基苯甲酸的 2 位着基酰化再与金属化 合物反应获得阿司匹林衍生物 105 , 该化合物对于 NCI-H460、SiHa、HCT116 和 SW480 癌细胞的 $\mathrm{IC}_{50}$ 值 均大于 $280 \mu \mathrm{mol} \cdot \mathrm{L}^{-1}$.

金属配位衍生，大多为阿司匹林先与简单醇类化合 物进行成酯修饰，再与无机金属配位制得. 配位金属皆 为 $\mathrm{Mn} 、 \mathrm{Ti} 、 \mathrm{Cu} 、 \mathrm{Ir}$ 等过渡金属, 获得的衍生物均呈现 出抗癌活性, 且活性较好, 但目前抗癌机制尚不明确. 通过金属配位制备新型抗癌衍生物是阿司匹林衍生的 可选方案.

\section{5 前景与展望}

阿司匹林作为人工合成药的鼻祖, 具有抗血栓、抗 炎、抗肿瘤等多种生物活性, 作为非甾体抗炎药已使用 上百年, 并具有良好的疗效. 2016 年阿司匹林在中国的 销售额为 159838 万元, 其中阿司匹林肠溶片及阿司匹 林肠溶胶囊分别位列化学止痛药年销售第 2 位与第 18 位，发展前景可观. 阿司匹林目前有骨架衍生、前药衍 生、孪药衍生及金属配位衍生四种方案, 根据修饰位点 的不同, 骨架衍生进一步分为 C(1)-COOH 位、 C(1)$\mathrm{COOH}$ 位与 $\mathrm{C}(2)-\mathrm{OAc}$ 位同时修饰、 $\mathrm{C}(2-) \mathrm{OAc}$ 位及苯环 修饰, 其中 $\mathrm{C}(1)-\mathrm{COOH}$ 位修饰的衍生物有 306 种, 占近 20 年阿司匹林衍生物总量的 $86 \%$. C(1)-COOH 位修饰的 衍生物中抗血栓衍生物占比 $36 \%$ 、抗炎衍生物占比 $11 \%$ 、抗癌衍生物占比 $24 \%$ 及其他活性衍生物 $15 \%$. 因 此, C(1)-COOH 位为结构修饰的主要位点, 并以抗血栓 衍生物为主, 而在抗血栓衍生物当中又以 NO-ASP 为 优, 如化合物 14i 对由胶原蛋白诱导的 PRP 血小板聚集 抑制活性 $\mathrm{IC}_{50}$ 值为 $14 \mu \mathrm{mol} \cdot \mathrm{L}^{-1}$. 前药衍生在改善阿司 匹林理化性质及提高药物靶向性等方面具有突出作用, 如化合物 62 通过引入葡萄糖, 使得衍生物水溶性大大 增加, 化合物 59 可选择性地于血栓部位释放出阿司匹 林而发挥药效. 孪药衍生使得衍生物制备目的性更强, 活性更高, 如由 SN38 和阿司匹林拼合所得的化合物 $\mathbf{8 5 b}$, 其对 $\mathrm{HepG} 2$ 细胞的 $\mathrm{IC}_{50}$ 值为 $(0.1208 \pm 0.0081)$ $\mu \mathrm{mol} \cdot \mathrm{L}^{-1}$, 较阿司匹林相比活性大大提高. 金属配位则 是制备抗癌衍生物的较好选择，涉及到的配位金属 $\mathrm{Tl}$ 、

$\mathrm{Mo} 、 \mathrm{Mn} 、 \mathrm{Rh} 、 \mathrm{Co} 、 \mathrm{Cu} 、 \mathrm{Ir} 、 \mathrm{Pt} 、 \mathrm{Ru}$ 和 $\mathrm{Fe}$ 均为过渡金 属. 为改善阿司匹林的胃肠道副作用, 目前主要的解决 方案有研发选择性的 COX-2 抑制剂, 将质子泵抑制剂 与阿司匹林联合用药, 制备 NO-ASP 衍生物. 其中采用 NO-ASP 方案较广, 现已报道 102 种 NO-ASP 衍生物, 占比 $29 \%$. 虽然阿司匹林的结构修饰取得了较好的进 展, 但目前仍无法完全避免其副作用, 多数活性优良的 衍生物暂未应用于临床.

\section{References}

[1] Dreser, H. Pflugers Arch. 1899, 76, 306.

[2] Van, F. J.; Buytenhek, M.; Nugteren, D. H.; Van, D. A. Eur. J. Biochem. 1980, 109, 1.

[3] Vane, J. R. Nature (London), New Biol. 1971, 231, 232.

[4] Tatsuguchi, A.; Matsui, K.; Shinji, Y.; Gudis, K.; Tsukui, K.; Kishida, K.; Fukuda, Y.; Sugisaki, Y.; Tokunaga, A.; Tajiri, T.; Sakamoto, C. Hum. Pathol. 2004, 35, 488.

[5] Denkert, C.; Winzer, K.; Hauptmann, S. Clin. Breast Cancer 2004, $4,428$.

[6] Zelenay, S.; Veen, A. G.; Böttcher, J. P.; Snelgrove, K. J.; Rogers, N.; Acton, S. E.; Chakravarty, P.; Girotti, M. R.; Marais, R.; Quezada, S. A.; Sahai, E.; Sousa, C. R. Cell 2015, 162, 1257.

[7] Chattopadhyay, M.; Kodela, R.; Nath, N.; Dastagirzada, Y. M.; Velazquez-Martinez, C. A.; Boring, D.; Kashfi, K. Biochem. Pharmacol. 2012, 83, 715 .

[8] Pircher, J.; Fochler, F.; Czermak, T.; Mannell, H.; Kraemer, B. F.; Wörnle, M.; Sparatore, A.; Soldato, P.D.; Pohl, U.; Krötz, F. Arterioscler., Thromb., Vasc. Biol. 2012, 32, 2884.

[9] Thomas, K.; Moody, T. W.; Jensen, R. T.; Tong, J.; Rayner, C. L.; Barnett, N. L.; Fairfull-Smith, K. E.; Ridnour, L. A.; Wink, D. A.; Bottle, S. E. Eur. J. Med. Chem. 2018, 147, 34.

[10] Zavodnik, I. B.; Lapshina, E.; Sudnikovich, E.; Boncler, M.; Luzak, B.; Róalski, M.; Heliñska, M.; Watala, C. Pharmacol. Rep. 2009, 61,476 .

[11] Zhang, Y.; Chen, S.; Wang, L.; Tang, X. Asian J. Chem. 2013, 25, 6550.

[12] Roy, J.; Adili, R.; Kulmacz, R.; Holinstat, M.; Das, A. J. Pharmacol. Exp. Ther. 2016, 359, 134.

[13] Li, Y. X.; Yu, L. B.; Zhang, Y. C.; Li, C. X. CN $1616404 A 2005$.

[14] Liang, R. M.; Cheng, C. R.; Liu, Y.; Zheng, Z.; Xu, K.; Yang, R.; Ding, J.; Liang, X. Y. CN 108129468, 2018.

[15] Plano, D.; Karelia, D.; Pandey, M.; Spallholz, J. E.; Amin, S. G.; Sharma, A. K. J. Med. Chem. 2016, 59, 1946.

[16] Moon, H. S.; Nam, S. I.; Kim, S. D.; Kim, D. Y.; Gwag, B. J.; Lee, Y. A.; Yoon, S. H. J. Pharm. Pharmacol. 2002, 54, 935.

[17] Mancuso, R.; Ferlazzo, N.; Luca, G. D.; Amuso, R.; Piccionello, A. P.; Giofrè, S. V.; Navarra, M.; Gabriele, B. Med. Chem. Res. 2019 , 28, 292.

[18] Ayyadevara, S.; Bharill, P.; Dandapat, A.; Hu, C.; Khaidakov, M.; Mitra, S.; Shmookler Reis, R. J.; Mehta, J. L. Antioxid. Redox Signaling 2013, 18, 481

[19] Strong, R.; Miller, R. A.; Astle, C. M.; Floyd, R. A.; Flurkey, K.; Hensley, K. L.; Javors, M. A.; Leeuwenburgh, C.; Nelson, J. F.; Ongini, E.; Nadon, N. L.; Warner, H. R.; Harrison, D. E. Aging Cell 2008, 7, 641

[20] Cha, B. C.; Lee, S. B. Arch. Pharmacal Res. 2000, 23, 116.

[21] Li, L.; Hsu, A.; Moore, P. K. Pharmacol. Ther. 2009, 123, 386.

[22] Godo, S.; Sawada, A.; Saito, H.; Ikeda, S.; Enkhjargal, B.; Suzuki, K.; Tanaka, S.; Shimokawa, H. Arterioscler, Thromb., Vasc. Biol. 2016, 36, 97 .

[23] Liu, X.; El-Mahdy, M. A.; Boslett, J.; Varadharaj, S.; Hemann, C.; Abdelghany, T. M.; Ismail, R. S.; Little, S. C.; Zhou, D.; Thuy, L. T. T.; Kawada, N.; Zweier, J. L. Nat. Commun. 2017, 8, 1.

[24] Jones, M.; Inkielewicz, I.; Medina, C.; Santos-Martinez, M. J.; Radomski, A.; Radomski, M. W.; Lally, M. N.; Moriarty, L. M.; Gaynor, J.; Carolan, C. G.; Khan, D.; O’Byrne, P.; Harmon, S.; Holland, V.; Clancy, J. M.; Gilmer, J. F. J. Med. Chem. 2009, 52, 6588.

[25] Xiao, M.; Yang, H.; Kleina, S. M.; Muenyib, C. M.; Stone, W. L.; Jiang, Y. L. Lett. Org. Chem. 2008, 5, 510.

[26] Lazzarato, L.; Donnola, M.; Rolando, B.; Chegaev, K.; Marini, E.; Cena, C.; Stilo, A. D.; Fruttero, R.; Biondi, S.; Ongini, E.; Gasco, A. J. Med. Chem. 2009, 52, 5058.

[27] Zhou, Z.; Lai, Y. S.; Zhang, Y. H.; Ji, H.; Li, L. W.; Peng, S. X. Chin. J. Org. Chem. 2008, 28, 819 (in Chinese).

(周洲, 赖宜生, 张奕华, 季晖, 李立文, 彭司勋, 有机化学, 2008, 28, 819.) 
[28] Lazzarato, L.; Chegaev, K.; Marini, E.; Rolando, B.; Borretto, E.; Guglielmo, S.; Joseph, S.; Stilo, A. D.; Fruttero, R.; Gasco, A. J. Med. Chem. 2011, 54, 5478.

[29] Xiang, G. Y.; Zhou, J.; Chen, S. Z.; Wu, J.; Luo, Z. J. Huazhong Univ. Sci. Technol. (Health Sci.) 2007, 36, 23 (in Chinese). (项光亚, 周军, 陈述增, 吴俊, 罗智, 华中科技大学学报(医学 版), 2007, 36, 23.)

[30] Cena, C.; Lolli, M. L.; Lazzarato, L.; Guaita, E.; Morini, G.; Coruzzi, G.; McElroy, S. P.; Megson, I. L.; Fruttero, R.; Gasco, A. J. Med. Chem. 2003, 46, 747.

[31] Szőke, K.; Czompa, A.; Lekli, I.; Szabados-Fürjesi, P.; Herczeg, M.; Csávás, M.; Borbás, A.; Herczegh, P.; Tósaki, A. Eur. J. Pharm. Sci. 2019, 131, 159.

[32] Larin, A. A.; Fershtat, L. L.; Ustyuzhanina, N. E.; Gening, M. L.; Nifantiev, N. E.; Makhova, N. N. Mendeleev Commun. 2018, 28, 595.

[33] Ferioli, R.; Folco, G. C.; Ferretti, C.; Gasco, A. M.; Medana, C.; Fruttero, R.; Civelli, M.; Gasco, A. Br. J. Pharmacol. 1995, 114, 816.

[34] Zhou, Z.; Jiang, L. Y.; Zhang, Y. H.; Ji, H.; Sun, Y.; Peng, S. X. Acta Pharm. Sin. 2006, 41, 1050 (in Chinese). (周洲, 蒋丽媛, 张奕华, 季晖, 孙易, 彭司勋, 药学学报, 2006, $41,1050$.

[35] Zhou, Z.; Jiang, L. Y.; Zhang, Y. H.; Ji, H.; Sun, Y.;Peng, S. X. Chin. J. Org. Chem. 2006, 26, 1403 (in Chinese). (周洲, 蒋丽媛, 张奕华, 季晖, 孙易, 彭司勋, 有机化学, 2006, 26, 1403.)

[36] Velázquez, C. A.; Chen, Q.; Citro, M. L.; Keefer, L. K.; Knaus, E. E. J. Med. Chem. 2008, 51, 1954.

[37] Basudhar, D.; Bharadwaj, G.; Cheng, R. Y.; Jain, S.; Shi, S.; Heinecke, J. L.; Holland, R. L.; Ridnour, L. A.; Caceres, V. M.; Spadari-Bratfisch, R. C.; Paolocci, N.; Velázquez-Martínez, C. A.; Wink, D. A.; Miranda, K. M. J. Med. Chem. 2013, 56. 7804.

[38] Samad, M. K.; Hawaiz, F. E. Bioorg. Chem. 2019, 85, 431.

[39] Ispir, E.; Ikiz, M.; Inan, A.; Sunbul, A. B.; Tayhan, S. E.; Bilgin, S.; Kose, M.; Elmastas, M. J. Mol. Struct. 2019, 1182, 63.

[40] Pradeepa, S. M.; Naik, H. S. B.; Kumar, B. V.; Priyadarsini, K. I.; Barik, A.; Prabhakara, M. C. Spectrochim. Acta, Part A 2015, 141, 34.

[41] Ho, B. K.; Ngaini, Z.; Neilsen, P. M.; Hwang, S. S.; Linton, R. E.; Kong, E. L.; Lee, B. K. J. Chem. 2017, 2017, 1.

[42] Ngaini, Z.; Mortadza, N. A. Nat. Prod. Res. 2019, 33, 3507.

[43] Nordin, N. A.; Chai, T. W.; Tan, B. L.; Choi, C. L.; Halim, A. N. A.; Hussain, H.; Ngaini, Z. J. Chem. 2017, DOI: 10.1155/2017/2378186.

[44] Ngaini, Z.; Arif, M. A. M.; Hussain, H.; Mei, E. S.; Tang, D.; Halimatulzahrah, D.; Kamaluddin, A. Phosphorus, Sulfur Silicon Relat. Elem. 2012, 187, 1.

[45] Zhen, X.; Zong, M.; Gao, S.; Cao, Y.; Jiang, L.; Chen, S.; Wang, K.; Sun, S.; Peng, H.; Bai, Y.; Li, S. PLoS One 2014, 9, 1.

[46] Vannini, F.; MacKessack-Leitch, A. C.; Eschbach, E. K.; Chattopadhyay, E. K.; Kodela, R.; Kashfi, K. Bioorg. Med. Chem. Lett. 2015, 25, 4677.

[47] Kodela, R.; Chattopadhyay, M.; Kashfi, K. ACS Med. Chem. Lett. 2012, 3, 257.

[48] Lazzarato, L.; Donnola, M.; Rolando, B.; Marini, E.; Cena, C.; Coruzzi, G.; Guaita, E.; Morini, G.; Fruttero, R.; Gasco, A.; Biondi, S.; Ongini, E. J. Med. Chem. 2008, 51, 1894.

[49] Bateman, L. A.; Zaro, B. W.; Miller, S. M.; Pratt, M. R. J. Am. Chem. Soc. 2013, 135, 14568.

[50] Lazzarato, L.; Cena, C.; Rolando, B.; Marini, E.; Lolli, M. L.; Guglielmo, S.; Guaita, E.; Morini, G.; Coruzzi, G.; Fruttero, R.; Gasco, A. Bioorg. Med. Chem. 2011, 19, 5852.

[51] Aguiar, R. P.; Aldawsari, F. S.; Wiirzler, L. A. M.; Silva-Filho, S. E.; Silva-Comar, F. M. S.; Bersani-Amado, C. A.; Velázquez-Martínez, C. A.; Cuman, R. K. N. Curr. Pharm. Des. 2017, 23, 6841 .

[52] Huang, X. B.; Wu, G. S.; Ke, L. Y.; Zhou, X. G.; Wang, Y. H.; Luo,
H. R. Molecules 2018, 23, 1359.

[53] Alagha, A.; Moman, E.; Adamo, M. F. A.; Nolan, K. B.; Chubb, A. J. Bioorg. Med. Chem. Lett. 2009, 19, 4213 .

[54] Aldawsari1, F. S.; Elshenawy, O. H.; Gendy, M. A. M. E; Aguayo-Ortiz, R.; Baksh, S.; El-Kadi, A. O. S.; Velazquez-Mart। nez, C. A. J. Enzyme Inhib. Med. Chem. 2014, 30, 884.

[55] Caldorera-Moore, M.; Guimard, N.; Shi, L.; Roy, K. Expert Opin. Drug Delivery 2010, 7, 479.

[56] Peng, S. Q.; Zhao, M.; Wu, J. H.; Wang, Y. J.; Ma, H. P. CN 104211763, 2014

[57] Hussain, M. A.; Abbas, K.; Lodhi, B. A.; Sher, M.; Ali, M.; Tahir, M. N.; Tremel, W.; Iqbal, S. Arabian J. Chem. 2017, 10, 1579.

[58] Dasgupta, Q.; Movva, S.; Chatterjee, K.; Madras, K. Int. J. Pharm. 2017, 528, 732 .

[59] Jacob, J. N.; Tazawa, M. J. Bioorg. Med. Chem. Lett. 2012, 22 , 3168 .

[60] Huang, G.; Cheng, H.; Liu, Y.; Hu, J. Saudi Pharm. J. 2018, 26, 263.

[61] Li, B. Q.; Li, N. G.; Feng, F.; Tang, Y. P.; Duan, J. A. J. China Pharm. Univ. 2009, 40, 486 (in Chinese).

(李宝泉, 李念光, 冯锋, 唐于平, 段金倣, 中国药科大学学报, 2009, 40, 486.)

[62] Li, J. Y.; Liu, X. W.; Yang, Y. J.; Ma, N.; Sun, X. J.; Li, S. H.; Qin, Z.; Du, W. B.; Jiao, Z. H. CN 105796575, 2016.

[63] Li, J.; Yu, Y.; Wang, Q.; Zhang, J.; Yang, Y.; Li, B.; Zhou, X.; Niu, J.; Wei, X.; Liu, X.; Liu, Z. Med. Chem. Res. 2012, 21, 995.

[64] Zhu, Y.; Fu, J.; Shurlknight, K. L.; Soroka, D. K.; Hu, Y.; Chen, X.; Sang, S. J. Med. Chem. 2015, 58, 6494.

[65] Sharma, A. K.; Sk, U. S.; Gimbor, M. A.; Hengst, J. A.; Wang, X.; Yun, J.; Amin, S. Eur. J. Med. Chem. 2010, 45, 4149.

[66] Moriarty, L. M.; Lally, M. N.; Carolan, C. G.; Jones, M.; Clancy, J. M.; Gilmer, J. F. J. Med. Chem. 2008, 51, 7991.

[67] Gao, H.; Yang, X. H.; Gu, X. F.; Zhu, Y. Z. Bioorg. Med. Chem. Lett. 2016, 26, 4650.

[68] Bednarczyk-Cwynar, B.; Wachowiak, N.; Szulc, M.; Kaminska, E.; Bogacz, A.; Bartkowiak-Wieczorek, J.; Zaprutko, L.; Mikolajczak, P. L. Front. Pharmacol. 2016, 7, 1.

[69] He, L. Q.; Chen, W. Z.; Wang, X. S. Chin. J. Med. Chem. 2011, 21, 32 (in Chinese).

(何黎琴, 陈维珍, 王效山, 中国药物化学杂志, 2011, 21, 32.)

[70] Zhu, Y.; Wang, F.; Zhao, Y.; Wang, P.; Sang, S. Sci. Rep. 2017, 7, 40119

[71] Shao, J. W.; Tang, Q.; Liu, Y. J.; Yang, X. CN 105111271, 2015.

[72] Ma, M. H.; Wu, X. H.; He, Y.; Huang, W. J. Sichuan Univ. (Med. Sci. Ed.) 2011, 42, 494 (in Chinese).

(马茂华, 吴晓华, 何杨, 黄文, 四川大学学报(医学版), 2011, 42, 494.)

[73] Zheng, H.; Wei, Z.; Xin, G.; Ji, C.; Wen, L.; Xia, Q.; Niu, H.; Huang, W. Bioorg. Med. Chem. Lett. 2016, 26, 3364.

[74] Chen, Z.; Luo, Y.; Fang, A.; Fan, C.; Zeng, C. Turk. J. Chem. 2018, 42,929

[75] Lu, S.; Obianom, O. N.; Ai, Y. Bioorg. Med. Chem. Lett. 2018, 28, 2869.

[76] Lu, S.; Obianom, O. N.; Ai, Y. MedChemComm 2018, 9, 1722.

[77] Huang, B.; Du, D.; Zhang, R.; Wu, X.; Xing, Z.; He, Y.; Huang, W. Bioorg. Med. Chem. Lett. 2012, 22, 7330.

[78] Lin, L.; Wu, F.; Liang, J. Chin. Chem. Lett. 2013, 24, 723.

[79] Kern, S.; Skoog, I.; Östling, S.; Kern, J.; Börjesson-Hanson, A. BMJ Open. 2012, 2, 1288.

[80] Berk, M.; Dean, O.; Drexhage, H.; McNeil, J. J.; Moylan, S.; Neil, A. O.; Davey, C. G.; Sanna, L.; Maes, M. BMC Med. 2013, 11, 74.

[81] He, D.; Ma, J.; Shi, X.; Zhao, C.; Hou, M.; Guo, Q.; Ma, S.; Li, X.; Zhao, P.; Liu, W.; Yang, Z.; Mou, J.; Song, P.; Zhang, Y.; Li, J. Chem. Pharm. Bull. 2014, 62, 967.

[82] Liu, Z.; Wang, X.; Zhang, H.; Zhang, S.; Li, Y.; Liu, L.; Peng, D. Med. Chem. Res. 2017, 26, 672.

[83] Chaturvedi, D.; Dwivedi, P. K.; Chaturvedi, A. K.; Mishra, N.; Siddiqui, H. H.; Mishra, Y. Med. Chem. Res. 2015, 24, 2799. 
[84] Yan, B. C.; Park, J. H.; Shin, B. N.; Ahn, J. H.; Kim, I. H.; Lee, J. C.; Yoo, K. Y.; Hwang, I. K.; Choi, J. H.; Park, J. H.; Lee, Y. L.; Suh, H. W.; Jun, J. G.; Kwon, Y. G.; Kim, Y. M.; Kwon, S. H.; Her, S.; Kim, J. S.; Hyun, B. H.; Kim, C. K.; Cho, J. H.; Lee, C. H.; Won. M. H. PLoS One 2013, $8,1$.

[85] Dasari, S.; Tchounwou, P. B. Eur. J. Pharmacol. 2014, 740, 364.

[86] Trudu, F.; Amato, F.; Vanhara, P.; Pivetta, T.; Pena-Mendez, E. M.; Havel, J. J. Appl. Biomed. 2015, 13, 79.

[87] Rubner, G.; Bensdorf, K.; Wellner, A.; Bergemann, S.; Ott, I.; Gust, R. Eur. J. Med. Chem. 2010, 45, 5157.

[88] Obermoser, V.; Baecker, D.; Schuster, C.; Braun, V.; Kircherb, B.; Gust, R. Dalton Trans. 2018, 47, 4341

[89] Ott, I.; Kircher, B.; Bagowski, C. P.; Vlecken, D. H. W.; Ott, E. B.;
Will, J.; Bensdorf, K.; Sheldrick, W. S.; Gust, R. Angew. Chem., Int. Ed. 2009, 48, 1160 .

[90] Shi, X.; Fang, H.; Guo, Y.; Yuan, H.; Guo, Z.; Wang, X. J. Inorg. Biochem. 2019, 190, 38.

[91] Wu, X. W.; Zheng, Y.; Wang, F. X.; Cao, J. J.; Zhang, H.; Zhang, D. Y.; Tan, C. P.; Ji, L. N.; Mao, Z. W. Chem.-Eur. J. 2019, 25, 7012.

[92] Weninger, A.; Baecker, D.; Obermoser, V.; Egger, D.; Wurst, K.; Gust, R. Int. J. Mol. Sci. 2018, 19, 1612.

[93] Rubner, G.; Bensdorf, K.; Wellner, A.; Kircher, B.; Bergemann, S.; Ott, I.; Gust, R. J. Med. Chem. 2010, 53, 6889.

[94] Ashraf, A.; Hanif, M.; Kubanik, M.; Sohnel, T.; Jamieson, S. M. F.; Bhattacharyya, A.; Hartinger, C. G. J. Organomet. Chem. 2017, 837,31 .

(Zhao, C.) 